\title{
IL Linfield
}

\section{Linfield University \\ DigitalCommons@Linfield}

\section{A Laboratory Manual of Vertebrate Embryology}

\author{
F.B. Adamstone \\ Waldo Shumway
}

Follow this and additional works at: https://digitalcommons.linfield.edu/jcde_docs

Part of the Ecology and Evolutionary Biology Commons

\section{Recommended Citation}

Adamstone, F.B. and Shumway, Waldo, "A Laboratory Manual of Vertebrate Embryology" (1939). Jane Claire Dirks-Edmunds Documents. Document. Submission 10.

https://digitalcommons.linfield.edu/jcde_docs/10

This Document is protected by copyright and/or related rights. It is brought to you for free via open access, courtesy of DigitalCommons@Linfield, with permission from the rights-holder(s). Your use of this Document must comply with the Terms of Use for material posted in DigitalCommons@Linfield, or with other stated terms (such as a Creative Commons license) indicated in the record and/or on the work itself. For more information, or if you have questions about permitted uses, please contact digitalcommons@linfield.edu. 


\section{A LABORATORI NANUAL}

\section{$0 \mathrm{~F}$ \\ VERTEBRATE EMBRYOLOGY \\ AXATONY OF SELGUED EMBRYOS OF THE FROG. CHLK, AND PIG}

BY

F. B. ADAMSTONE, Ph.D.

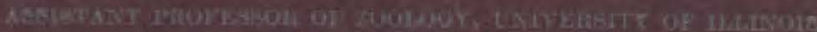

AND

WALDO SHUMUAY, Ph.D.

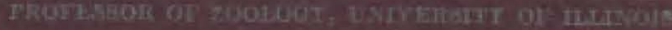

math

JOHN WHEY \& SONS, ING. LoNboN: CHAPMAS AS HALL, Lisuren 10 ำ 
A LABORATORY MANUAL OF VERTEBRATE EMBRYOLOGY 


\section{A LABORATORY MANUAL}

$\mathrm{OF}$

\section{VERTEBRATE EMBRYOLOGY}

ANATOMY OF SELECTED EMBRYOS OF THE

FROG, CHICK, AND PIG

BY

F. B. ADAMSTONE, Ph.D.

ABSISTANT PROFESSOR OF ZOOLbGY, UNTVBRSITY OF TLLTYOIS

AND

WALDO SHUMWAY, Ph.D.

PROFESSOR OF ZOOLOGY, UNIVERSITY OF IIIINOIS

NEW YORK

JOHN WILEY \& SONS, INC.

LONDON: CHAPMAN \& HALL, LMITED 
Copyront, 1989, Bx

FRANK B. ADAMSTONE

AND

WALDO SHUMWAY

All Rights Reserved

This book or any part thereof must not

be reproduced in any form without

the written permission of the publisher.

PRINTEO IN U. B. A.

MRAUNWORTH OCO.. INO.

DULDERS OF BOOKE

CERCla BINDING U. S. PAT. NO. 19634A7 


\section{FOREWORD}

In teaching laboratory classes in vertebrate embryology the instructor is confronted with a number of difficulties, chief of which is the fact that most students have had no previous experience with the methods which must be employed. This manual attempts to introduce these methods and to substitute a thorough, careful study of the anatomy of certain developmental stages of the frog, chick, and pig for the time-honored method of drawing a few individual and supposedly representative sections of these forms. The outline has been developed over a period of time comprising the past ten years. The results of this work were first embodied in a manual on the chick and 10-mm. pig published by one of us (F. B. A.) in 1938. After a year's employment in the laboratory, the original work has been enlarged and a chapter devoted to the anatomy of frog embryos has been added. All drawings have been specially prepared by us, and those of models depict wax reconstructions made by students in our courses.

The preliminary work on frog eggs and embryos up to the 6-mm. stage and the 18-, 24-, and 33-hour chicks is carried out by the old method for three reasons, namely: that the embryo is still comparatively simple, the student is usually unfamiliar with any other method of study, and in addition the old method gives the student an opportunity to become familiar with the general appearance of the structures which are most frequently encountered in the more intensive study of serial sections.

At the 6-mm. frog and the 48-hour chick stage the transition is made from the old to the new method. The student is expected first to draw a number of representative sections in the orthodox manner, but he must, before this, study carefully the numbered drawings presented in order to be able to recognize structures in the section. After this has been done he is required to study the entire series, make a record of the structures identified, and begin the process of learning to recognize them by means of their diagnostic features and their relation to each other. The study of the 11-mm. tadpole, the 72-hour chick, and the 10-mm. pig dispenses entirely with drawings except for those of the total mount and for the informal sketches made by the student as reference records. Marginal spaces are provided for these records and sketches. We have prefixed an asterisk to certain structures of which we ask the students in our laboratory to make informal sketches in the marginal spaces opposite. It is also suggested that all unnamed structures in the text figures should be carefully labeled by the student. Drawings and similar records are not overemphasized, and the success or failure of the student is determined by individual quizzes.

As here organized, the material for laboratory work is divided into three parts, treating the embryology of the frog, chick, and pig respectively. Since in many courses time does not permit the intensive study of more than two forms, the part dealing with the frog or pig may be omitted at the choice of the instructor. In our own laboratory, sections on the $6-\mathrm{mm}$. and $11-\mathrm{mm}$. frog embryo are omitted in order to permit the students to make their own preparations of the 72 -hour chick and 10-mm. pig.

The following programs are suggested:

A. For a course including 6 clock hours in the laboratory, any of the following combinations:

1. Frog (complete) and chick.

2. Frog (omitting 11-mm.), chick, and pig.

3. Frog (omitting 6- and 11-mm.), chick, and pig, including practice in microscopical technique. This program is used by the authors.

B. For a course including 4 clock hours in the laboratory, any of the following combinations:

4. Chick and pig.

5. Frog (omitting 11-mm.) and chick.

F. B. A. W.S.

URBANA, ILLINOIS 1999 


\section{CONTENTS}

PART I. ANATOMY OF FROG EMBRYOS

The Gar Cage

The Germ Cells and Fertilization . . . . . . . . . 1

Cleavage . . . . . . . . . . . . . . . . . . . . 2

Germ Layer Formation $\cdot$.

NeUral TUbe Formation . . . . . . . . . . . . . . 5

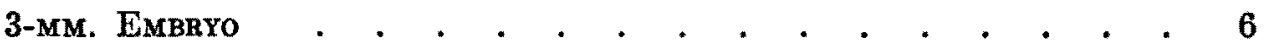

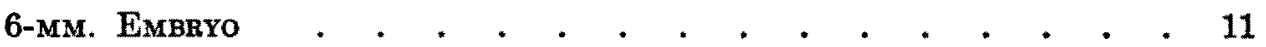

11-мм. EMBRYO

PART II. ANATOMY OF CHICK EMBRYOS

The Grrm Ceills and Fertilization . . . . . . . . . . 31

Cleavage and Germ Layer Formation . . . . . . . . . 32

18-hour EMrbro . . . . . . . . . . . . . . . . . 33

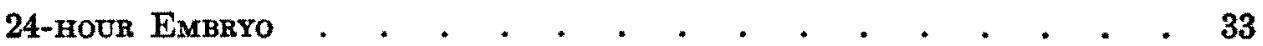

33-hour EMBriro . . . . . . . . . . . . . . . . 38

48-hour Embryo . . . . . . . . . . . . . . . 40

72-HоOR EMBRYo . . . . . . . . . . . . . . . . . . 56

PART III. ANATOMY OF THE 10-MM. PIG

EXTERNAL Form . ." . . . . . . . . . . . . . 67

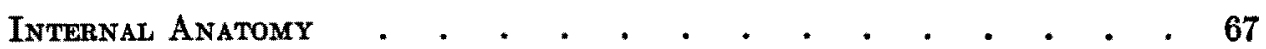




\title{
LABORATORY MANUAL OF VERTEBRATE EMBRYOLOGY
}

\author{
PART I \\ ANATOMY OF FROG EMBRYOS \\ THE GERM CELLS AND FERTILIZATION
}

The Ovum

The frog's egg is spherical with a diameter of $1.7 \mathrm{~mm}$. Its upper or animal hemisphere is black; the lower or vegetal hemisphere is white. It is surrounded by a very thin envelope, called the vitelline membrane, which is tightly pressed against the egg. Outside this is a thicker and tougher layer, the chorion, which is not to be confused with the chorion formed by developing birds and mammals. Outside the chorion is the egg jelly, w'ich consists of an inner and an outer layer. These egg envelopes are best observed in living eggs.

The nucleus, which lies in the animal hemisphere, can be seen in sections of ovarian or uterine eggs. This hemisphere is marked by the dark pigment granules lying just under the periphery. Scattered through the cytoplasm of the egg are the ovoid yolk granules.

\section{The Spermatozoön}

The male germ cell is extremely minute, approximately $0.1 \mathrm{~mm}$. in length. There is a long cylindrical head containing the nucleus and a slender tail which is twice the length of the head.

Fertilization (The Ferteling $\mathrm{kg} g$.

Under natural conditions the eggs of the frog mature simultaneously in the spring, a condition which may be brought about in the laboratory

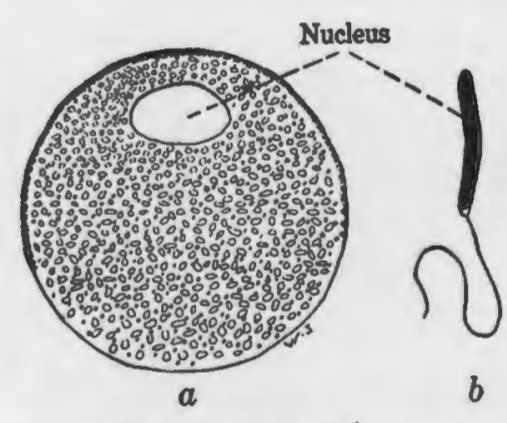

Fia. 1. Germ cells of the frog (Rana pipiens). a, Cross-section of ovarian ègg (approximately $25 \times$ ); $b$, Spermatozoön (approximately $1000 \times$ ). by injections of pituitary gland ${ }^{1}$ into the body cavity.

The eggs escape from the follicles of the ovary and are collected in the oviducts. When stimulated by the embrace (amplexus) of the male, the eggs are discharged from the cloaca, while the spermatozoa of the male are simultaneously emitted as a stream of milt. Pituitary-induced eggs may be artificially fertilized with spermatozoa removed from the sperm ducts of the male.

In living material it is possible to see at the animal pole two polar bodies, one formed before, and one after, fertilization. One can also recognize a narrow gray crescent lying between the black animal and white vegetal hemispheres on one side of the egg. This is the side opposite the one on which the sperm entered the egg. These observations are extremely difficult to make on preserved eggs.

As the eggs enter the water, the egg jelly swells and the outer layer becomes sticky so that all the eggs from one ovary tend to form a large mass of spawn containing about 2000 eggs.

\section{Laboratory Directions}

Examine the demonstrations of eggs and sperm provided.

${ }^{1}$ See R. Rugh, "Embryonic Material for Laboratory Experimentation," Am. Biol. Teacher, 1:8:184, 1939. 


\section{CLEAVAGE}

First Cleavage. A furrow appears in the animal hemisphere about $21 / 2$ hours after fertilization if the eggs are kept at a constant temperature of $18^{\circ}$ Cent. This furrow grows down through the vegetal hemisphere, thus separating the egg into the first two blastomeres. In fresh material it can be seen readily that this furrow usually passes through the gray crescent.

Second Cleavage. The second cleavage plane also commences at the animal pole, crossing the first at right angles and dividing the egg into four blastomeres. Careful inspection of the animal hemisphere shows that the two furrows do not meet in an exact cross. Two of the blastomeres are in close contact, forming a short longitudinal groove known as the polar furrow.

Third Cleavage. This stage is marked by the formation of a latitudinal furrow slightly above the equator of the egg and lying in the animal hemisphere. It divides the egg into eight blastomeres. Careful examination shows that this furrow is not an exact circle but has irregularities where it intersects the other cleavage planes. 
Fourth Cleavage. Two furrows appear at this stage, beginning in the animal hemisphere, and grow down through the vegetal hemisphere to produce sixteen blastomeres. These furrows may intersect each other at the animal pole or may be parallel to each other. Careful examination of the animal hemisphere should be made.

Fifth Cleavage. Again two furrows are formed, one in the animal hemisphere and one in the vegetal. The one in the animal hemisphere appears first. On the completion of the lower furrow, thirty-two blastomeres are formed. Those in the animal hemisphere are smaller and are called micromeres; those of the vegetal hemisphere are larger and are called macromeres. From this stage on increasing irregularity of the cleavage planes is apparent.

Blastula. The fifth cleavage stage is followed by the sixth, etc., until the end of the cleavage period comes with the formation of the blastula. In this stage the pigmented area has increased at the expense of the unpigmented area. The cells in the pigmented area are so small that they are seen only with difficulty even when observed with a hand lens. If the blastula is split with a safety-razor blade through the animal pole, ${ }^{1}$ it will be seen that it contains a large cavity, the blastocoel. The roof of this cavity (animal hemisphere) is very thin; its floor (vegetal hemisphere) is very thick. This is because of the concentration of yolk in the macromeres of the vegetal hemisphere.

\section{Laboratory Directions}

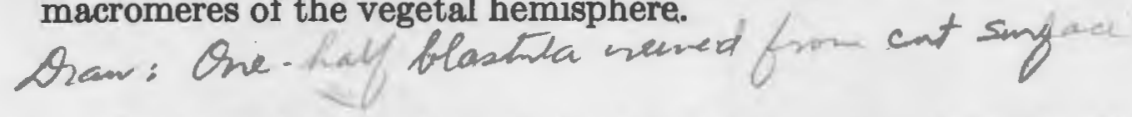

Examine the stages described above and make outline sketches (about one inch in diameter) of each in the space provided opposite each of the paragraphs above.

\section{GERM LAYER FORMATION}

After the formulation of the blastula the embryo is converted into a gastrula with several germ layers. Externally the process of germ-layer formation or gastrulation is marked by the progressive formation of the blastopore, conveniently divided into three stages: (1) the appearance of the dorsal lip (24 hours at $18^{\circ}$ Cent.); (2) the development of the lateral lips from the dorsal lip; and (3) the formation of the ventral lip by the union of the lateral lips.

The study of sections shows that at the dorsal lip, surface cells roll inward to form the roof of a slitlike cavity, the gastrocoel. As the dorsal lip advances over the surface of the vegetal hemisphere, it also elongates to form the lateral lips, where a similar in-rolling occurs, thus adding to the side walls of the gastrocoel. In its advance the dorsal lip moves almost completely over the vegetal hemisphere so that when the lateral lips unite to form the ventral lip, the completed lip of the blastopore forms a small circle enclosing the only white area left on the surface of the egg. This white area

1 This may be done by demonstration. 
which protrudes slightly above the level of the blastopore is the yolk plug.

The partition between the newly formed gastrocoel and the old blastocoel is either ruptured or pushed back until the blastocoel is obliterated, and the gastrocoel is the only cavity persisting. Since the heavy mass of yolk-laden macromeres is now on one side of the gastrula, the embryo rotates until the weight is at the bottom, which brings the blastopore to the posterior end of the embryo (Fig. 2).
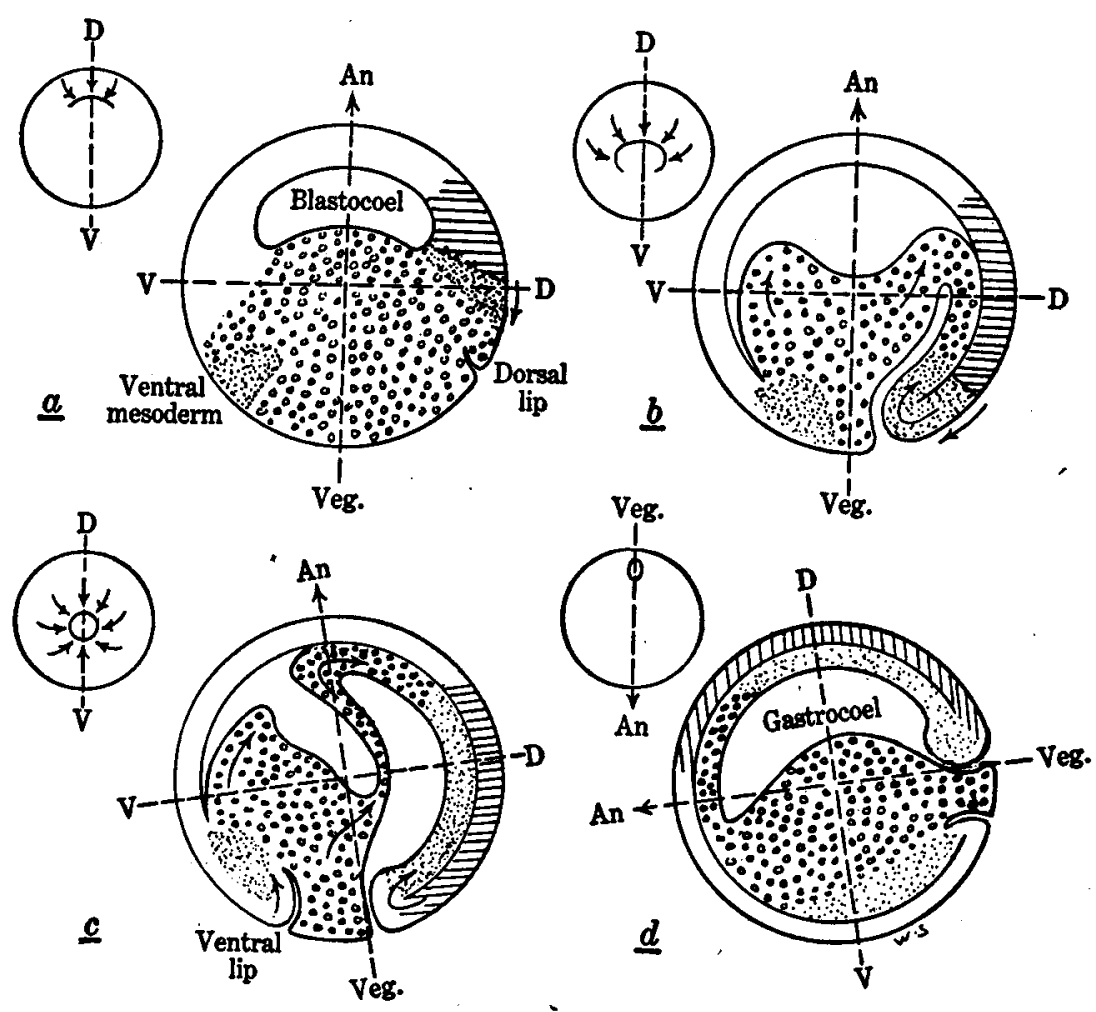

Fra. 2. Germ layer formation in the frog. Diagrammatic. $a$, dorsal lip stage; $b$, lateral lip stage; $c$, ventral lip stage; $d$, yolk plug stage after rotation. The smaller figures to the upper left are surface views; the larger ones to the right are sagittal sections. An, animal pole; veg., vegetal pole; $D$, dorsal; $V$, ventral. The small arrows indicate the direction of cell movements. The presumptive germ layers are designated after the data of Vogt and Pasteels; epidermal ectoderm, white; neural plate ectoderm, cross lines; notochord and mesoderm, stipple; endoderm, small circles.

In the frog's egg the layer of cells left on the surface after gastrulation is complete is the ectoderm. The layer of cells turned in at the lips of the blastopore is mes-endoderm. Almost as rapidly as it turns inward, however, it separates into an inner layer which is the endoderm, lining the roof and sides of the gastrocoel, and an outer layer between the ectoderm and endoderm which is the chordamesoderm. The median axial strip of this middle layer is the primordium of the notochord; the rest becomes the mesoderm which soon grows out between the ectoderm and endoderm in other regions of the embryo. In an exactly sagittal section it can be seen that the notochord forms part of the roof of the gastrocoel (Fig. $2 d$ ). During the formation of the neural tube the endoderm grows beneath the notochord from either side (Fig. 3):- 


\section{Laboratory Directions}

Examine total preparations of the dorsal-lip, lateral-lip, and ventral-lip (yolk-plug) stages of gastrulation. Make outline sketches in the space provided as in the last exercise. Prepare a half gastrula ${ }^{1}$ by splitting a yolk-plug stage from top to bottom, bisecting the yolk plug. Observe the gastrocoel and its lining of small white cells, the endoderm. Sketch and label. Examine demonstration slides which show the position of all three germ layers.

FORMATION OF THE NEURAL TUBE

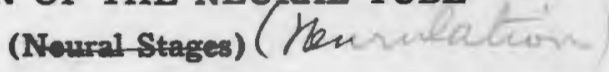

Neural Plate Stage. Soon after gastrulation is completed (56 hours at $18^{\circ}$ Cent.) it will be seen that the blastopore is flattened from side to side to form a slit. Meantime the dorsal surface of the embryo is flattened to make a plate elevated slightly around its margin. This flattened area, called the neural plate, is the primordium of the nervous system.

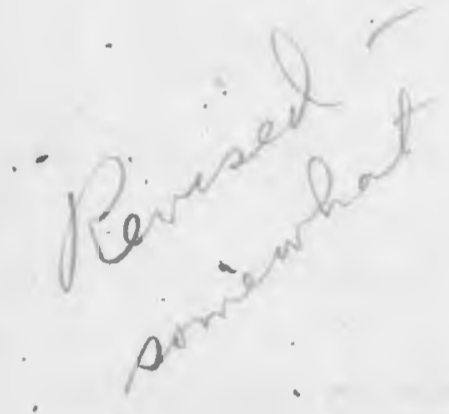

Neural Fold Stage. The embryo is now changing its shape, elongating along the anteroposterior (cephalocaudal) axis. A longitudinal depression appears in the middle of the neural plate forming the'neural groove. The margins of the plate are considerably elevated to form the neural folds. On the dorsal side at the anterior end of the embryo on either side of the neural folds is a crescentic elevated area known as the sense plate. Just posterior to each sense plate and lying alongside the neural folds is the gill plate. The blastopore has become a very amall, inconspicuous slit which is now being enclosed between the neural folds at the posterior end.

Neural Tube Stage. The neural folds have now grown together to form a neural tube which is elevated above the dorsal surface of the embryo. This whole process by which the neural plate sinks in to form the neural groove and is eventually cut off as the neural tube is an example of a common embryological phenomenon known as invagination. From the dorsal aspect the embryo is pear shaped and is marked on each side by short transverse grooves representing the anterior and posterior margins of the gill plates. These grooves are the primordia of the first and fifth visc ral clefts. At the anterior end two swellings may be seen on the ventral surface. These are the primordia of the mucous glands. Between them is a depression, the beginning of the stomodeum. At the posterior end, the blastopore is now covered by the fused neural folds, forming a neurenteric canal, and at the ventral end of the strip resulting from this fusion a depression indicates the beginning of the proctodeum. In side view transverse depressions indicate the presence of six somites. The living embryo is now approximately $21 / 4 \mathrm{~mm}$. in length. The epidermis has developed cilia by means of which the embryo rotates freely inside the egg jelly.

1 This may be shown by demonstration. 

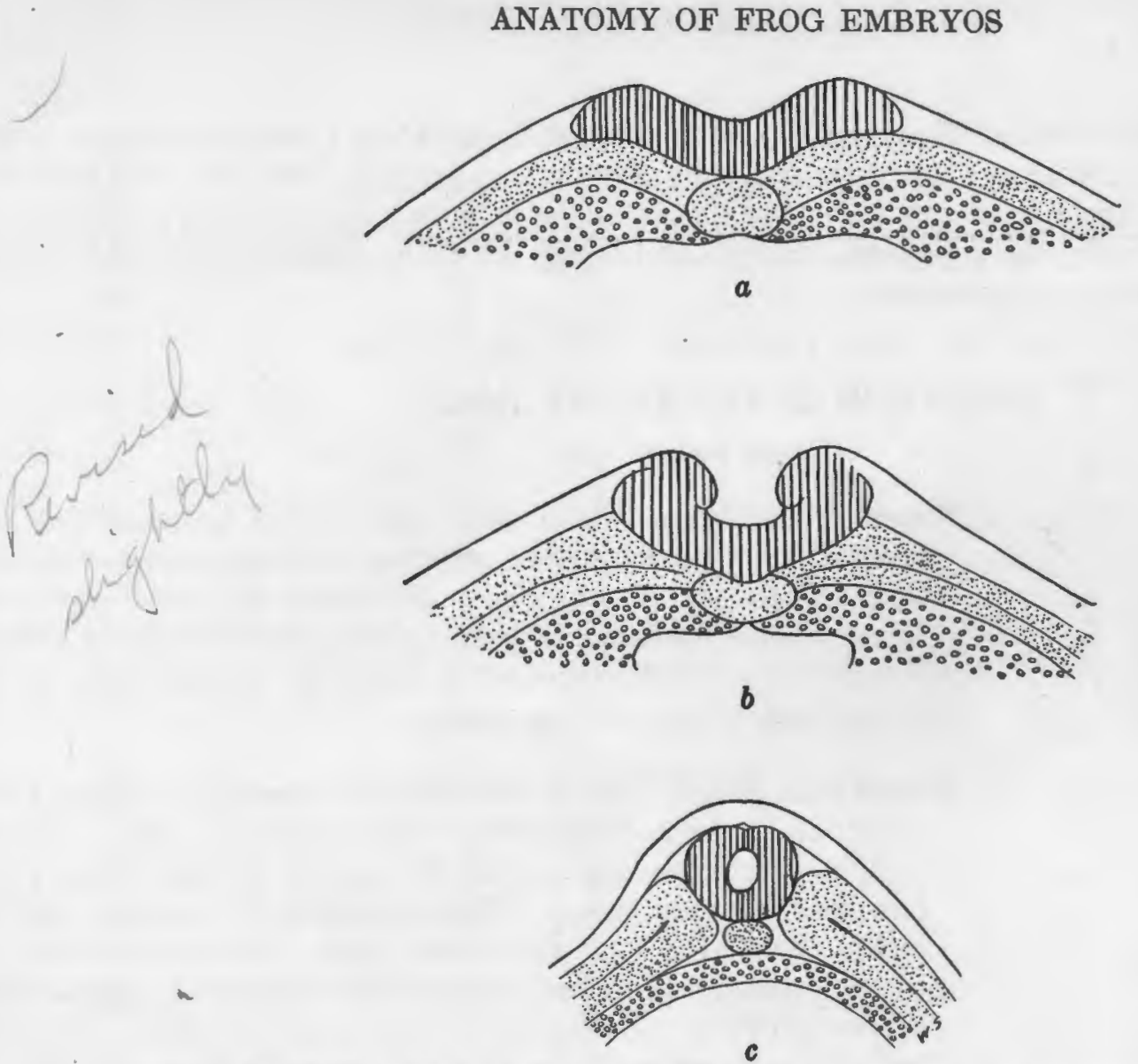

Fro. 3. Neural tube formation in the frog (Rana pipiens). $a$, transverse section through neural plate; $b$, transverse section through neural folds and groove; $c$, transverse section through neural tube. All at $50 \times$. Germ layers represented as in Fig. 2.

\section{Laboratory Directions}

Examine the three stages in neural-fold formation described above and sketch each from the dorsal aspect in the space provided. Examine demonstrations of transverse sections through each stage.

\section{3-MM. EMBRYO}

\section{(Tail Bud Stage)}

The embryo of $3 \mathrm{~mm}$. body length is chosen somewhat arbitrarily as an example of an early embryo. It is about three days old ( 74 hours at $18^{\circ}$ Cent.). Externally it is marked by the possession of a distinct tail bud. This has grown backward from the posterior end of the fused neural folds. The gill plate now shows four slight visceral grooves known as the hyoid, first, second, and fourth branchial grooves, respectively. The third branchial groove appears at a later stage. The mucous glands have enlarged considerably. In ventral view, a groove extending from the posterior end forward in each gives them the appearance of an elongated U. Between them the stomodewm may be identified. At the posterior end of the body, a short distance ventral and anterior to the base of the tail bud, is the proctodeum, which now opens into the hind-gut. In lateral view, a swelling in the sense plate region indicates the outgrowth of the optic vesicle. Posterior to the gill plate and at a level approximating the base of the neural folds a series of slight transverse grooves marks the presence of twelve or thirteen somites. Ventral to these and just behind the gill plate is a swelling caused by the developing nephrotomal band. (These details may be seen better in a cleared and stained specimen. 
TABLE 1

Pharyngear Derivatives and Assoctated Structures

\begin{tabular}{|c|c|c|c|c|}
\hline $\begin{array}{c}\text { Visceral } \\
\text { (pharyngeal) } \\
\text { pouches } \\
\text { Endodermal }\end{array}$ & $\begin{array}{l}\text { Visceral } \\
\text { (branchial) } \\
\text { arches }\end{array}$ & $\begin{array}{c}\text { Visceral } \\
\text { (pharyngeal) } \\
\text { clefts }\end{array}$ & Aortic arches & $\begin{array}{c}\text { Visceral } \\
\text { (branchial) } \\
\text { grooves } \\
\text { Ectodermal }\end{array}$ \\
\hline-- & $\frac{\text { I }}{\text { Mandibular }}$ & - & I & -- \\
\hline$\stackrel{\text { I }}{\text { Hyomandibular }}$ & -- & $\stackrel{\text { I }}{\text { Hyomandibular }}$ & - & $\stackrel{\text { I }}{\text { Hyomandibular }}$ \\
\hline-- & $\begin{array}{c}\text { II } \\
\text { Hyoid }\end{array}$ & -- & II & -- \\
\hline II & -- & II & - & II \\
\hline- & $\begin{array}{c}\text { III } \\
\text { 1st branchial }\end{array}$ & $\dot{-}-$ & $\underset{\text { Carotid }}{\text { III }}$ & -- \\
\hline III & -- & III & -- & III \\
\hline-- & $\begin{array}{c}\text { IV } \\
\text { 2nd branchial }\end{array}$ & -- & $\begin{array}{c}\text { IV } \\
\text { Systemic }\end{array}$ & -- \\
\hline IV & -- & IV & -- & IV \\
\hline-- & $\begin{array}{c}\mathrm{V} \\
\text { 3rd branchial }\end{array}$ & -- & V & -- \\
\hline $\mathrm{V}$ & -- & V & -- & V \\
\hline-- & $\begin{array}{c}\text { VI } \\
\text { 4th branchial }\end{array}$ & - & $\begin{array}{c}\text { VI } \\
\text { Pulmonary }\end{array}$ & -- \\
\hline $\begin{array}{c}\text { VI } \\
\text { Vestigial in frog }\end{array}$ & -- & $\begin{array}{c}\text { VI } \\
\text { Lacking in frog }\end{array}$ & - & $\begin{array}{c}\text { VI } \\
\text { Lacking in frog }\end{array}$ \\
\hline
\end{tabular}

The confusion arising in the minds of students who attempt to do collateral reading concerning the arches and ponches may be avoided by tho stndy of this table. It will be apparent that the difficulty centers about the indiscriminate use of the word "branchial" in respect to the arches. Some authors use the word for all the arches, others restriet its nse to the gill-bearing arches as we have done here. We have, however, given the sternative usage in parentheses, sase have no desire to appear to force our solution on our collesgues. See also Fugs. 10 and 31 . 


\section{Laboratory Directions}

Make an outline sketch of the 3-mm. embryo from the left side in the space provided below. Label all structures you have identified.

The 3-mm. Embryo.

\section{Serial Sections}

The internal anatomy of embryos from this stage onward is studied much better from embryos which have been cut into a continuous series of sections or slices and mounted in order on slides for mi-

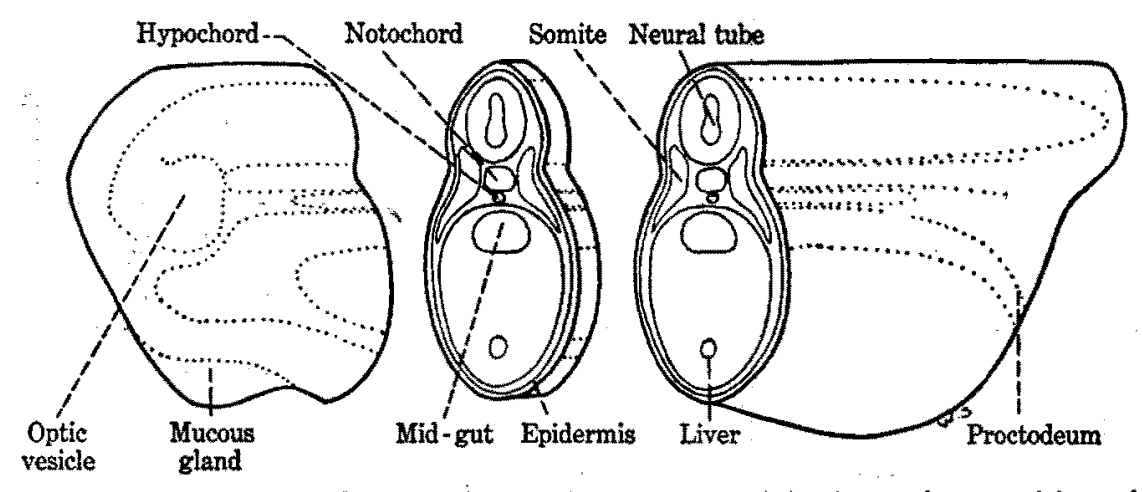

Fic. 4. Block diagram of 3-mm. frog embryo (Rana pipiens), to show position of transverse section through liver primordium in relation to the whole embryo represented as a transparent body.

croscopic observation. Figure 4 indicates the relationship of a transverse section to the embryo as a whole. In order to read a series of sections you should examine each section, identifying the structures you observe. 


\section{ECTODERMAL DERIVATIVES}

The epidermis is ciliated except on the ventral side, but the cilia themselves are too small to be seen with your microscope. It will be noticed with high power that the ectoderm is divided into two layers, the epidermal layer and the nervous layer. The stomodeum, between the two mucous glands, has not yet joined the fore-gut. From the stomodeum a solid hypophysis grows toward the forebrain. Notice with high power the structure of the mucous glands. The cells in these glands are more specialized at this time than any others of the body. The proctodeum has opened into the hind-gut, thus forming the cloaca. The neurenteric canal has now been closed owing to the growth of the tail bud.

The neural tube is now completely cut off from the exterior. The anterior end or prosencephalon is bent slightly around the anterior end of the notochord, owing to the cranial flexure. The prosencephalon extends backward on its ventral side to the posterior level of the optic vesicle. On the dorsal side it extends backward to the anterior end of a thickening in the roof of the brain. The mesencephalon extends backward from these boundaries to the anterior level of the notochord. The rhombencephalon begins at this point. The boundaries of the mesencephalon and rhombencephalon are not easily distinguished in transverse sections. These and the epiphysis are distinguished more easily in sagittal section. The spinal cord has grown into the tail bud.

From the ventral halves of the lateral walls of the prosencephalon, the optic vesicles protrude outward, so producing a bulge on either side of the embryo. Farther back, in the region of the rhombencephalon, the nervous layer of the ectoderm is greatly thickened and has invaginated on each side to form an otic (auditory) pit. Notice that the epidermal layer of the ectoderm is not invaginated. The nose at this time is in the form of thickenings of the nervous ectoderm, the olfactory (nasal) placodes, in sections anterior to, or at, the level of the prosencephalon.

\section{ENDODERMAL DERIVATIVES}

The gastrocoel is now lengthened and dilated in the region anterior to the yolk mass to form a foregut. A depression in the floor of the fore-gut extends towards the stomodeum but the two are still separated. Posteriorly a fingerlike evagination of the fore-gut extends into the yolk mass as the primordium of the liver. Frontal sections show the beginnings of the visceral pouches I, II, and III growing out from each side of the fore-gut towards the corresponding visceral grooves already noticed in the ectoderm.

The mid-gut is formed from the gastrocoel overlying the yolk mass. It has a very thick floor and relatively thin roof. Above it lies a thin rod much like the notochord but smaller. It is called the hypochord and is formed from the endodermal roof of the mid-gut, has no known function, and disappears early.

The hind-gut, posterior to the yolk mass, has united with the proctodeum to form the cloaca, opening to the exterior by the small vent already noticed.

\section{MESODERMAL DERIVATIVES}

The notochord extends forward to the base of the mesencephalon where it turns down very slightly. At the posterior end it joins a mass of relatively undifferentiated tissue which forms the core of the tail bud.

On either side of the notochord is the axial mesoderm from which twelve or thirteen somites have been formed. The axial mesoderm terminates in the core of the tail bud mentioned in the last paragraph. The intermediate mesoderm was partially divided into nephrotomes at an earlier stage. These have now fused together to form a nephrotomal band. This is best seen in sections cut through the region of the liver. The lateral mesoderm is divided into an outer thinner somatic layer and an inner thicker splanchnic layer. No coelom is formed between them as yet except beneath the fore-gut where it is to be seen in sections cut in the region of the otic pit. Here the space represents the beginning of the pericardial cavity. 


\section{Laboratory Directions}

Study the set of sections provided you and make sketches of sections through: (1) the optic vesicles, (2) the otic pits, (3) the liver, and (4) the cloaca.

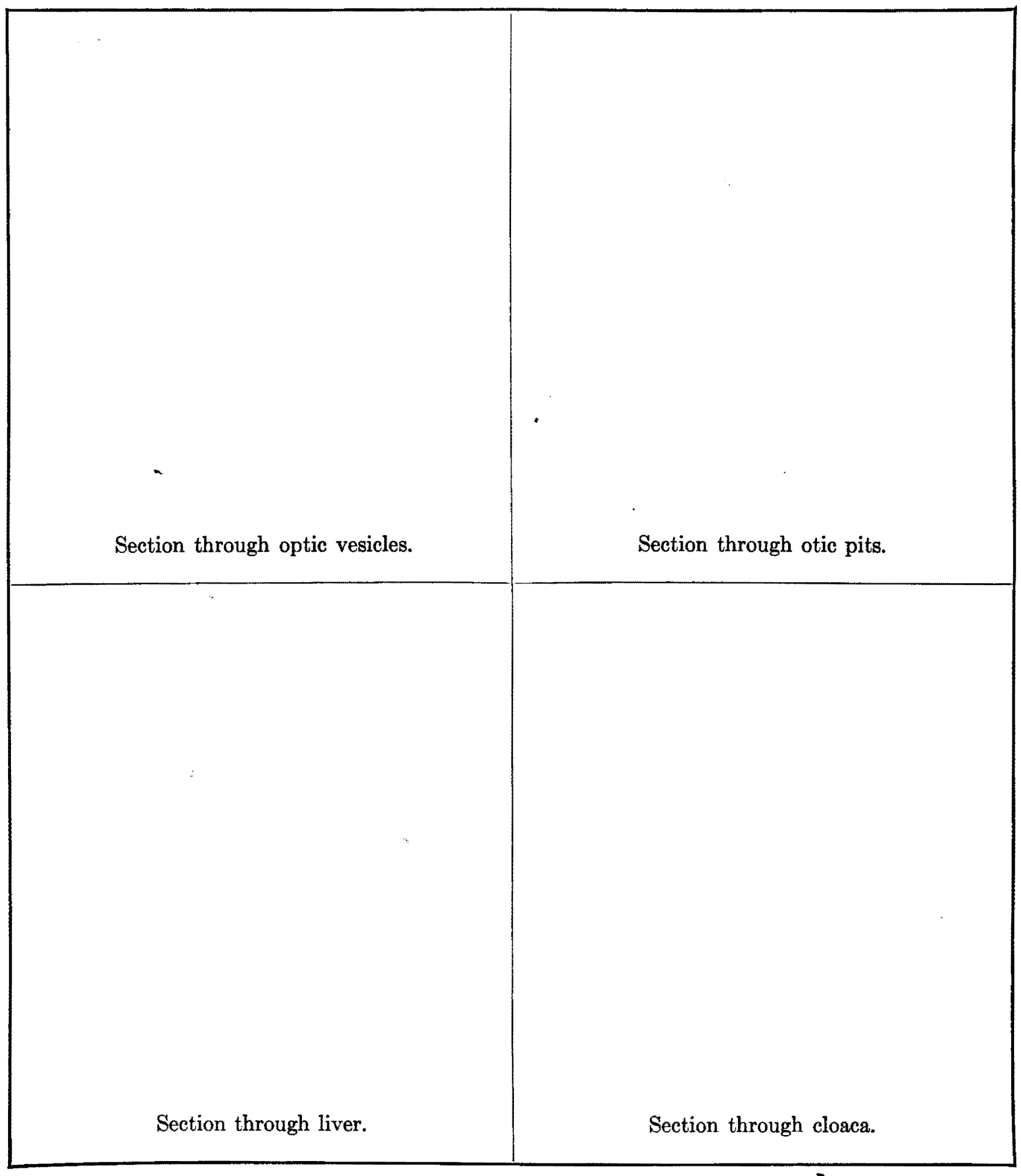

Transverse Sections of 6-mm. Frog. 
6-MM. EMBRYO

\section{(Hatching Stage)}

The embryo of Rana pipiens hatches spontaneously when it is 110 hours old (at $18^{\circ}$ Cent.) at a length of $6 \mathrm{~mm}$. Muscular movements may be initiated in this species by stimulation when the embryo is between $3 \frac{1}{2}$ and $4 \mathrm{~mm}$. in length, and when it is a little more than $5 \mathrm{~mm}$. long the heart starts beating. The stage now to be described is marked exactly by the beginning of circulation in the capillary loops of the first external gill.

\section{External Form}

The head is marked off from the trunk by a notch behind the mucous glands which have approached each other at their posterior ends. The stomodeum, now a deeper pit, is anterior and slightly dorsal to the anterior ends of the mucous glands but has not yet opened into the fore-gut. On either side of the stomodeum and somewhat dorsal to it is a nasal pit. On the sides of the head optic bulges are still prominent. All five visceral groves (hyomandibular and branchials 1-4) have appeared but have not opened into the corresponding visceral pouches. External gills are developing on the first and second branchial arches, and circulation can be demonstrated in the first of these.

Transverse intersomitic grooves appear on the trunk, and beneath them a slight ridge marks the region of the pronephric duct. On the ventral side the cloacal opening is to be seen just anterior to the base of the tail.

The tail is now one-half of the body length. Intersomitic grooves continue into the tail. A prominent tail fin extends completely around the tail from the vent on the ventral side to the dorsal junction with the truñk.

\section{Laboratory Directions}

Make a drawing of the 6-mm. embryo from the left side. 


\section{Representative Sections of the 6-Mm. Embryo}

The sections described and illustrated are selected from a series of 275 sections cut transversely to the long axis of the embryo at a thickness of 20 microns $(0.02 \mathrm{~mm}$.). They are reproduced from preparations made to compensate for the reversal produced by the compound microscope. Right on the illustration is right on the embryo. The student is cautioned that because of slight variations in the developmental tempo of embryos and variations in the plane of section he will probably never encounter sections exactly like those illustrated.

\section{A. Section through the Epiphysis and Nasal Pit (Section 10, Fig. 5)}

A slight lateral curvature of the head results in this section's showing a slight asymmetry, the plane of section passing through the left side at a region more anterior than that on the right. The nasal pit (1), therefore, is cut on the left through its opening to the exterior, and on the right through its posterior side wall. The groove on the ventral side is the beginning of the stomodeum (2). The brain is cut through its most anterior division, the telencephalon (3), at the level of the primordium

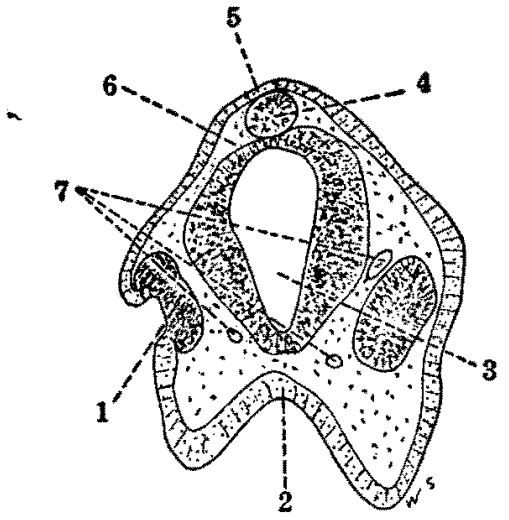

Fre. 5. Rana pipiens, 6-mm. embryo. Transverse section through nasal pit. $50 \times$.

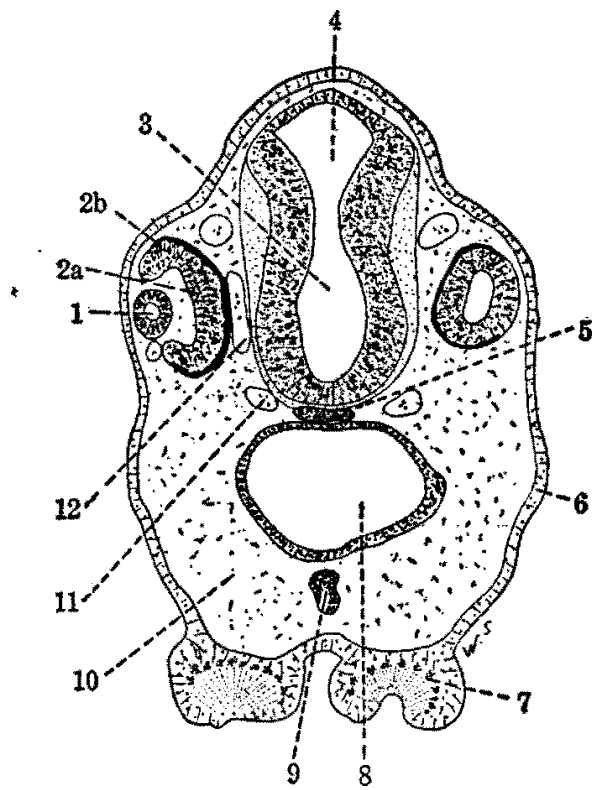

Fra. 6. Rana pipiens, 6-mm. embryo. Transverse section through optic cup. $50 \times$.

of the pineal gland, or epiphysis (4). An examination of the epidermis (5) with the high power will reveal a few larger rounded cells, projecting slightly from the surface, which bear cilia. The space between these structures (all of ectodermal origin) is filled with a loosely connected tissue, the mesenchyme (6), partly of mesodermal derivation and partly from the ectoderm of the neural crest. A few small cavities represent the neural capillary plexus (7) from which the blood vessels of the head are forming at this time.

\section{B. Section through Optic Cup and Lens Vesicle (Section 22, Fig. 6)}

There is still a slight asymmetry so that the section passes through the lens vesicle (1) on the left and behind it on the right. The vesicle has just detached itself from the epidermis and has a small central cavity. The optic cup has two layers, an outer thicker sensory layer (2a) and an inner, very thin, heavily pigmented one $(2 \mathrm{~b})$. The neural tube is partially divided by a constriction into the ventral diencephalon (3) and the more dorsal mesencephalon (4). Beneath the floor of the diencephalon lies a flat thick plate of cells, the hypophysis (Rathke's pocket), (5). The epidermis (6), with its ciliated cells, covers the surface of the embryo. On the ventral side are two large mucous glands (7), the one on the right cut through its cuplike groove. 
In the ventral half of the section is the large cavity of the thin-walled pharynx (8) and beneath it a solid laterally compressed rod, the thyroid gland (9).

Between these structures lies the mesenchyme (10) containing a few blood vessels. Those located between the eye and brain are parts of the ophthalmic vein (12) which lead to the anterior cardinals (see later). Those between the brain and the pharynx are part of the cerebral arteries (11) which represent anterior extensions from the carotids (see later).

\section{Section through Otic Vesicles, Heart, and External Gills (Section 38, Fig. 7)}

At this level the curvature which resulted in the asymmetry of the two preceding sections has now been passed. As this section passes through the two otic vesicles (1), the portion of the brain between them must be referred to the myelencephalon (3) with its thin-walled roof. A slight projection on the inner dorsal angle of each otic vesicle is the beginning of its endolymphatic duct (2).

Beneath the brain is the conspicuous notochord (4) with large vesicular cells. Beneath this in turn lies the widely expanded pharynx (5). The lateral thickenings of its walls represent the fourth visceral pouch (6). Ventral to this in the cavity of a great bulging projection lies the heart, represented by the dorsal atrium (8) and ventral ventricle (7). It is contained in the most anterior part of the coelom, the pericardial cavity (9). Note that this cavity is lined on the outside by the somatic layer of the mesoderm (10) and on the inner side by the splanchnic layer of the mesoderm (11), which gives rise to the myocardium and visceral pericardium. The endocardium (12) separated at an earlier stage.

From either side of the embryo projects the first external gill (13) borne on the third visceral arch. This gill is now branched and has several capillary loops (14). Circulation in this gill can be seen in the living embryo. The capillary loops receive blood from the first afferent branchial artery (15), which is beneath the pharynx. The capillary loops of the gill discharge their blood to the first efferent branchial artery (16), which is dorsal to the side of the pharynx. These arteries represent the third aortic arch of vertebrates. Between the otic vesicle and the brain may be seen portions of the internal carotid arteries (18) and at the ventro lateral margins of the otic vesicles the anterior cardinal veins (17) appear. The mesenchyme and epidermis are readily identified.

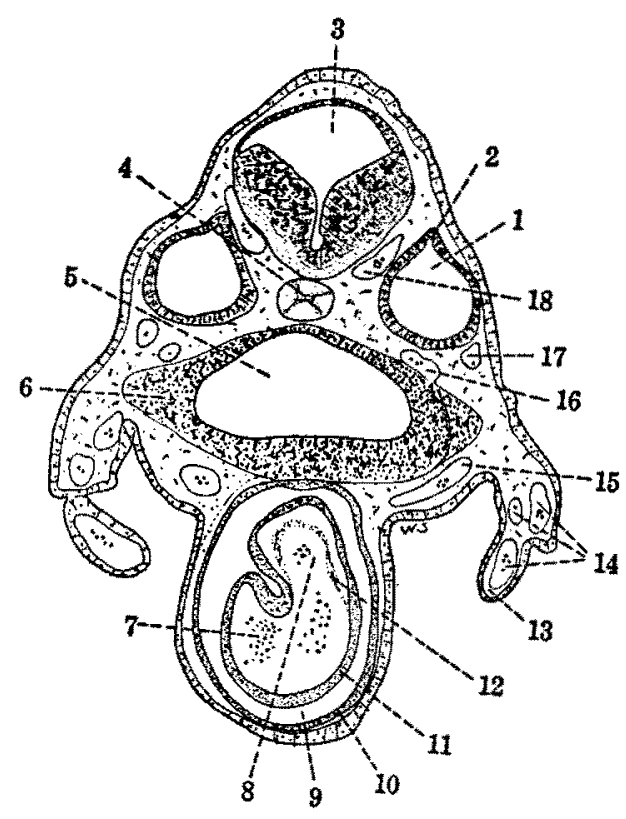

Fro. 7. Rana pipiens, 6-mm. embryo. Transverse section through otic vesicle, gills and heart. $50 \times$.

\section{Section through Pronephros and Liver (Section 55, Fig. 8)}

This section cuts through the region where the liver (1) joins the intestine (2). The brain is cut in the region of the myelencephalon $(7)$ as shown by the thin roof. Lying beneath it is the notochord (9) and just below this is a smaller rod, the hypochord (10), formed from the roof of the gut but now separated from it by the dorsal aortae (6) which are here uniting together.

On either side of the notochord and stretching up alongside the myelencephalon is a myotome (8), with which the dermatome is still associated. The intermediate mesoderm or nephrotomal band is greatly enlarged, and in it have appeared the three pronephric tubules (5). One of these is cut to show the nephrostome (3) or opening into the coelom (13). This cavity is lined on the outside by the somatic layer of the mesoderm (14) and on the inside by the splanchnic layer (15). Note the slight bulges at the inner dorsal angles of the coelom caused by the outward growth of each glomus (4) from the dorsal aorta. Above and to the outer side of each glomus, the large anterior cardinal veins (11) appear. The posterior cardinal veins (12) are seen beneath the pronephric tubules. On 
the ventral side of the liver, enclosed by the splanchnic layer of the mesoderm, are the large vitelline veins (16). The epidermis (17) presents nothing different from other sections.

\section{E. Section through Proctodeum (Section 159, Fig. 9)}

If it were not for the presence of the proctodeum (1) this would be a typical section through the tail region. Note the tail fin (2) above and below. In the mid-region are seen the spinal cord

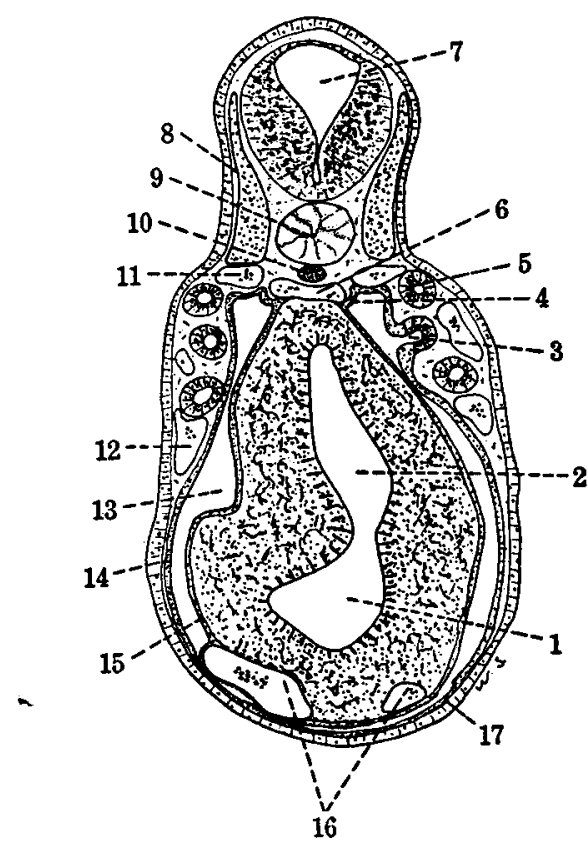

Fig. 8. Rana pipiens, 6-mm. embryo. Transverse section through liver and pronephros. $50 \times$.

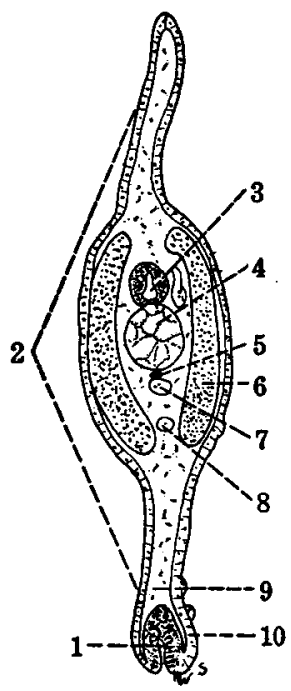

Fig. 9. Rana pipiens, 6-m m. e mbryo. Transverse section through tail at level of cloacal opening. $50 \times$.

(3), notochord (4), and hypochord (5). On either side is one of the tail myotomes (6). Beneath the hypochord is the small caudal artery (7), and some little distance beneath this the caudal vein (8). The tail fin is composed chiefly of mesenchyme (9) and epidermis (10) with many ciliated cells.

\section{The Study of Serial Sections}

After studying the representative sections just described the student should be ready to survey the anatomy of an embryo from a complete set of serial sections. Such a set consists of a complete set of slices across the long axis of the embryo arranged in order from the tip of the head to the end of the tail. Everything which could be found by dissection, if the embryo were larger, can be identified in some part of the series. Once identified the structure can be traced forward and backward until a complete mental picture of the organ and its relationship to others is formed. It is advisable before proceeding further to identify the plane of sectioning by laying a ruler across the lateral view of the whole embryo you have drawn earlier and tracing lines at the levels of the representative sections just studied.

As you succeed in identifying the structures mentioned in the following paragraphs, make a record of each, by writing in the blank spaces provided: (1) the number of the slide in the set you use; (2) the number of the row of sections in which you first identify the structure (counting from top to bottom); and (3) the number of the section in the row (counting from left to right). A certain number of the structures are starred. It is recommended that you make in the margin of this manual opposite the starred structure a simple line sketch to show its appearance in the section you have identified. 
ECTODERMAL DERIVATIVES

I. EPIDERMAL STRUCTURES

II. BRAIN AND SPINAL CORD. Starting at anterior end identify:

a. Telencephalon. First portion of the brain to appear in the series.

b. Diencephalon. Commences at the point where the epiphysis joins the brain. From its sides the optic stalks emerge. Beneath, a backward groove finally separates from the diencephalon to form the infundibulum.

1. Epiphysis. Extends forward from its point of origin. Now has lost its cavity.

* 2. Infundibulum. Find a section where the brain appears in two parts. The ventral portion is closely applied to the hypophysis (see below).

3. Hypophysis (Rathke's pouch), a derivative from the anterior end of the stomodeum. It will unite with the infundibulum to form the pituitary gland.

c. Mesencephalon. With a thick roof. Lies between optic cups and above the infundibulum.

d. Metencephalon. A thin roof. Lies between otic vesicles.

e. Myelencephalon. A thin roof. Hardly to be distinguished from metencephalon. Continues backward to spinal cord.

f. Spinal cord. Thick walls, thinner roof and floor. Continues back into tail almost to the end.

III. SENSE ORGANS OF THE HEAD

a. Nasal (olfactory pit). Most anterior sense organ, on ventral side of head, marked by thickness of epithelium and opening to the exterior only.

b. 1. Optic cup. Consist of pigment layer and thick sensory layer, joined to diencephalon by optic stalk.

2. Lens vesicle. With central cavity, located in mouth of optic cup and separated from epidermis.

c. Otic vesicle. Located alongside myelencephalon. A thick-walled hollow vesicle with an endolymphatic duct just forming.

IV. CRANIAL NERVES. At this stage there are four masses of tissue resembling the tissue of the walls of the brain in the mesenchyme on either side of the metencephalon and myelencephalon. These are ganglia which will supply sensory neurones to certain cranial nerves. 
a. Anterior to the otic vesicle and proceeding forward

* 1. Facial-acoustic complex. Immediately in front of the otic vesicle. Supplies afferent fibers to cranial nerves VII and VIII.

-2. Trigeminal ganglion. Very large. Supplies afferent fibers to cranial nerve $\mathrm{V}$.

b. Posterior to the otic vesicle and proceeding backward

* 1. Glossopharyngeal ganglion. Just posterior to the otic vesicle and ventral to it. Supplies afferent fibers to cranial nerve IX.

* 2. Vagus ganglion. Some distance farther back and a little dorsal to the last. Supplies afferent fibers to cranial nerve $\mathrm{X}$.

\section{ENDODERMAL DERIVATIVES}

a. Mouth. The region of the fore-gut just behind the plate separating it from the stomodeum will form the oral cavity of the mouth. This continues as pharynx.

b. Pharynx. This region with its visceral (pharyngeal) pouches is best seen in frontal section (Fig. 10). Lay your ruler across

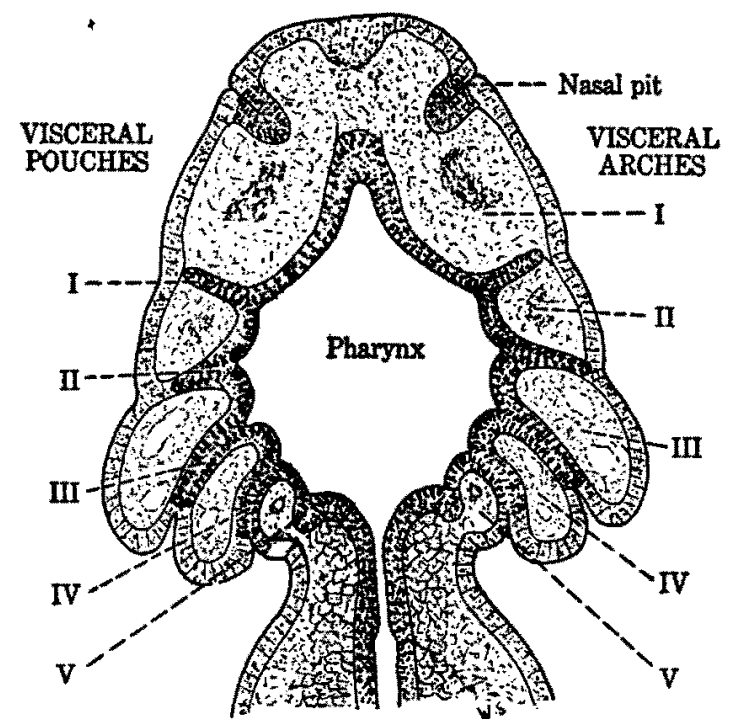

Fra. 10. Rana pipiens, 6-mm. embryo. Frontal section through head at level of visceral pouches and arches. $50 \times$.

this figure and draw a line to show the position of the transverse section shown in Fig. 7.

c. Thyroid gland. Originates from the floor of the pharynx as a solid rod from the level of the second visceral pouch to the fifth.

d. Liver. The liver diverticulum noted in the 3-mm. embryo has grown forward towards the heart. The posterior ventral portion shown in Fig. 8 will become the gall bladder.

e. Intestine. From the liver backward the mid-gut becomes the intestine, with a small cavity and an exceedingly thick floor which contains the yolk. 
f. Cloaca. Starting with the proctodeum trace the cloaca forward until it unites with two small longitudinal tubes, the pronephric ducts (see later).

g. Hypochord. This is a small rod of endoderm separating from the roof of the gut and lying beneath the notochord. It extends back into the tail.

\section{MESODERMAL DERIVATIVES}

I. NотосноRD. Cylindrical rod with characteristic vesicular cells. Lying beneath brain and spinal cord. Commencing behind infundibulum and extending well back into the tail.

II. MESENCHYME. Loose reticular embryonic connective tissue filling space between organs.

III. DERIVATIVES OF THE somites. The somites extend from behind the otic vesicle well into the tail. There are thirteen somites in the trunk and approximately twenty more in the tail. The inner ventral portion of each somite (sclerotome) is now broken down into a mesenchymal tissue investing the notochord and neural tube from which the axial skeleton will be formed. The dermatome or outer layer (from which the dermis of the skin will develop) is still associated with the muscleforming remainder of the somite or myotome. In these myotomes muscle fibers are developing.

IV. DERIVATIVES OF THE INTERMEDIATE MESODERM. In the frog this region forms the nephrotomal band from which the kidney and gonads develop.

a. Pronephric tubules. Three on each side. Well-defined wall of thick cells. Pigment concentrated at the cell margin nearest the cavity. Communicates with the coelom by funnel (nephrostome). It is not ciliated at this time.

b. Pronephric duct. Originates from the last pronephric tube and continues in the ventral portion of the nephrotomal band. Trace the pronephric duct to its junction with the cloaca.

V. DERIVATIVES OF THE LATERAL MESODERM

a. Somatic mesoderm. Closely applied to the ectoderm in the trunk.

b. Splanchnic mesoderm. Closely applied to the endoderm in the trunk region.

c. Coelom. The cavity located between the somatic and splanchnic layers of mesoderm. The anterior portion of the coelom known as the pericardial cavity surrounds the heart. This coelom is not to be found in the head or tail.

d. Mesenteries. The right and left splanchnic and somatic layers of the mesoderm unite above the intestine and heart. These regions constitute the dorsal mesentery and dorsal mesocardium respectively.

vi. CIRCULATORY SYSTEM. The blood vessels and lymphatics of the frog embryo originate in a system or network of capillaries (plexus) associated with the organ systems and derived from splanchnic mesoderm in the trunk region or from mesenchyme in the head or tail. They are best demonstrated by injection ${ }^{1}$ preparations.

${ }^{1} \mathrm{H}$. M. Knower, "A Resurvey of the Developments of Lymphatics and Associated Blood Vessels in Anuran Amphibia by the Method of Injection," Wistar Institute, 1939. 
a. Heart. Locate the heart, at the level of the external gills, proceeding backward until it divides into two large vessels entering from the liver.

* 1. Sinus venosus. The point where the two vessels converge, forming a stubby inverted $\mathrm{Y}$.

2. Atrium. The sinus continues forward and dorsal, bending to the right, to enter the thin-walled atrium.

3. Ventricle. The heart in more anterior sections takes on the appearance of a reversed C. The lower limb bending from the atrium to the left side is the ventricle.

* 4. Bulbus arteriosus. Continuing forward, the lower left portion of the reversed $\mathrm{C}$ becomes detached from the atrium and is now known as the bulbus.

b. Arteries

1. Of the head

* Ventral aorta (truncus arteriosus). Following the bulbus towards the head, it immediately assumes the form of a letter T. The base represents the bulbus, the shaft the short ventral aorta, and the right and left arms at the top are the branches of the truncus which later subdivide to form the afferent branchial arteries.

Afferent branchial arteries. Three on each side, located in the first, second, and third branchial arches (visceral arches III, IV, and V). Those of the fourth branchial arch have not yet appeared.

Efferent branchial arteries. Also three on each side, connected by capillary loops with the afferent branchials. ${ }^{1}$

* Radices aortae. The efferent branchial arteries on each side unite to form an aortic root.

Dorsal aorta. Formed by the union of the right and left radices aortae in the region of the pronephros.

Internal carotid arteries. These are anterior prolongations of the radices aortae.

2. Of the trunk

* Glomus. This is a short side projection from the point where the radices aortae are fusing, bulging out into the coelom opposite each pronephros.

3. Of the tail

Caudal artery. The direct continuation of the dorsal aorta.

c. Veins

1. Splanchnic

Vitelline (omphalomesenteric) veins. These arise on the ventral side of the thick-walled gut and pass forward around the liver to join the heart at the sinus venosus.

2. Somatic (cardinal system)

Anterior cardinal veins. These collect the blood from nu-

${ }^{1}$ The afferent and efferent branchial arteries are the representatives of the aortic arches III, IJ, and V, generally developed in vertebrate embryos. 
merous small tributaries in the head and convey it backward as far as the pronephros, where they turn and bend sharply downward to course along the anterior surface of that organ.

Posterior cardinal veins. These vessels course forward from the region of the cloaca ventral and lateral to the dorsal aorta, passing along the ventral surface of the pronephros until they meet and join the anterior cardinal veins.

Common cardinal veins (ducts of Cuvier). These vessels, formed by the union of the anterior and posterior cardinals on each side, course downward and enter the sinus venosus at points just dorsal to and lateral of the vitelline veins.

Caudal vein. This courses through the tail just ventral to the caudal artery. It divides into two branches which unite with the posterior cardinal veins on meeting the cloaca. Further details of the smaller arteries, veins, and lymphatics are omitted. The more advanced student is referred to the textbook and its references.

\section{1-MM. EMBRYO}

\section{(Larval Stage)}

The embryo of Rana pipiens attains the length of 11-mm. after 284 hours at a temperature of $18^{\circ}$ Cent. At this stage it has assumed the familiar tadpole shape with head and trunk forming an ovoid compressed dorsoventrally whereas the tail, compressed laterally, is twice the length of the body. The mouth is open and surrounded by horny raspers or oral combs. The mucous glands have degenerated but persist as two small vestiges. The large eyes protrude slightly. The openings of the nose, external nares, are located anterior to the eyes. The external gills are covered by folds developed from the hyoid arches (visceral arch II). This fold is fused with the ectoderm of the body on the right side, but on the left an opening, the spiracle, or opercular aperture, persists. At the base of the tail is the vent or cloacal aperture. On either side and dorsal to the vent are the buds of the posterior limbs.

\section{Laboratory Directions}

Make a drawing of the 11-mm. embryo from the left side (page 20).

\section{Directions for Study of Transverse Serial Sections}

The 11- $\mathrm{mm}$. tadpole is a larval stage in the development of the frog. It is a free-swimming animal carrying on all the functions of animal life except that of reproduction. It is to be expected, therefore, that its internal anatomy will be more complex than that of the embryos studied heretofore. Accordingly drawings of certain organ systems are provided, based on wax reconstructions. The student is expected to trace the organ systems through the series of transverse sections, noting in the marginal blanks the number of the slide, row, and section in which each particular structure is well represented. It is suggested that the study be commenced by examining a typical section of the tail and comparing it in detail with the tail of the 6-mm embryo. It will usually be easier to commence at the region of the cloaca and trace all structures forward. 
The 11-mm. Embryo from the Left Side.

ECTODERMAL DERIVATIVES

I. EPIDERMIS. No longer ciliated except on the tail.

II. SPINAL CORD AND BRAIN

a. Spinal cord. Extends forward until the roof thins.

b. Myelencephalon. The cavity widens in more anterior sections. The thin roof is the primordium of the choroid plexus of the fourth ventricle.

c. Metencephalon. Distinguished with difficulty from the myelencephalon. Located between the otic vesicles. At the anterior end, the roof thickens suddenly to become the primordium of the cerebellum.

* d. Mesencephalon. Just anterior to the thickened primordium of the cerebellum, two swellings form the optic lobes (corpora bigemina) of the mesencephalon. The roof of the mesencephalon expands widely anterior to the optic lobes. Its cavity is the mesocoel, iter, or aqueduct.

e. Diencephalon. Roof narrower than that of mesencephalon. Cavity called diacoel. Anterior boundary marked by epiphysis. 1. Epiphysis. Projects dorsally and anteriorly from roof of diencephalon. 
2. Infundibulum. Broad evagination from floor of mesencephalon. Extends posteriorly beneath mesencephalon as far as anterior end of notochord.

* 3. Optic chiasma. A swelling on each side of the floor of diencephalon anterior to infundibulum. Marks point of entrance of optic nerve.

4. Optic recess. Small evagination from floor of diencephalon. Marks anterior boundary.

f. Telencephalon. Its posterior boundary is the optic recess. Roof thin. From roof a folded vascular membrane called the anterior choroid plexus hangs down into cavity known as telocoel. Telocoel and diacoel (see above) make up third ventricle.

* 1. Cerebral hemispheres. Formed by dorsal anteroposterior constriction from roof of telencephalon. Cavity of each called lateral ventricle.

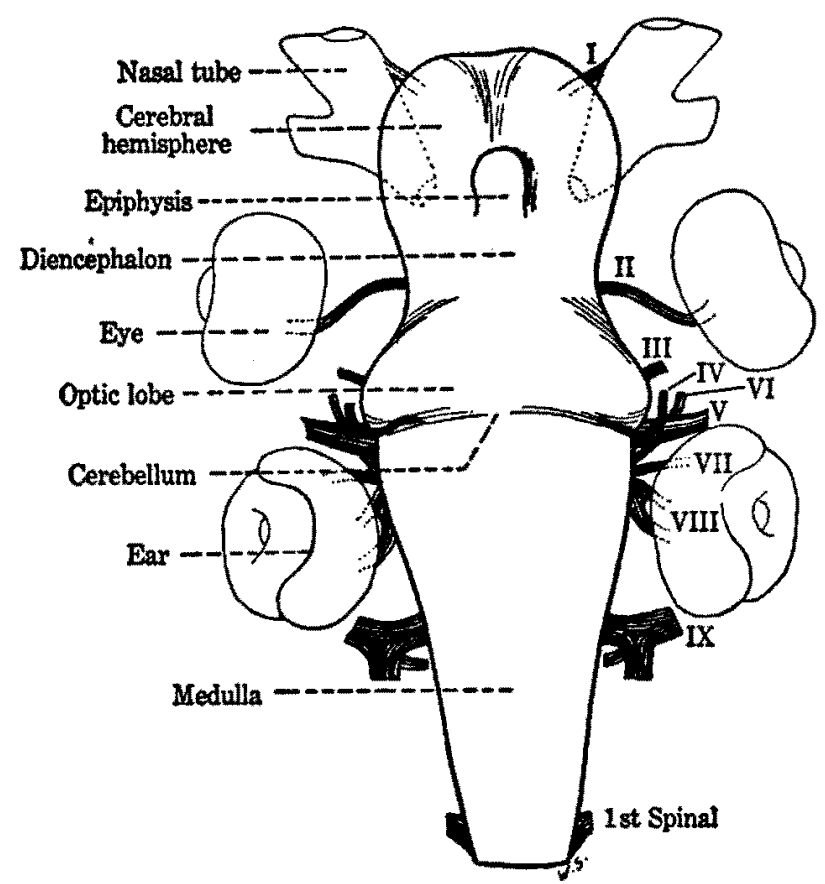

FIG. 11. Brain and sense organs of 11-mm. Rana pipiens embryo. From a wax plate reconstruction. Dorsal view. (Nots: Cranial nerve $X$, closely associated with IX, does not appear from this view.)

III. CRANLAL NERVES

a. Associated with nose

(I) Ophthalmic (olfactory). From ventral side of each cerebral hemisphere at its anterior end and passing directly to the mesial side of each nasal tube.

b. Associated with eye and listed in order from front to rear

* (II) Optic. From optic chiasma of diencephalon lateral and posterior to each eyeball. Can be seen passing through retina. (III) Oculomotor. Very small. Emerges from floor of diencephalon on each side, just dorsal to infundibulum.

(IV) Trochlear. Very small. Emerges from dorsolateral angle of metencephalon, just posterior to optic vesicles. 
(VI) Abducens. Very small. Emerges from floor of myelencephalon, just anterior and ventral to root of large trigeminal nerve (see below).

Note: These three nerves supply the muscles of the eyeball. They are very small and require the highest power lenscs of the student microscope.

c. Associated with ear and listed in order from front to rear

1. Just anterior to ear.

(V) Trigeminal. Large nerve with ganglion. Arises from ventrolateral angle of myelencephalon. Sends branches to maxillary and mandibular processes of first visceral arch.

2. Between ear and myelencephalon. Closely associated with each other.

(VII) Facial. Arises from side of myelencephalon. Sends branches towards trigeminal and to hyomandibular arch. Ganglion.

* (VIII) Acoustic. Arises with (posterior portion) facial. Supplies saccule and utricle of ear. Ganglion.

3. Just posterior to ear. Closely associated with each other. (IX) Glossopharyngeal. Arises with vagus but sends branches to first branchial arch. Ganglion.

(X) Vagus. Arises with glossopharyngeal but sends branches to second, third, and fourth arches to viscera and lateral line organs.

* IV. SPINAl CORd AND Nerve. Best examined in region posterior to pronephros.

a. Central canal. Expanded dorsal and ventral to a constricted central portion.

b. Ependymal layer. Layer of cells lining central canal.

c. Mantle layer. Thicker layer of cell bodies expanding on either side. Gray matter.

d. Marginal layer. Outermost layer of axons. White matter.

e. Dorsal root. Thin bundle of afferent fibers, running ventral to join dorsal root ganglion.

f. Dorsal root ganglion. Elongate thick bundle of neurones on either side of ventral half of spinal cord.

g. Ventral root. Thin bundle of efferent fibers, leaving ventrolateral angle of spinal cord to join nerve trunk.

h. Nerve trunk. Composed of efferent fibers from ventral root and afferent fibers from ganglion.

i. Dorsal ramus. Branch from trunk to dorsal muscles.

j. Ventral ramus. Branch from trunk to ventral muscles.

k. Communicating ramus. Passes around notochord to join sympathetic ganglion.

1. Sympathetic ganglion. A small mass of ganglion cells on either side of dorsal aorta. Not a part of the spinal nerve but associated with it. 
a. Ear. Now partially divided into two regions.

1. Utricle. Mesial and dorsal portion.

Semicircular canals. Two: anterior dorsoventral canal, and outer horizontal canal. (The third, posterior dorsoven-

2. Saccule tral has not developed.)

* Endolymphatic duct. Posterior to level at which anterior semicircular canal joins utricle. Between utricle and brain. Joins saccule.

Cochlea. Heavily pigmented and ciliated area on inner ventral angle of saccule.

b. Eye

* 1. Sensory layer of retina. Rods and cones, inner and outer granular layers and ganglion layer can be distinguished with high magnification.

2. Pigmented layer. Still characterized by heavy pigmentation.

3. Lens. Solid, lying in mouth of optic cup.

4. Choroid. Thin vascular layer (formed from mesenchyme).

5. Sclera. Layer of mesenchyme investing choroid.

6. Cornea. Continuation of sclera between lens and skin.

7. Eyeball muscles. Small masses of muscle between eye and brain.

c. Nose. The nasal pits have grown back to open into pharynx.

1. External nares. Open to exterior.

2. Internal nares. Open to pharynx.

3. Sensory epithelium. On side of tube nearest brain.

\section{ENDODERMAL DERIVATIVES}

The endodermal tube now opens to the exterior at both ends, by means of the ectodermal stomodeum and proctodeum respectively. The boundaries between ectoderm and endoderm at these points cannot be traced. Commence at the mouth and trace the digestive tube and its derivatives back to the cloacal opening.

a. Mouth. Extends from the oral aperture to the point where the internal nares mark the entrance of the nasal tubes.

b. Pharynx. The tube now flattens dorsoventrally to form the pharynx.

c. Visceral (branchial) clefts. The pharynx opens to the exterior at four points on each side where the visceral pouches (II, III, IV, and V) have opened into the corresponding branchial grooves. Pouch VI is vestigial and does not make contact with the exterior. The operculum covers the external gills. The clefts do not open directly to the exterior but ventrally into the opercular cavity. The external gills are now degenerated and will be replaced by internal gills. The opercular chamber approaches the ear very closely.

*d. Thyroid gland. Beneath the floor of the pharynx. Completely separated from it. The thyroid gland is now dividing at the posterior end. Pigmented and located just anterior to the heart. 
e. Thymus glands. Those from the first visceral pouch have disappeared, those from the second visceral pouch have separated from the dorsal end of the pouch. They are not easily to be identified and may be omitted.

f. Parathyroid glands (epithelioid bodies). Small masses of tissue formed on the ventral ends of the third and fourth visceral pouches. Their identification may be omitted.

g. Ultimobranchial bodies. Small pigmented bodies on the ventral side of the sixth visceral pouch, at the level of the trachea. Identification may be omitted.

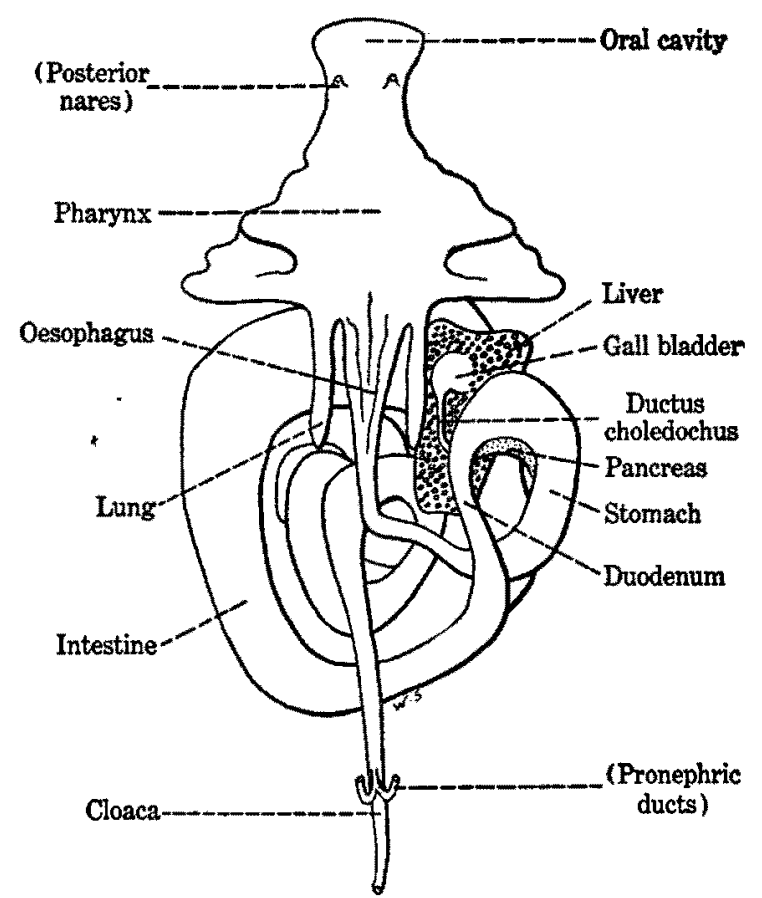

Fra. 12. Endodermal derivatives of 11-mm. Rana pipiens embryo. From a wax plate reconstruction representing a cast of the digestive tract. Dorsal view.

* h. Trachea and lungs. A slitlike dorsoventral evagination from the ventral side of the pharynx in the region of the visceral clefts. This is the Laryngotracheal groove. After passing a few sections this groove separates from the oesophagus above, becomes a tube, and sends out a branch, at sharp right angles to either side. These are the bronchi. As each bronchus proceeds backward its walls become highly vascular until at the end they condense again at the growing point.

i. Oesophagus. From the region of the laryngotracheal groove the oesophagus narrows rapidly and bends to the right at a level behind the liver to enter the stomach.

j. Stomach. Easily recognized by its wrinkled lining. The stomach may be traced forward and dorsally until it curves backward to join the duodenum.

k. Duodenum. From the pyloric end of the stomach, the narrow duodenum crosses over the oesophagus, swings to the left under the hind-gut to join the coiled intestine. - 
1. Liver. This large gland is now on the right side of the coelom. It has grown around the vitelline veins and is highly vascularized. On the dorsal side is the original liver diverticulum, now the gall bladder. From the posterior end of the gall bladder the common bile duct (ductus choledochus) proceeds through the mesentery connecting liver and stomach until it enters the duodenum on its anterior surface.

* $\mathrm{m}$. Pancreas. This gland is found alongside the inner curvature of the stomach. The pancreatic duct joins the common bile duct shortly before the latter enters the duodenum.

n. Intestine. Following the duodenum, the intestine increases greatly in diameter, and forms two complete spiral coils ventrally. It then ascends as a much smaller tube coiling within the larger spirals just described. On approaching the oesophagus it bends sharply backward, rapidly decreases in diameter, and slowly bends downward until it joins the proctodeum. There is no cloacal swelling. Shortly after crossing the duodenum the intestine receives the fused ends of the pronephric ducts.

\section{MESODERMAL DERIVATIVES}

I. MESENCHYME. In the head region condensations of mesenchyme have laid down the membranous cranium in which cartilage-forming (chondrogenous) centers have appeared. These give rise to the neurocranium. (See page 29.) Connective tissue of various kinds and the blood and lymph vessels of the head are also formed from the head mesenchyme. In the tail fin, mesenchyme is also present in great amount. Elsewhere in the body mesenchyme fills in the spaces between organs not occupied by body cavities.

II. NотосноRD. Still large and conspicuous. When examined with high magnification a thin layer of mesenchyme cells (from sclerotome) may be found around it, and continuing up around the spinal cord. This is the beginning of the axial skeleton, which lags behind the cranial skeleton.

III. somires. The most anterior somites are disappearing. Specimens may have eleven or twelve in the trunk, and a much larger number (thirty to thirty-five) in the tail.

a. Dermatome. This region of the somite is now broken up into mesenchymatous cells which have made their way to the ectoderm of the dorsal half of the embryo where they will form the dermis (cutis) of the skin. This layer apparently arises from somatic mesoderm in the ventral portion of the body.

b. Sclerotome. Now forms the mesenchymatous zone, from which the axial skeleton will develop.

c. Myotome. The remainder of the somite is now converted into muscle bundles lying close to the notochord. In the tail region each is divided into a dorsal and a ventral bundle.

IV. INTERMEDIATE MESODERM

a. Pronephros. Greatly enlarged owing to the coiling of its tubules. The nephrostomes are ciliated.

" b. Pronephric ducts. May be traced back on either side of the dorsal aorta and dorsal to the posterior cardinals until they unite. The fused portion bends ventrally and anteriorly to join the narrow cloaca.

c. Mesonephros. Not yet commenced its development. 
d. Gonad. Not yet developed. At the level of the pancreas it is possible to find with high magnification primordial germ cells. They are located in the roof of the coelom ventral to the posterior cardinal veins and in the dorsal mesentery at its junction with the coelomic roof.

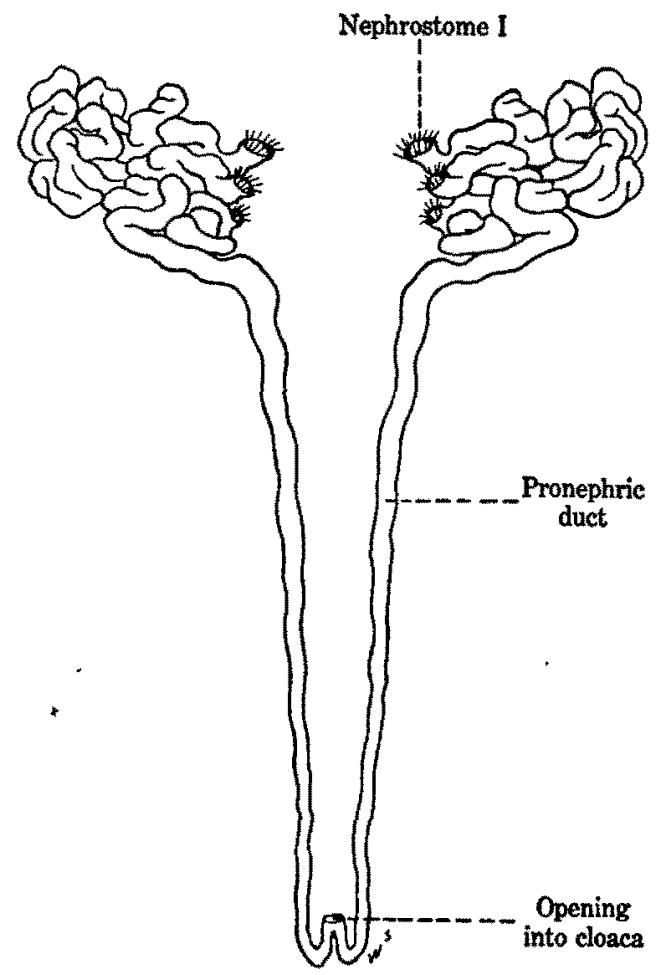

Fra. 13. Excretory gystem of 11-mm, Rana pipiens embryo. From a wax plate reconstruction. Ventral view.

v. LATERAL MESODERM. Somatic and splanchnic layers are closely opposed to the ectoderm of the ventral body wall and the endoderm of the viscera respectively.

a. Coelom. Three regions may be distinguished.

1. Pericardial cavity. Still connects with the abdominal cavity posterior to it.

* 2. Pronephric chamber. In the process of being separated from the abdominal cavity beneath it by the growth of the lungs.

3. Abdominal cavity. Does not extend behind cloaca.

b. Mesenteries. The dorsal mesentery is very thin but its two layers are apparent at high magnification. The ventral mesentery is represented only by the thin sheet between stomach and liver (gastrohepatic omentum).

vi. circulatory system. Consists of heart, arteries, veins, and lymphatics. Red blood corpuseles now easily distinguished.

a. Heart. Beneath pharynx. Commence at anterior end.

1. Bulbus arteriosus. First section of heart encountered.

* 2. Truncus arteriosus. Opens dorsally from bulbus. A short vertical vessel.

3. Ventricle. Thick walled and muscular, the most ventral of the two cavities seen in the same section. Communicates with bulbus arteriosus. 
4. Atria. Lie dorsal to ventricle. Partially separated into right and left atria by interatrial septum. Both communicate with ventricle through common *atrioventricular foramen. Left atrium receives the pulmonary vein (see below) on dorsal posterior surface.

5. Sinus venosus. Most posterior region of heart. Communicates with right atrium. Receives common cardinal veins (see below) at extreme right and left angles. Receives postcaval vein from liver (see below) ventral to right common cardinal vein.

\section{ARTERIES}

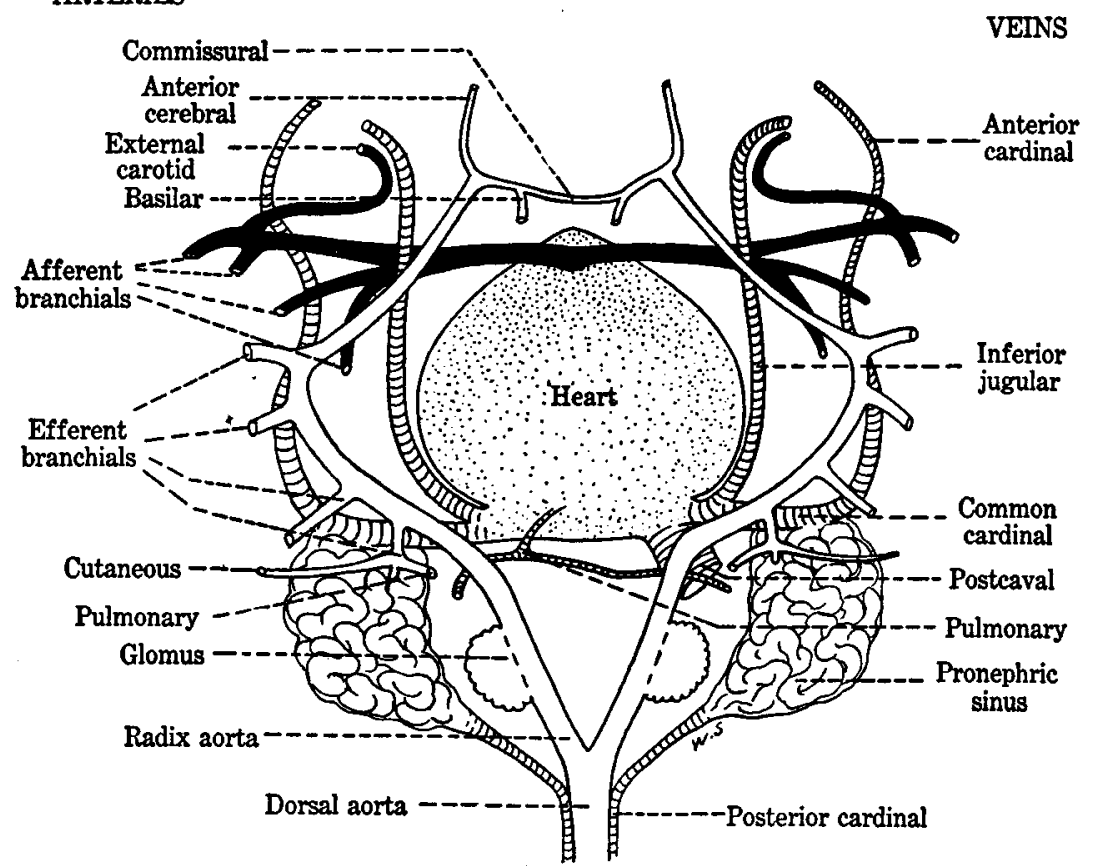

Fig. 14. Plan of circulation in 11-mm. Rana pipiens embryo. From a graphic reconstruction. Dorsal view.

b. Arteries. Only the main arteries are to be identified.

1. Afferent branchial arteries. Commence at level of truncus arteriosus. This vessel divides into left and right branches. Each branch divides into two portions. The anterior portion swings forward and laterally and then divides to form the first and second afferent branchial arteries. The second branch swings laterally and divides to form the third and fourth branchial arteries. From the first branchial artery, the external carotid (lingual) artery passes forward to the lower jaw.

2. Efferent branchial arteries. Locate the dorsal aorta at a level just posterior to the liver. Running forward it divides into the two * radices aortae (aortic roots), which run forward at the lateral margins of the pharynx. Where the pharynx begins to widen each root is joined by the fourth efferent branchial artery. From the fourth efferent branchial artery on each side a pulmonary artery grows out under the pharynx to supply its lung, and a cutaneous artery makes its way to the skin. 
Just anterior to the point where the fourth efferent branchial joins the aortic root, the third efferent branchial can be found. Anterior to the point where the third efferent branchial artery joins it, each root moves towards the midline, dorsal to the pharynx. They are then joined by large vessels, the second and first efferent branchial arteries, respectively. Anterior to the point where the first efferent branchial artery joins it, each root continues anteriorly and dorsally on either side of the base of the brain, to become an internal carotid artery. These arteries connect by a commissure beneath the infundibulum of the brain and divide into several smaller vessels of the head.

3. Dorsal aorta. From junction of aortic roots backward until it enters the tail as the caudal artery. Gives off numerous intersegmental arteries in its course.

* 4. Glomus. A vascular mass of tissue, supplied by branches from aortic roots anterior to their point of junction. Suspended in pronephric chamber median to pronephros on each side.

5. Mesenteric artery. Large vessel leaving dorsal aorta on ventral side and proceeding down dorsal mesentery to supply intestine.

c. Veins. Usually have thinner walls than those of arteries.

1. Hepatic-portal system. Formed from vitelline veins after the liver has grown around them.

Hepatic veins. Originally from liver to sinus venosus. They are now connected with the postcaval vein, a very large vessel (see below). From this stage on, the name hepatic veins is applied to the vessels inside the liver, whereas the portion from liver to sinus venosus is called the postcaval vein.

Portal vein. Branches from pancreas, stomach, and intestine unite to enter liver at posterior surface.

2. Cardinal system. The posterior cardinals now in process of transformation to postcaval.

Posterior cardinal veins. Best studied by commencing with caudal artery in tail. This divides into two vessels which join posterior cardinals at level where pronephric duct enters cloaca. They run forward ventral to dorsal aorta and mesial to pronephric ducts. In some specimens, a little further developed, these veins fuse.

* Postcaval vein (posterior vena cava). At the level where the mesenteric artery leaves the dorsal aorta, this large vein enters the dorsal surface of the liver. It can be traced back to right posterior caval vein which it joins. It runs forward through the liver to enter sinus venosus ventral to right common cardinal vein.

Nore: Anterior to point where postcaval vein unites with right common cardinal vein, the cardinal veins become much reduced and can be seen only with high magnification. They follow the pronephric duct of each side to enter the pronephric sinus, a saclike structure partially enveloping each pronephros. 
* Common cardinal veins (ducts of Cuvier). Drain pronephric sinus. Descend vertically across front surface of pronephroi to enter sinus venosus at posterior lateral angles.

Anterior cardinal veins (superior jugular). Join common cardinals at their most dorsal level. Accompany aortic roots into head. Finally take position dorsal and lateral to internal carotid artery.

Inferior jugular veins. Join common cardinals at their most ventral levels. Run forward on each side of heart. Accompany external carotid arteries to lower jaw.

d. Lymphatic system. Difficult to trace without assistance of injected specimens.

Spleen. Thickening in wall of dorsal mesentery alongside mesenteric artery. Represents lodgment of lymph cells which will later develop into spleen.

vir. ChondRocranium. The plan of the embryonic skull is laid down in connective tissue under the brain, around the sense organs, and in the visceral arches. In this embryonic stage many cartilage centers, easily recognizable by the large cells with their relatively clear cytoplasm, may be identified. The point of departure is the notochord, at the leyel of the anterior margin of the otic capsule, which is still in the precartilage stage, but will later form a cartilaginous capsule around the inner ear.

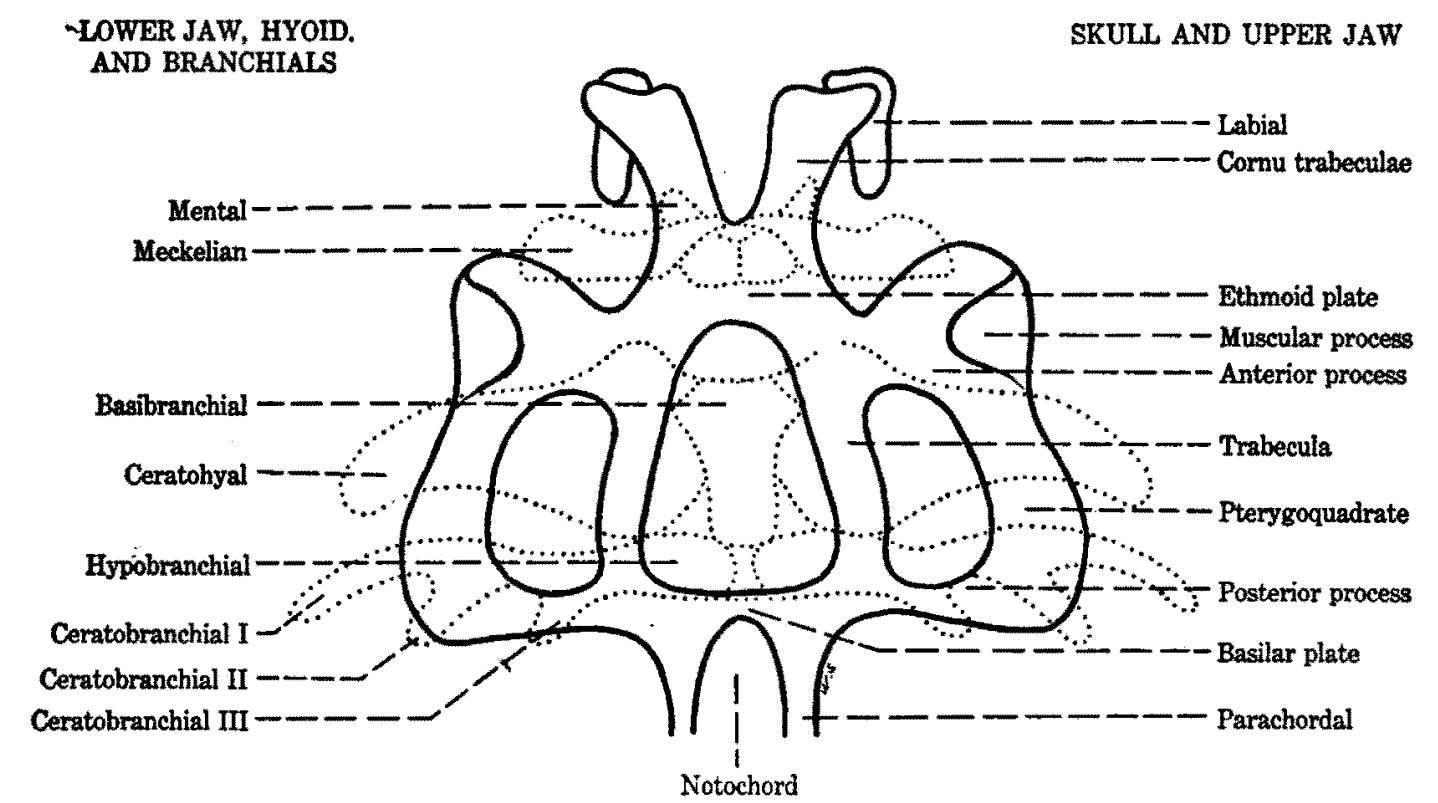

Fua. 15. Chondrocranium of $11-\mathrm{mm}$. Rana pipiens embryo. From a graphic reconstruction. Dorsal view. Neurocranium outlined in unbroken lines; splanchnocranium in dotted lines. (Nore: Pterygoquadrate, although formed from the first visceral arch, is outlined in unbroken lines because it is now fused with the neurocranium.)

a. Neurocranium. Around brain and sense organs.

1. Parachordals. On either side of the notochord at its anterior end.

2. Basilar plate. Immediately in front of the notochord, united with the parachordal on each side.

3. Trabeculae. These bars of cartilage swing wide to right or left and then extend anteriorly on either side of basicranial fontanelle. 
* 4. The basicranial fontanelle. This cavity is the seat of the pituitary gland.

5. Pterygoquadrate (palatoquadrate). Joins posterior end of the trabecula by its posterior ascending process, swings ventrally and to the side, and continues forward. This cartilage is formed from the maxillary portion of the first visceral arch but is mentioned here because of its union with the trabecula. At a level in front of the eye is the vertical muscular process for the attachment of jaw muscles. At the anterior end it swings toward the median line and rejoins the trabecula by its anterior ascending process.

6. Ethmoid (internasal) plate. Formed by the union of the trabeculae in the median line. Just anterior to the connection between trabecula and anterior ascending process of the pterygoquadrate.

7. Cornua tracecularum (trabecular horns). Two bars which diverge at the anterior end of the ethmoid plate and continue towards the anterior end of the head, accompanying the nasal tubes.

8. Labial (suprarostral) cartilages. Two short cartilages in the upper lip, one on each side of the mouth. They meet the cornua trabecularum.

b. Splanchnocranium. Formed in visceral arches. Follow from front to rear.

1. Mental (infrarostral) cartilages. In the lower lip on either side of the mouth. Meet in the mid-line at their posterior ends.

* 2. Meckelian cartilages. On the dorsal side of each mental cartilage and posterior to it. These rapidly extend to the side where muscles can be seen connecting them with the muscular process of the pterygoquadrate.

3. Ceratohyal. Several sections posterior to the last appearance of the meckelian cartilage. This large cartilage is formed in the hyomandibular arch.

4. Basibranchial (copula). An unpaired cartilage between the two ceratohyals. The basihyal (anterior to the basibranchial) has not yet developed cartilage. Its position may be recognized by the U-shaped thyroid gland which lies beneath it.

* 5. Hypobranchials. Posterior to each basibranchial and ceratohyal and articulating with each. A platelike cartilage formed in the third visceral arch.

6. Ceratobranchials. Extending back from the hypobranchials as four slender processes. The most lateral of these ceratobranchials, that is, the one in the third visceral arch, is the first to be noticed as one goes through the sections from front to rear. The second is in the fourth visceral, third in the fifth visceral, and fourth in the sixth visceral arch. The ceratobranchials have not yet appeared in the dorsal portions of the arches. 


\section{PART II}

\section{ANATOMY OF CHICK EMBRYOS}

\section{The Ovum}

\section{THE GERM CELLS AND FERTILIZATION}

The egg cell or ovum of the hen is the portion of the egg usually referred to as the yolk. It consists of a minute island of cytoplasm, the germ spot or germinal disc, floating on the yolk, which is a large ball of stored-up food material. The whole egg cell is enclosed in a very thin, delicate vitelline membrane. In addition to the egg cell proper, the egg, as we ordinarily know it, is made up of several layers of albumen surrounding the yolk; and these in turn are enclosed in tough shell membranes lining the hard calcareous shell (Fig. 16).

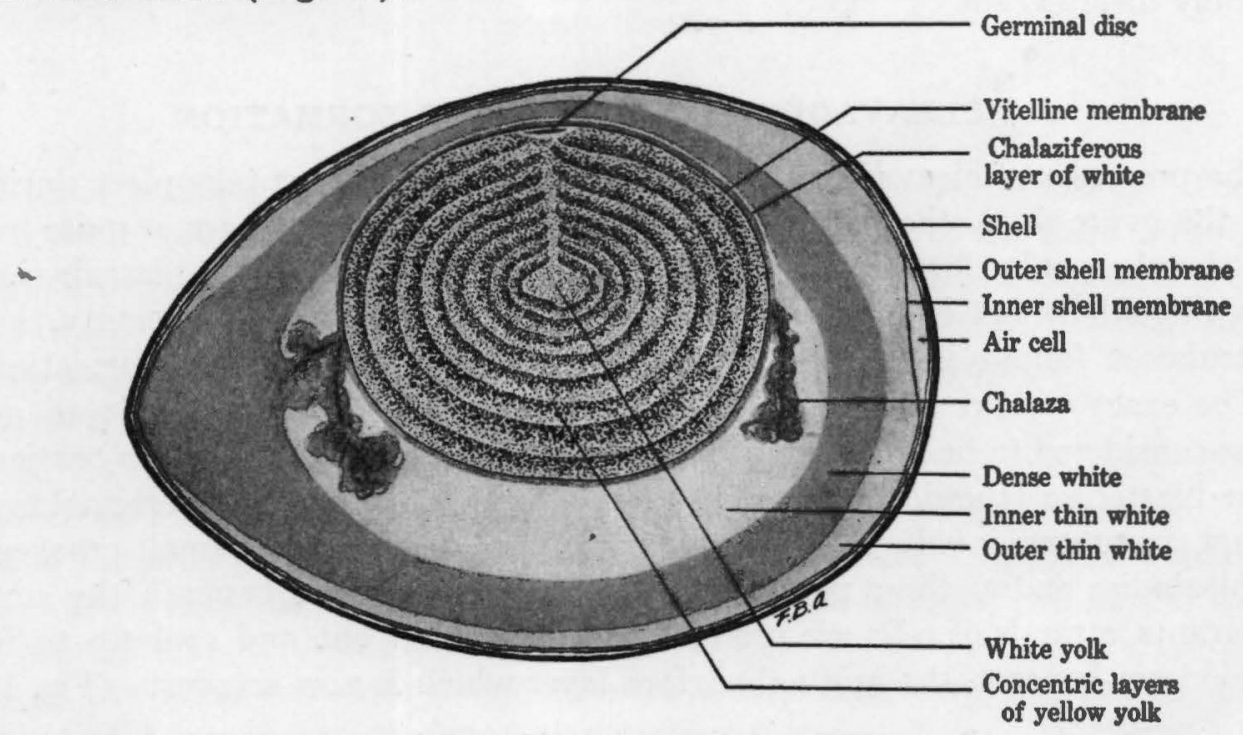

Frg. 16. Diagrammatic vertical section of a fresh hen's egg. From "Poultry Production," courtesy L. E. Card and the publishers, Lea and Febiger.

The yolk is laid down in concentric alternating light and dark layers around a central mass of white yolk called the latebra. This extends upward to the surface as a stalk of white yolk, where it spreads out as the isthmus of Pander, beneath the germinal disc. The innermost layers of albumen become twisted into coiled strands, the chalazae, which extend out from the yolk toward the ends of the egg. The parchmentlike shell membranes are separated from one another at the blunt end of the egg, thus forming the air chamber.

The albumen, shell membranes, and shell are membranes added to the egg during its passage down the oviduct. The albumen is a source of protein food material for the growing embryo, and the shell membranes and shell have a protective function.

It is interesting to note that a great deal of the stored-up yolk material is still present at the end of the period of incubation, when it is resorbed; and hence it is available as nutriment for the newly hatched chick.

Eggs vary greatly in size and in coloration, but the yolk is about $40 \mathrm{~mm}$. in diameter and the germinal disc about $4 \mathrm{~mm}$.

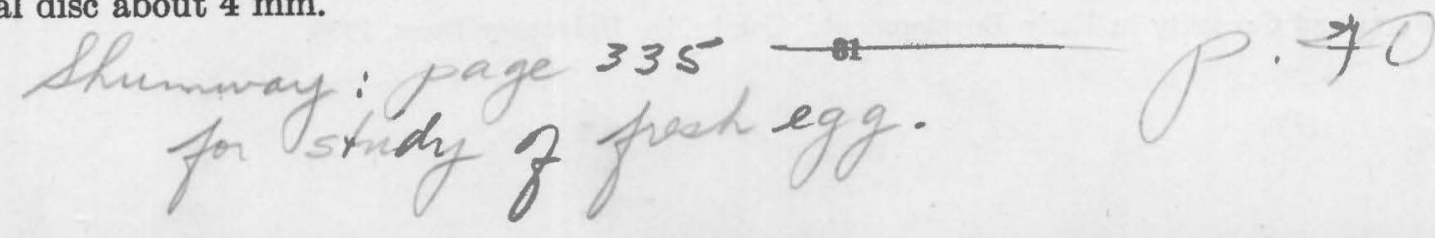




\section{The spermatozoön}

The male germ cell or spermatozoön, in contrast to the female reproductive cell, is a very minute body of microscopic size. It consists of an elongate head and a long, slender, filamentous tail which merges almost imperceptibly with the head (Fig. 17). The head, which is made up largely of nuclear materials, is surmounted by a slightly recurved acrosome.

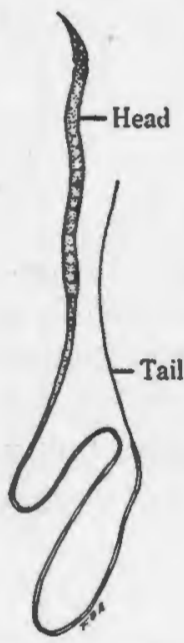

FIG. 17. Spermatozoön of the fowl.

\section{Fertilization}

The ovary of the laying hen contains numerous ova in various stages of development. The rate of growth of the vast majority of them is very slow and they are very small in consequence. In succession, certain ova, a few at a time, begin to increase rapidly in size, so that in the last 5 to 8 days of development fully $99 \%$ of the yolk material is added to each egg. Then, when the maturing egg has completed its growth, it is set free from the follicle of the ovary in which it developed and is picked up by the funnel of the oviduct. Immediately after it is liberated into the oviduct it is surrounded by fluids which contain myriads of spermatozoa received from a male in a prior copulation. Some of these enter the egg cell, and one fertilizes it. The remainder migrate to the periphery of the germ spot where they ultimately disintegrate.

\section{CLEAVAGE AND GERM LAYER FORMATION}

The processes of cleavage and gastrulation in the hen's egg take place during the passage of the ovum down the oviduct. Cleavage, from its earliest stages, is quite irregular and, since it involves only the tiny island of cytoplasm lying on the yolk, a blastula is soon formed consisting of a thin, discoidal sheet of cells separated from the yolk by a fluid-filled cavity, the blastocoel. The process of gastrulation follows immediately after cleavage and results in the formation of a twolayered embryo. The exact manner in which this is brought about is very difficult to demonstrate. Until recently it was considered to be a process of involution whereby the cells along a particular portion of the margin of the blastodisc (the dorsal lip of the plastopore) rolled under the original layer. Lately it has been shown that the process involves polyinvagination, that is, numerous small grooves appear on the surface of the blastodisc and at these points cells insinuate themselves beneath the surface layer." From these first migrants, strands of cells are produced which spread out and coalesce to form a continuous sheet of endoderm beneath the original surface layer which is now ectoderm (Fig. 18).

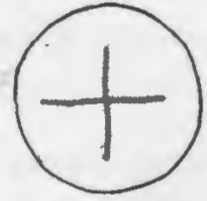

$a$

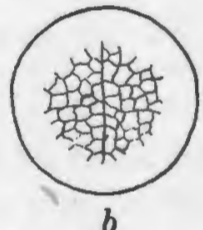

b

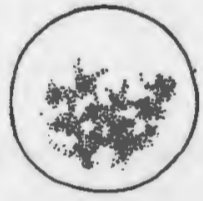

c

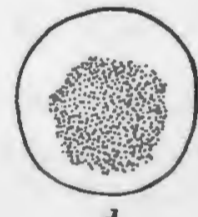

$d$

Fra. 18. Cleavage and endoderm formation in the chick. $a, b$, early cleavage; $c$, endoderm formation by polyinvagination: small solid lines represent furrows along which future endoderm (stippled) invaginates; $d$, the completed sheet of underlying endoderm Mesoderm Formation (stippled).

When development is resumed during incubation, the blastoderm begins to grow out rapidly over the yolk and formation of mesoderm from the two-layered gastrula begins. This involves an intermediate step, namely, the formation of the primitive streak. This structure has the appearance of a thickened line on the blastoderm. Until recently it was considered to be due to concrescence, a process involving the forcing together of the two halves of the dorsal lip of the blastopore. Actually it appears to be formed by convergence of surface material toward the future primitive streak accompanied by complicated streaming movements of cells in certain surface areas. ${ }^{1}$ The whole effect, therefore, is to force

${ }^{1}$ A. M. Daleq, "Form and Causality in Early Development," Cambridge University Press, 1938.
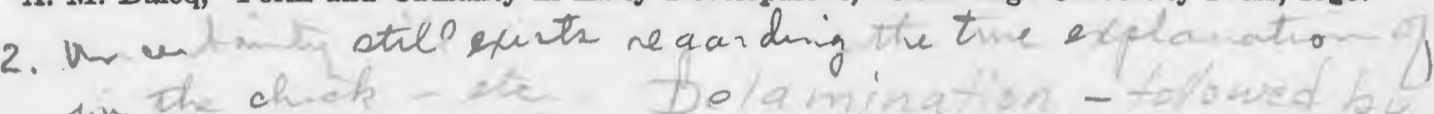
together cells from the right and left sides of the blastodisc as a linear thickening and to allocate certain cell groups to special regions of the blastoderm where they are destined to give rise to particular parts of the embryo. Some of the cells which move to the primitive streak invaginate and spread out between the two layers thus forming the mesoderm (Fig. 19). It grows out on each side from the tissue of the primitive streak as a broad winglike sheet extending forward and laterally. A rod of cells which constitutes the notochord also grows forward from the anterior end of the primitive streak, and is, therefore, considered to be of mesodermal origin.

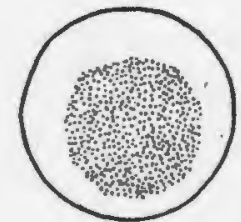

$a$

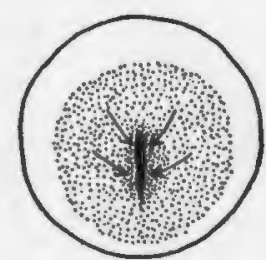

$b$

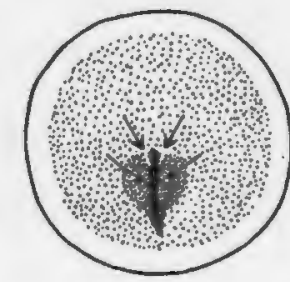

c

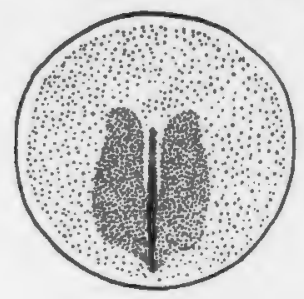

$d$

Fia. 19. Formation of the primitive streak and mesoderm in the chick. $a$, the gastrula; $b$, convergence of surface cells toward future primitive streak; $c, d$, lateral mesoderm and notochord extending outward from the primitive streak. Mesoderm heavily atippled, primitive streak solid black.

18-HOUR EMBRYO

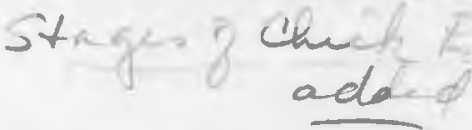

After 18 hours of incubation the chick embryo'begins to take definite form. The early part of this period is occupied by the process of gastrulation and the formation of the third germ layer, or mesoderm. Consequently, at this stage the blastoderm has the form of a small round plaque of tissue about $1 \mathrm{~cm}$. in diameter. In this blastoderm there can be seen a general division into a small, clear, inner area, the area pellucida, and a broad, outer, heavily stained margin, the area opaca.

The following parts of the embryo can be distinguished:

Head fold. A heavily staining crescentic fold of blastoderm near one end of the area pellucida.

Primitive streak. A heavily staining thickened streak tailing off away from the head fold toward the opposite side of the area pellucida. The primitive ridges constitute the lateral margins of the streak, and between these is seen the sunken primitive groove. The anterior end of the streak is marked by the nodelike primitive knot.

Notochord. A rodlike structure composed of mesoderm extending forward from the primitive knot toward the head fold can be seen in favorable specimens.

\section{Laboratory Directions}

Study carefully a stained total mount of an 18-hour embryo and identify the structures described above. Make a drawing of this embryo 2 inches in diameter and label all parts (page 34).

\section{4-HOUR EMBRYO}

\section{BODY FORM}

In the 6-hour interval of incubation which has elapsed since the 18-hour stage, considerable change has occurred in the embryo:

The head fold has become much more prominent and appears as a flattened finger-shaped structure protruding forward from the blastoderm, beginning at the level of the anterior intestinal portal (Fig. 20). The body is well marked out, and a number of paired blocklike somites have been formed on each side of the mid-line in the space between the head fold and the primitive knot. 


\section{Total Mount of an 18-Hour Chick Embryo.}

The blastoderm surrounding the chick shows several characteristic developments:

The area immediately surrounding the embryo, which is somewhat slipper shaped in general outline, is lighter and clearer in appearance and forms the area pellucida. Beyond the area pellucida the blastoderm is more opaque and hence is called the area opaca. In this region, particularly where it

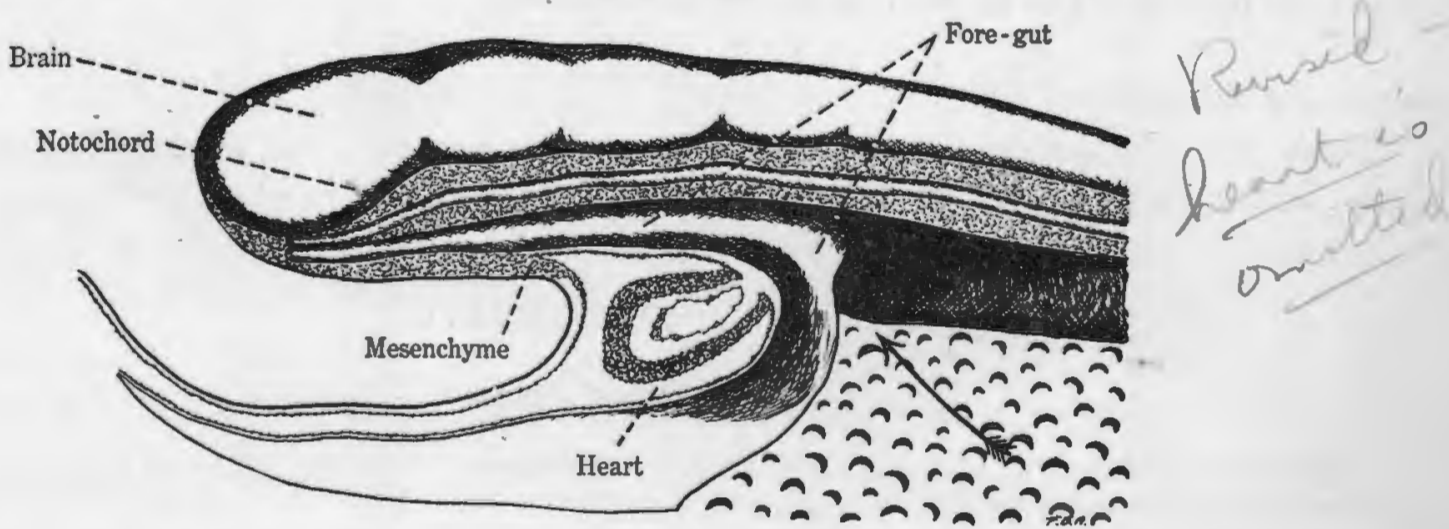

Fia. 20. Diagrammatic lateral view of the head fold of a 24-hour chick. Arrow indicates anterior intestinal portal.

adjoins the area pellucida, the blastoderm is splotchy in appearance owing to the development of heavily staining scattered aggregates of cells. These are blood islands, and the whole region is known as the area vaculosa. It is terminated laterally by a definite margin which later forms a blood vessel, the sinus terminalis. Beyond the sinus terminalis the blastoderm continues as the area opaca externa. 
chick Embryology

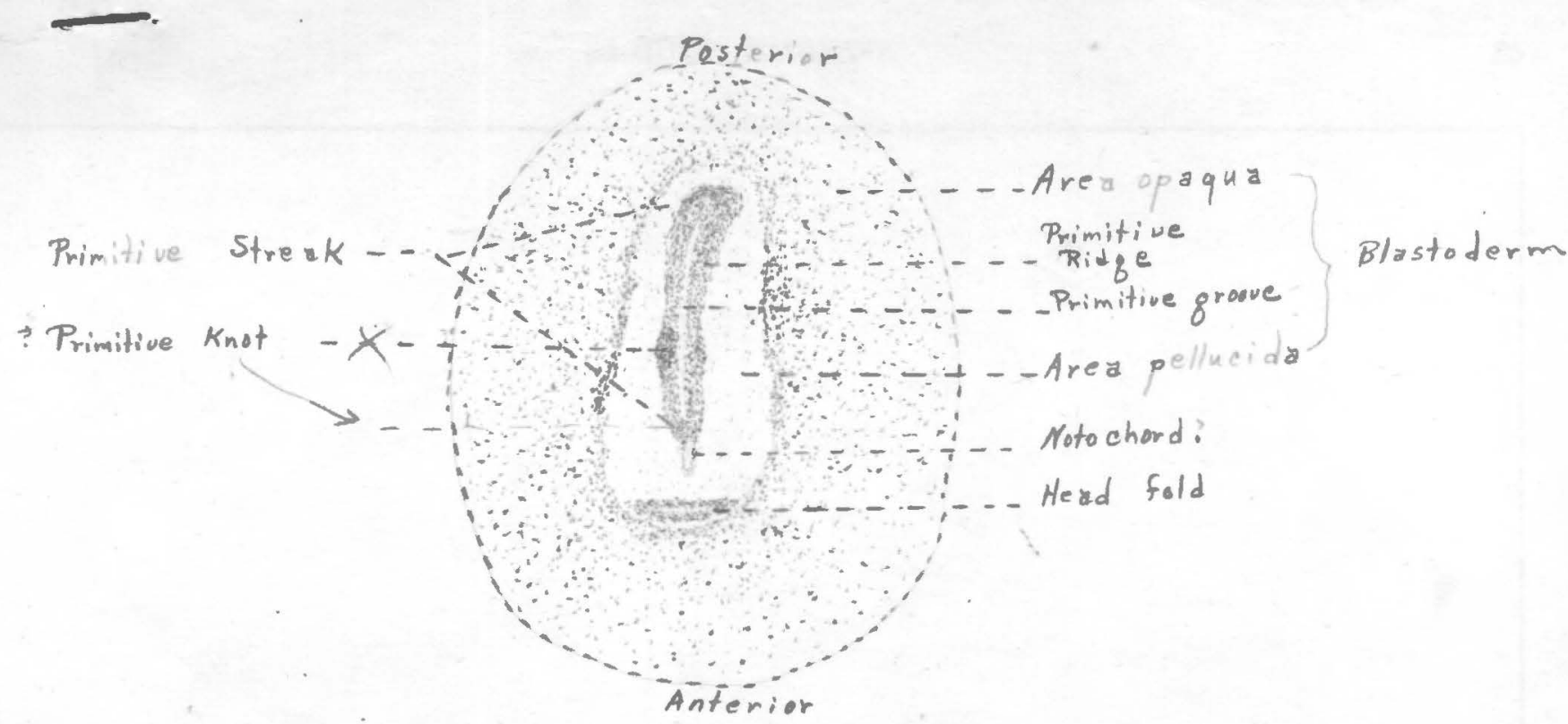
Fig I. Total Mount of 18 -hr. Chick
Embryo $x 7,5(1 . p)$

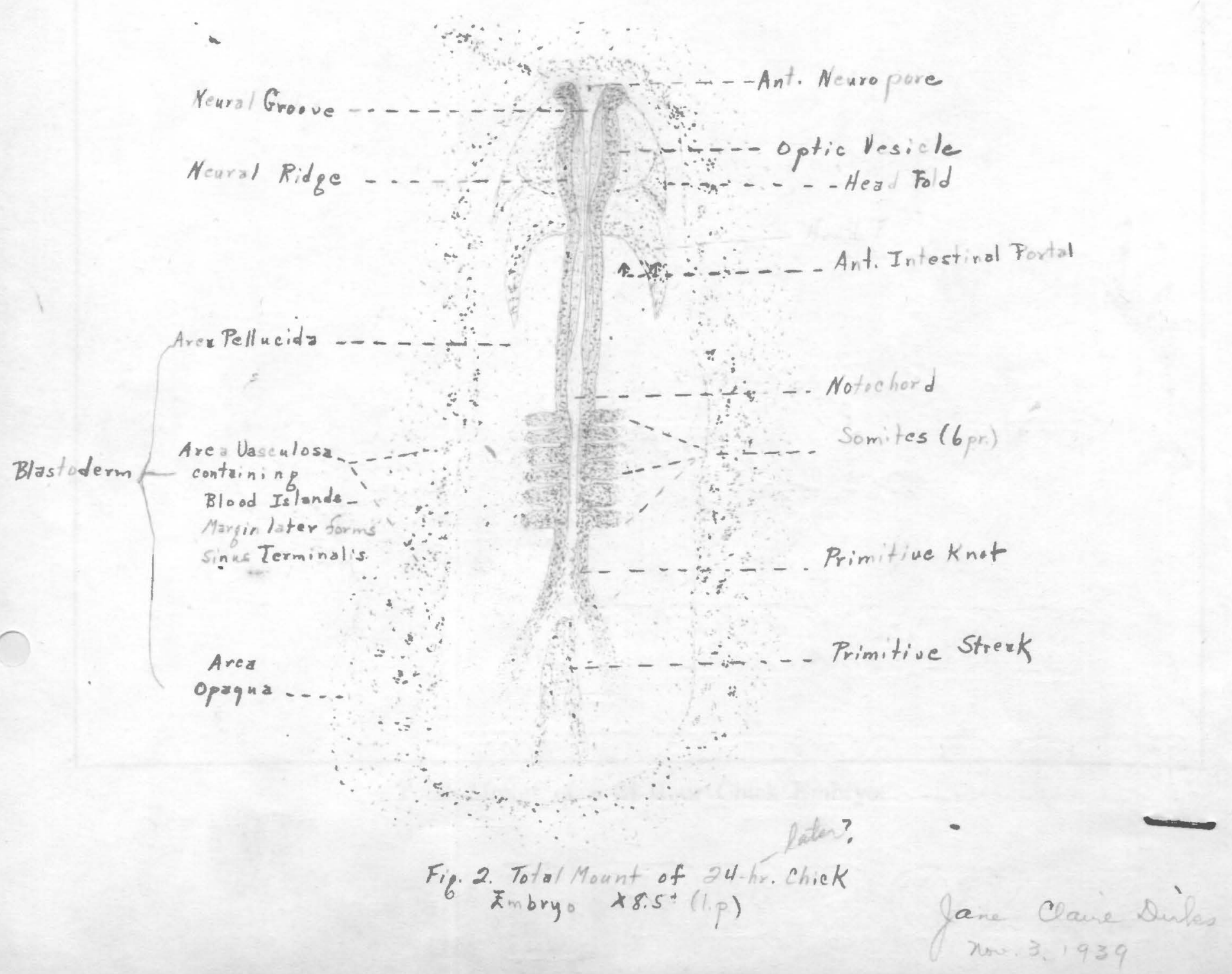




\section{Ectodermal Derivatives}

The ectoderm which forms the outer covering of the dorsal side of the head fold has already begun to differentiate into the beginnnings of the neural tube. This is brought about by the development of a furrow extending longitudinally down the dorsal side of the body. This furrow is bounded laterally by two ridges, the neural ridges, and the depression between is the neural groove. As the depression deepens the neural ridges ultimately meet in the mid-dorsal line, thus forming 'a closed tube, the neural tube. This process begins in the anterior end of the head fold and gradually works backward, so that at 24 hours the neural tube is usuially closed as far back as the posterior end of the head fold. Behind this point the neural ridges gradually open out so as to form the boundaries of the original neural groove. This process, which involves the sinking-in and closing-off of the tissues in a certain area, such as the surface ectoderm in this particular case, is known as invagination.

It is to be noted that at this stage the anterior end of the neural tube still retains a small opening to the outside which is known as the anterior neuropore. Some differentiation may already be apparent in that portion of the neural tube within the head fold to the extent that the anterior end of the tube, the forebrain, has prominent lateral bulges indicating formation of the optic vesicles.

\section{Endodermal Derivatives}

At this stage the endoderm, which lies next to the yolk, protrudes up into the head fold in the form of a flattened fingerlike pouch constituting the fore-gut. This lies beneath the brain, which is developing as described above. The fore-gut is a tubular structure communicating with the mid-gut by way of the anterior intestinal portal (Fig. 20). The mid-gut is open ventrally over the yolk, and lacks a floor.

\section{Mesodermal Derivatives}

At this stage the notochord extends forward from the anterior end of the primitive streak, beneath the neural tube, and up into the head fold in the form of a solid, cylindrical rod. Its anterior end frequently appears to merge with the neural tube. The lateral sheets of mesoderm which extend alongside the notochord do not extend into the head proper but instead proliferate a delicate netlike tissue, the mesenchyme, which grows up into the head and occupies the space between the developing organs already present. The lateral sheets do not meet beneath the head fold, and consequently there is no mesoderm in this region, which is known as the proamnion. In the region of the body proper, the portions of the lateral sheets adjacent to the notochord become divided off transversely into paired blocks known as somites. Little differentiation in the individual somites is evident at this stage beyond the fact that a cavity, the myocoel, is present in the center of each. Six pairs of somites are usually present at this stage. Lateral to the somites the mesoderm is separated tangentially into two sheets of cells; the upper in contact with ectoderm is the somatic mesoderm, and the lower in contact with endoderm is the splanchnic mesoderm. In the splanchnic mesoderm, cell aggregates forming the blood islands are to be found.

\section{Laboratory Directions}

A. Study carefully a stained total mount of the 24-hour chick and make a drawing of the embryo showing detailed structure. in the body proper and in a narrow strip of the blastoderm. The body should be drawn approximately 4 inches long. Label all parts.

B. Study through the transverse serial sections supplied and make a set of drawings of sections corresponding to the following levels: (1) forebrain, (2) anterior intestinal portal, (3) a somite, (4) primitive streak. Label all parts. 
Chick Embryology _.... ..... Plate II

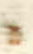

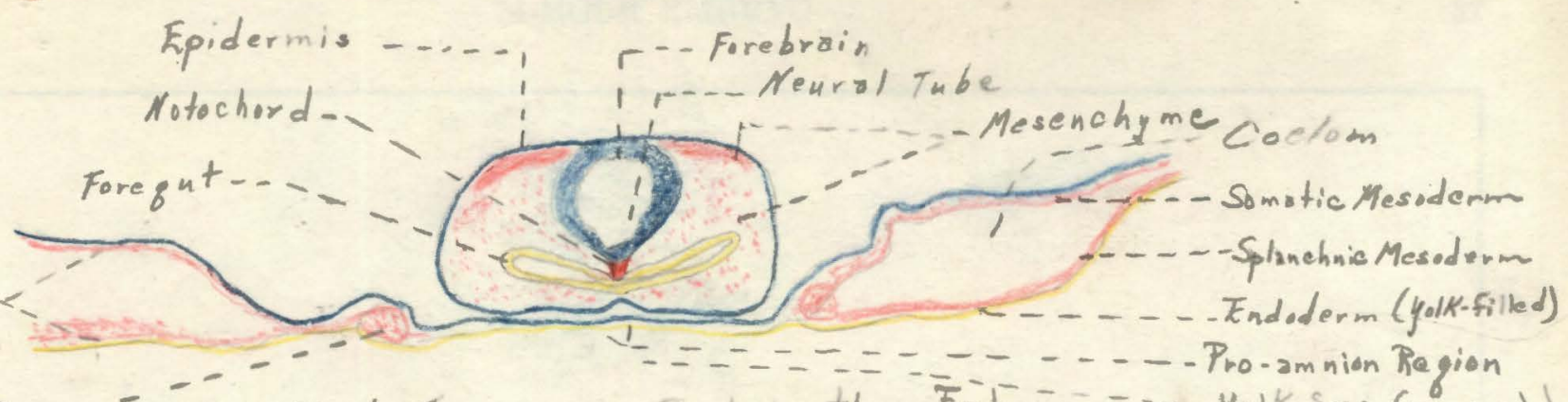

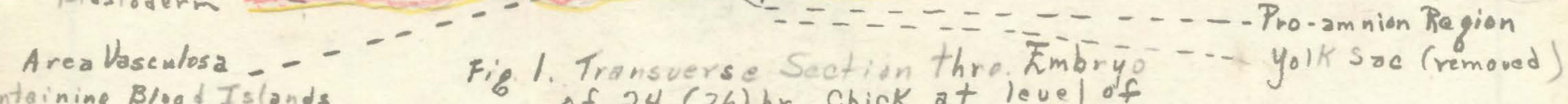
contrining Blood Islands

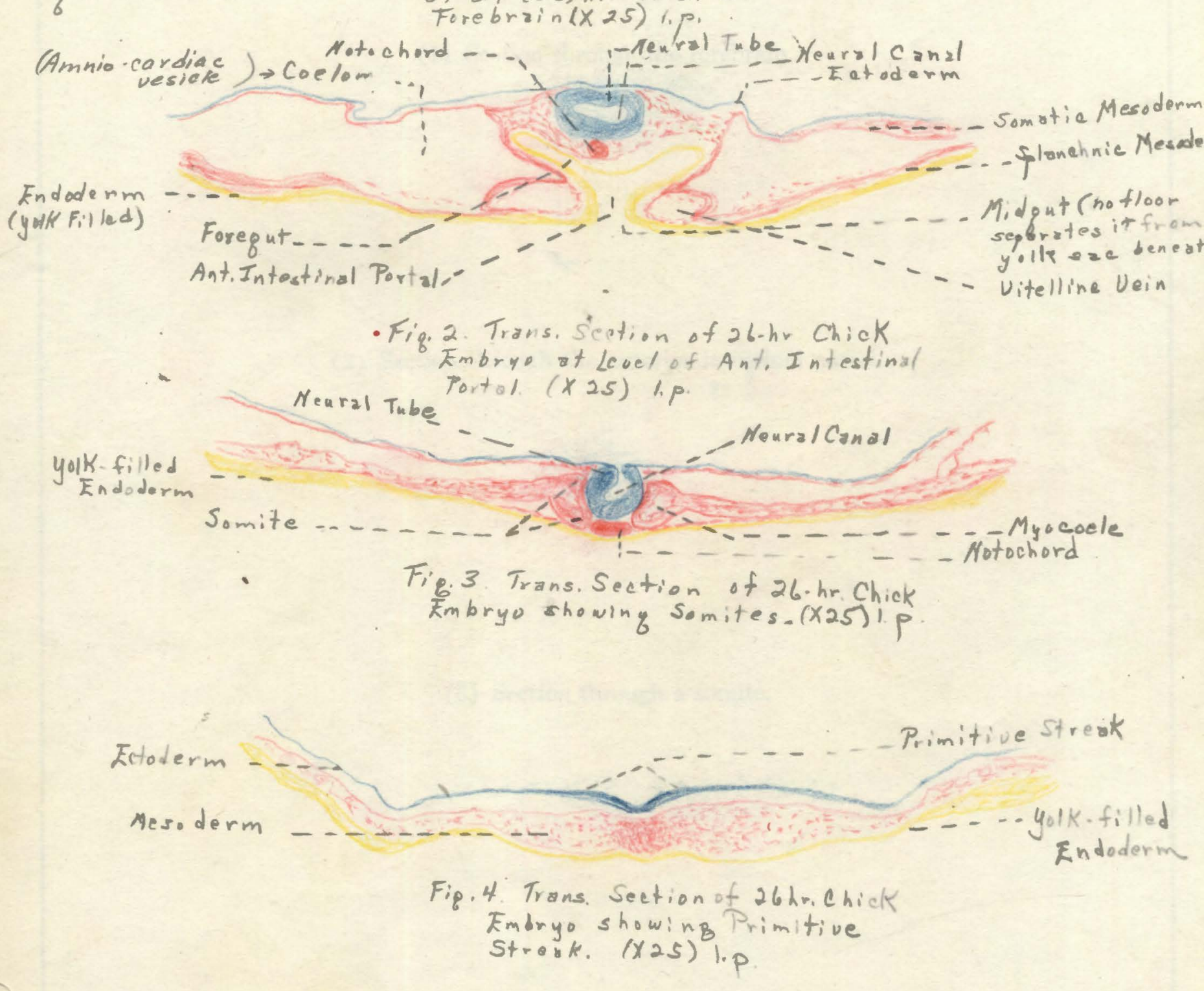

Fig. 4 Trans Section of 26 hr. Chick Emdryo showing Primitive
Strouk. $(x 25)$ l.p. 
(1) Section through the forebrain.

(2) Section through the anterior intestinal portal.

(3) Section through a somite.

(4) Section through the primitive streak.

Transverse Sections of a 24-Hour Chick. 


\section{3-HOUR EMBRYO}

\section{BODY FORM}

After 33 hours of incubation the embryo has increased in size to a little over $4 \mathrm{~mm}$. The head fold is considerably longer and bends downward slightly over the anterior end of the notochord. The body proper has also increased in length, and at this stage about 12 pairs of somites are present. Thickened ridges, extending out laterally just in front of the anterior intestinal portal, mark the beginnings of the vitelline veins. In the area vasculosa the blood islands are very prominent, and there is some indication that they are beginning to coalesce to form the blood vessels of the yolk sac.

\section{Ectodermal Derivatives}

The developing neural tube has closed over throughout almost its entire length. The anterior neuropore has usually been obliterated, but at the extreme posterior end the neural folds still remain broadly open, producing the large rhomboidal sinus. The brain shows three prominent vesicles at the anterior end, which named in order posteriorly are as follows: the prosencephalon, mesencephalon, and rhombencephalon. Behind the rhombencephalon a varied number of small constrictions are apparent. The sides of the forebrain or prosencephalon show prominent lateral bulges, which are the optic vesicles. On the sides of the head fold alongside the rhombencephalon the auditory placodes form thickened ectodermal areas which later invaginate to become the otic (auditory) vesicles.

\section{ENDODERMal ‘DeRIVATIVES}

Little change has taken place in the endodermal derivatives except that the fore-gut, extending up into the hèad fold, has grown in length along with the head fold.

is

\section{Mesodermal Derivatives}

The notochord is still present as a median rodlike structure beneath the neural tube. The lateral sheets of mesoderm are blocked off into twelve pairs of somites alongside the notochord. Mesenchyme is present in the head as at 24 hours.

In the region of the anterior intestinal portal the splanchnic mesoderm lying alongside the lateral walls of the intestinal portal bulges out laterally into the body cavity so as to leave a narrow space between it and the endoderm. This is occupied by a delicate tube formed from cells proliferated off the adjacent splanchnic mesoderm. In front of the anterior intestinal portal these two tubes fuse, and ultimately the dividing wall between them breaks down. In this manner the inner lining or endocardium of a single-chambered, tubular heart is formed. In a similar manner the thick, overlying bulges of splanchnic mesoderm also meet and fuse above and below this tubular structure so as to form the thicker epimyocardium of the heart and the supporting dorsal and ventral mesocardium. It will be noted, therefore, that the heart arises from two fused primordia, and consequently the vessels which grow forward from the heart are also paired.

These tubes growing forward from the heart are the ventral aortae. They are located beneath the fore-gut, and as they grow forward from the heart swing dorsally around the anterolateral ends of the fore-gut as the first aortic arches. They then course backward, dorsal to the gut, as the paired dorsal aortae. The actual extent to which this development has progressed at 33 hours varies with individual specimens, but at least the heart and vitelline veins are uniformly present.

\section{Laboratory Directions}

A. Study carefully a stained total mount of the 33-hour embryo. Make a drawing stressing particularly the form of the brain and also what can be seen of the developing circulatory system.

B. Study through the series and make drawings as follows: (1) through the region just in front of the anterior intestinal portal showing the heart; (2) through the region of the anterior intestinal portal to show the vitelline veins. 


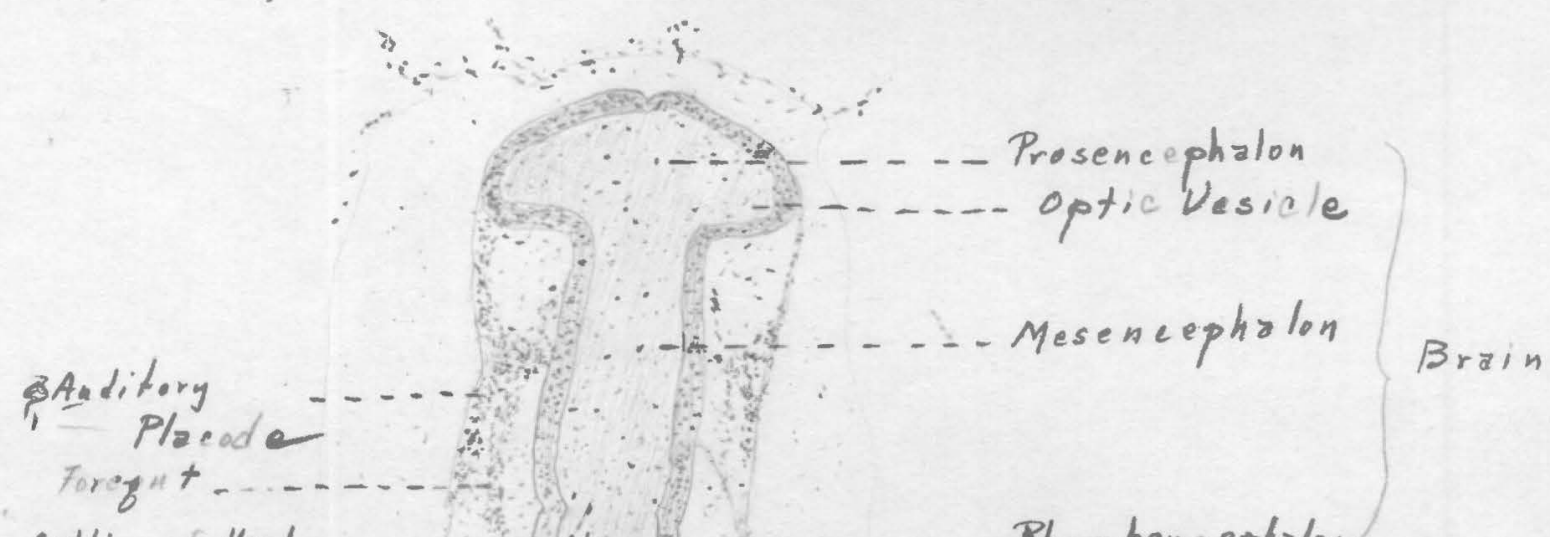

- Ant. Inteatinal Portal

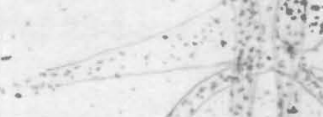
Sinus Venosus Heart a

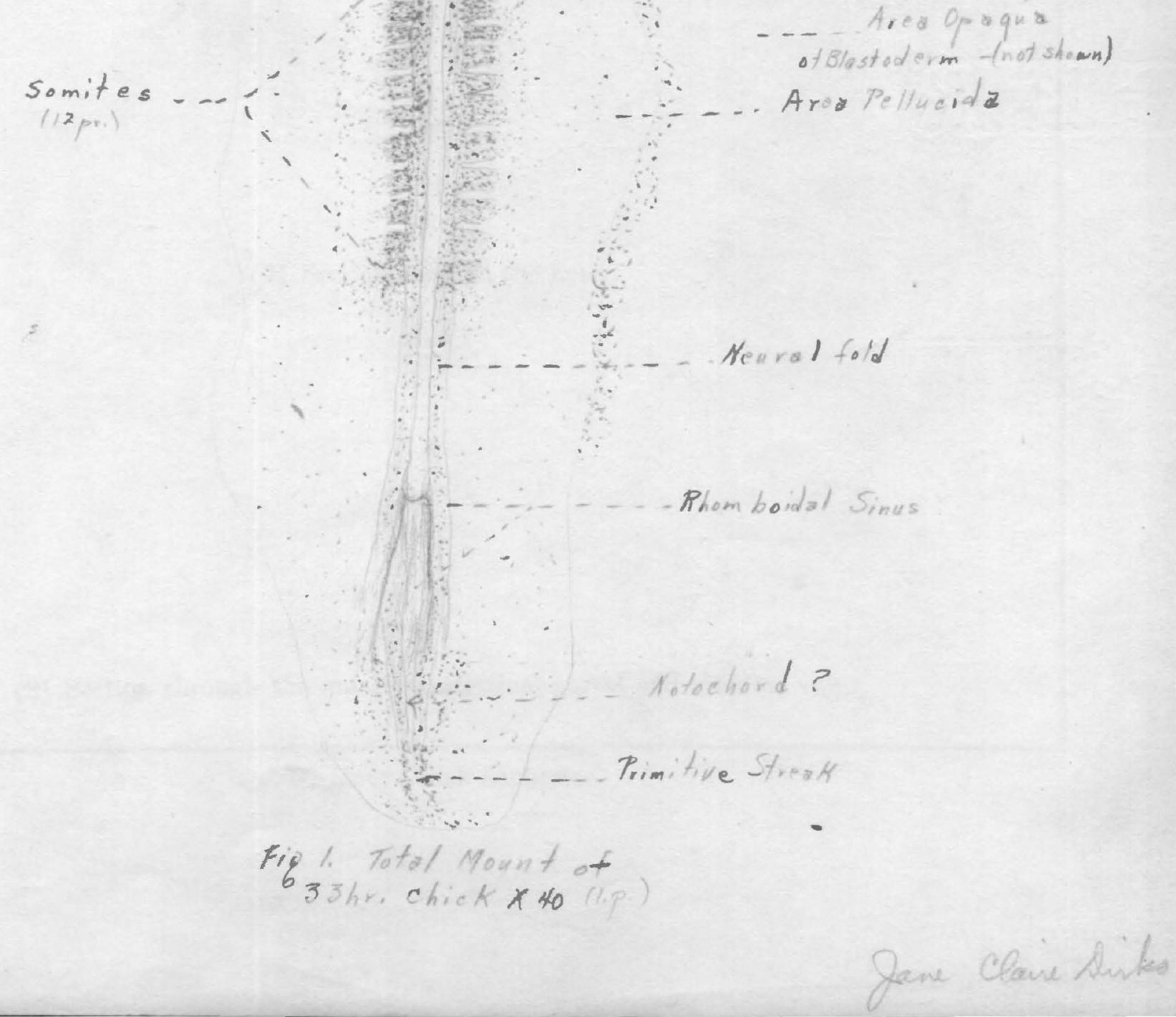


(1) Anterior end of 33-hour chick showing heart and forebrain.

(2) Section through the heart.

(3) Section through the anterior intestinal portal and vitelline veins. 


\section{8-HOUR EMBRYO}

\section{External Form}

From the 33- to the 48-hour stage the body of the chick has increased greatly in size, and its shape has been altered profoundly. The increase in size is due largely to the growth of the head and the addition of more somites to the body, so that its length is now about $7 \mathrm{~mm}$. and the number of somites approximately 26. The change in form is brought about by the development of several flexures or bends in the head fold and by twisting or torsion in the body proper so that the anterior portion lies mostly on its left side. As a result of this change in form, the head is more readily accommodated in the small space available beneath the shell since it lies flat on the yolk. At this stage the cranial flexure, which usually begins to appear in the region of the midbrain at 33 hours, has become so pronounced that, taken in conjunction with the cervical flexure in the region of the neck, the anterior end of the head is directed backward. Twisting or torsion occurs at the level where the head fold rises from the blastoderm. Hence the posterior half of the body lies in its original position with the ventral side down. At the extreme caudal end, the tail fold is being marked out very much in the same manner as that by which the head fold originated.

The head at this stage exhibits a number of prominent bulges corresponding to the divisions of the brain. There are also present the beginnings of the sense organs-nose, eye, and ear. Just posterior to the head on the lateral walls of the head fold three transverse slitlike openings can be seen. These mark the pharyngeal region. Protruding out ventrally from the body at about this level is the prominent heart.

\section{Amnion and Chorion (Fig. 21)}

The anterioc part of the body of the chick is covered by a fold of somatopleure (ectoderm + somatic mesoderm), which is thrown up over the body, beginning first in front of the head fold in the region recognized earlier as the proamnion. Mesoderm, however, has grown into this region in the meantime.

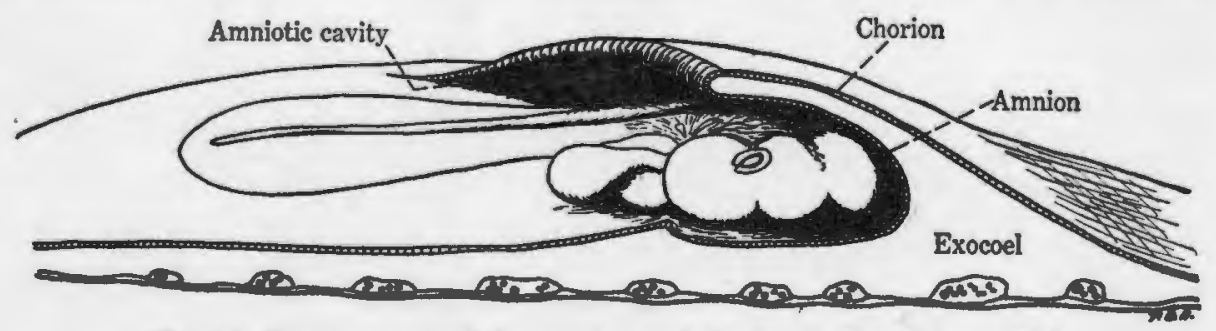

Fra. 21. Development of the amnion and chorion in the 48-hour chick.

Since the fold is reflected back out over the yolk sac again, two independent coverings are formed, namely: the amnion, which lies next to the embryo, and the chorion outside the amnion. The amnion contains a cavity, the amniotic cavity, which becomes filled with amniotic fluid. The space between the amnion and chorion represents an outward extension of the coelom called the exocoel.

\section{Laboratory Directions}

A. Study carefully a stained total mount of the 48-hour chick, and make a drawing of the embryo showing detailed structures. The body of the embryo should be drawn approximately 6 inches long. Label all parts.

\section{Circulatory System}

The circulatory system of the 48-hour chick represents a feature of fundamental importance. It should, therefore, be studied with the greatest care in both injected total mounts and in serial sections. The system is of mesodermal origin. Most of the details described below can be readily identified in injected specimens, and after they have been worked out should be recorded by a drawing. 


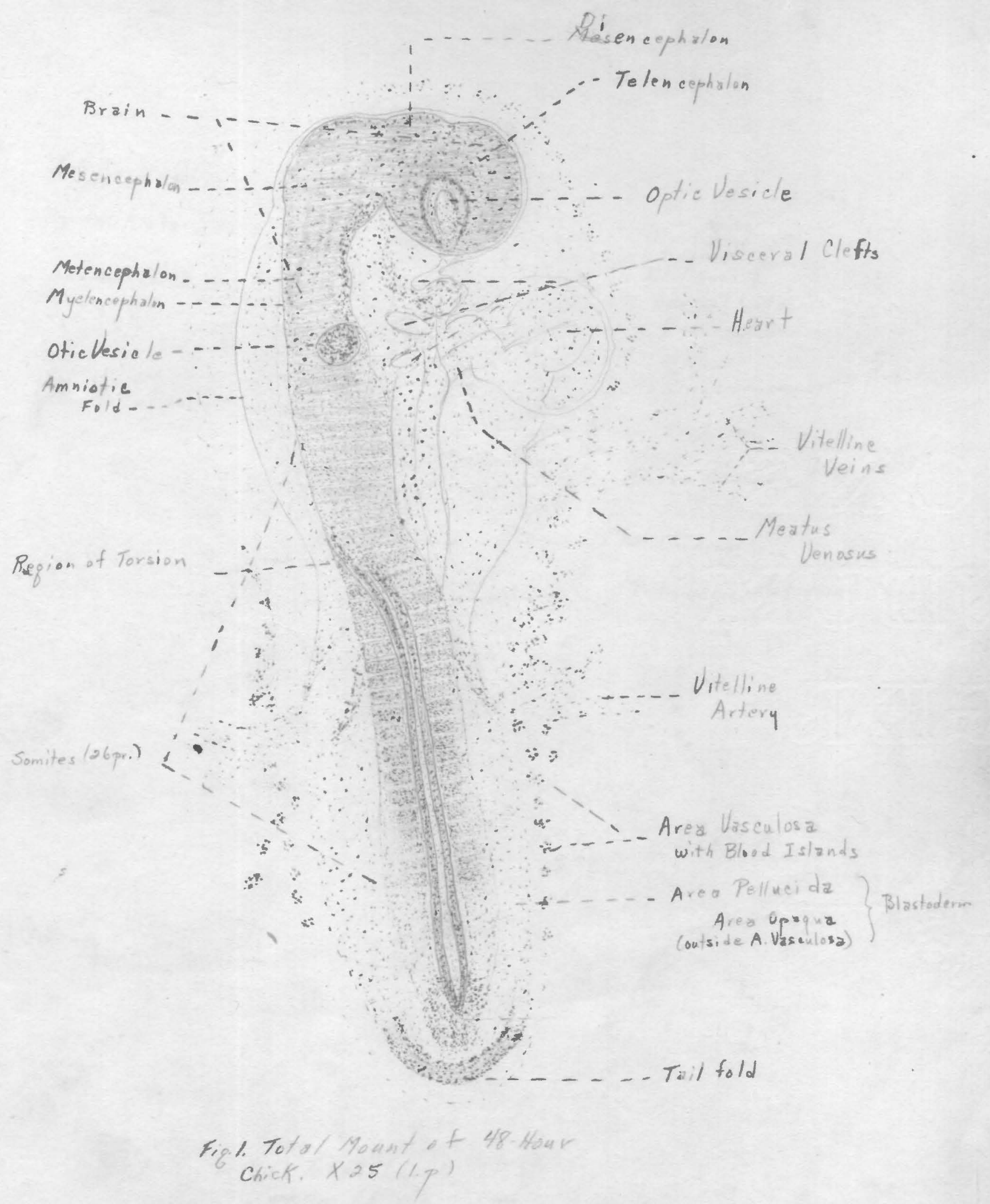




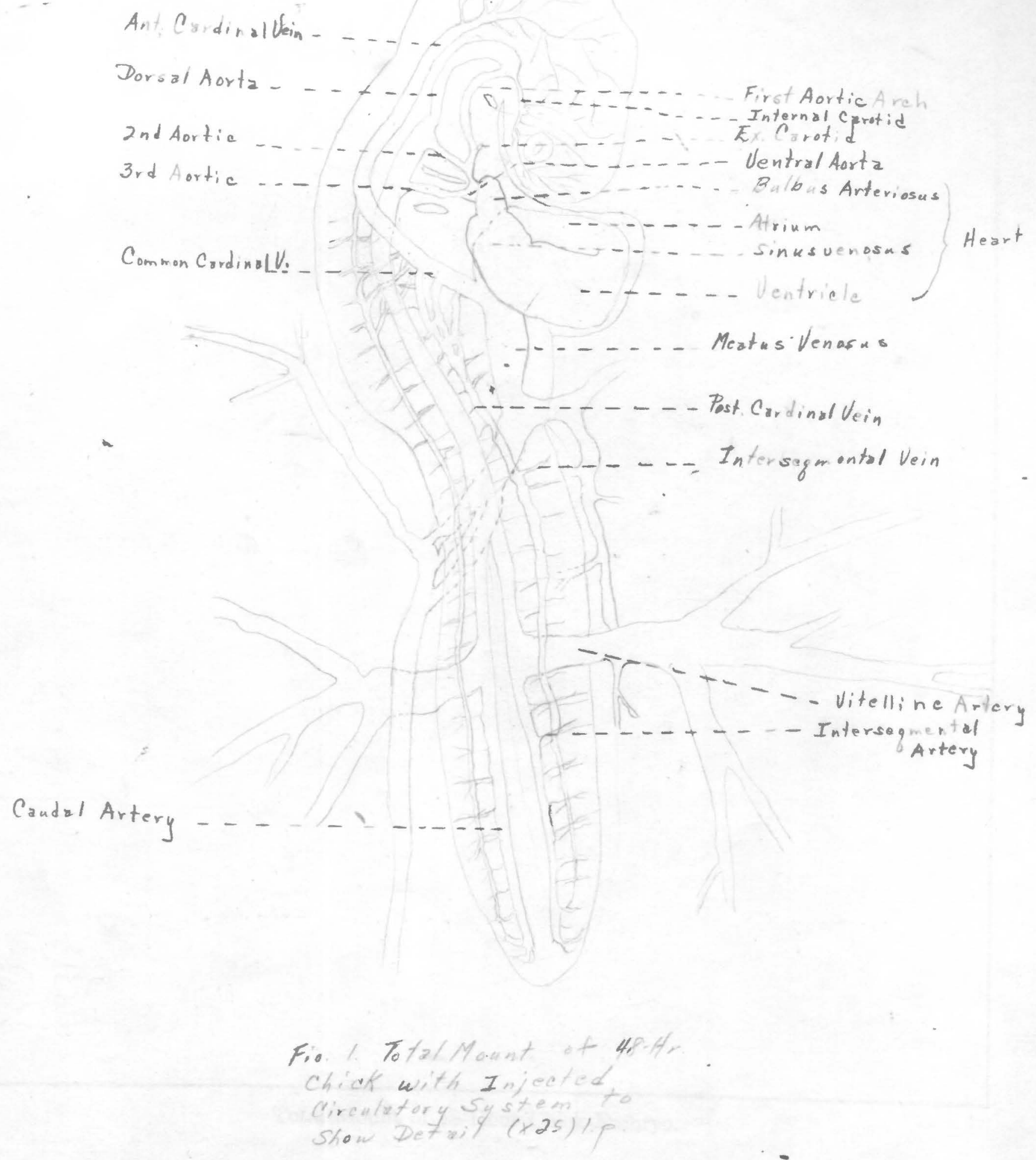


HEART

As pointed out in the study of the 33-hour chick, the heart develops from paired primordia, the posterior ends of which represent the stumps to which the vitelline veins from the yolk sac will ultimately attach themselves. The tubular structure lying in front of the anterior intestinal portal grows much more rapidly than the space in which it is accommodated. It adjusts itself to this situation by:

(1) Bending outward to the right (as at 33 hours) (Fig. 22).

(2) By looping so that the posterior end is pushed up under the anterior end (as at 48 hours) (Fig. 22).

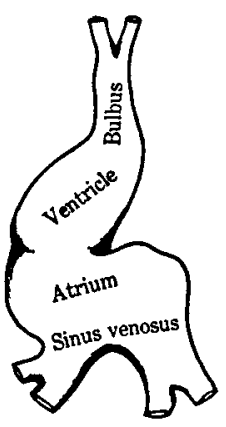

33 Hour

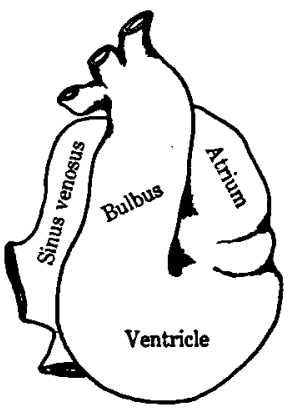

48 Hour

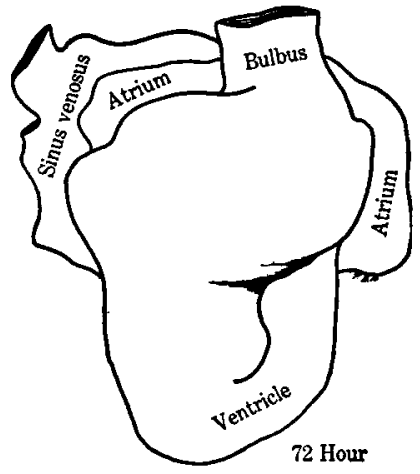

2 Hour

Fia. 22. Stages in the development of the heart of the chick.

Furthermore, a certain amount of differentiation in the character of the walls of the chambers of the heart has occurred at this stage so that we may recognize:

Sinus Venosus. The thin-walled posterior end situated in the mid-line which serves as a general receiving chamber. This region receives the fused vitelline veins, and hence can be readily recognized by locating them alongside the anterior intestinal portal and tracing them, after they have fused to become the meatus venosus, forward into the heart.

Atrium. Thin-walled and receiving blood from the sinus venosus. This chamber lies anterior to the sinus venosus but swings posteriorly to join the ventricle.

Ventricle. Thicker-walled with a developing reticulum of muscle bands, lined by a delicate endothelium and receiving blood from the atrium. The ventricle constitutes the posterior portion of the loop formed by the heart.

Bulbus Arteriosus. Thick-walled, round or oval in cross-section and possessing a delicate endothelium. This chamber runs forward from the ventricle and swings toward the mid-ventral line just below the visceral arches and clefts of the pharyngeal region.

Ventral Aortae. The blood leaves the bulbus arteriosus by way of the ventral aortae, which at this stage have almost ceased to exist, owing to their failure to keep pace with the growth of related vessels.

\section{ARTERIAL SYSTEM}

Aortic Arches. From the ventral aorta the blood was originally carried to the dorsal aorta by means of paired vessels swinging around the front end of the fore-gut and constituting the first aortic arch. These vessels still persist as the paired first aortic arch flowing through the first visceral arch, which has been established by the demarcation of the first visceral cleft. In addition, paired aortic arches have developed in the second and third visceral arches. These are the second and third aortic arches, respectively. They also course upward from the ventral aorta to join the paired dorsal aortae.

External Carotid. A minute vessel located at the point of origin of the first aortic arch. It can sometimes be seen to extend into the base of the first visceral arch where it breaks up into a capillary network. 
Internal Carotid Arteries. From the point where the first aortic arch meets the dorsal aorta, the latter extends forward into the head as the internal carotid artery to supply a capillary network to the brain.

Dorsal Aortae. The dorsal aortae are still paired in the region of the pharynx, and each vessel is often spoken of as a "radix" of the dorsal aorta. At about the level of the heart they fuse to form a single dorsal aorta. This opens out again to the paired condition slightly anterior to the level at which the vitelline arteries flow out to the yolk sac.

Vitelline Arteries. These course out laterally over the yolk sac about the level of the twentysecond somite.

Caudal Arteries. The backward prolongations of the dorsal aortae beyond the vitelline arteries form the caudal arteries.

Intersegmental Arteries. Since the body is growing rapidly by the lengthening of the head fold and the addition of somites to the trunk, a series of intersegmental arteries develop to supply its nutritional needs. These vessels are paired and course outward and dorsally between the somites arising from the dorsal aorta (or aortae).

VENOUS SYSTEM

\section{A. SPLANCHNIC VESSELS: VITELLINE VEINS}

The blood distributed to the yolk sac by the vitelline arteries is returned to the heart by the vitelline veins. The latter converge toward the region of the anterior intestinal portal, where the two main trunks fuse to form the meatus venosus just before entering the sinus venosus. The vitelline arteries and veins anastomose freely over the yolk sac, but large trunks from both arteries and veins communicate with the sinus terminalis encircling the blastoderm.

B. SOMATIC VESSELS: THE CARDINAL SYSTEM

Since a great increase has occurred in the amount of blood supplied to the developing body, a new set of veins, the cardinals, develop to drain blood back to the heart. These are laid down following the general plan of the letter $\mathrm{H}$-modified, of course, to the contours of the body.

Anterior Cardinal Veins. These vessels drain the head arising from the capillary plexus of the internal carotids over the brain. They course backward, following the ventrolateral angles of the neural tube until they have just passed the level of the otic vesicles. At this point they begin to swing ventrally but pass lateral to the dorsal aorta to join the common cardinals.

Common Cardinal Veins. These vessels (also paired) receive blood from the anterior and posterior cardinals and empty into the dorsolateral angles of the sinus venosus.

Posterior Cardinals. These vessels drain the somites of the posterior end of the body coursing lateral to the dorsal aortae and in close association with the developing mesonephroi, or embryonic kidneys.

Intersegmental Veins. The blood distributed by the intersegmental arteries is returned to the cardinals by way of the intersegmental veins which lie between somites and anastomose with the intersegmental arterioles.

NOTE: One of the most outstanding features of the developing circulatory system is the fact that all primordia of the original system are paired and that practically all new additions to the system are also paired. Future development depends on elimination of certain parts of the system and general simplification.

\section{Laboratory Directions}

B. Using injected 48-hour total mounts, study the circulatory system carefully and make a drawing showing the vessels described above. Label all parts. 


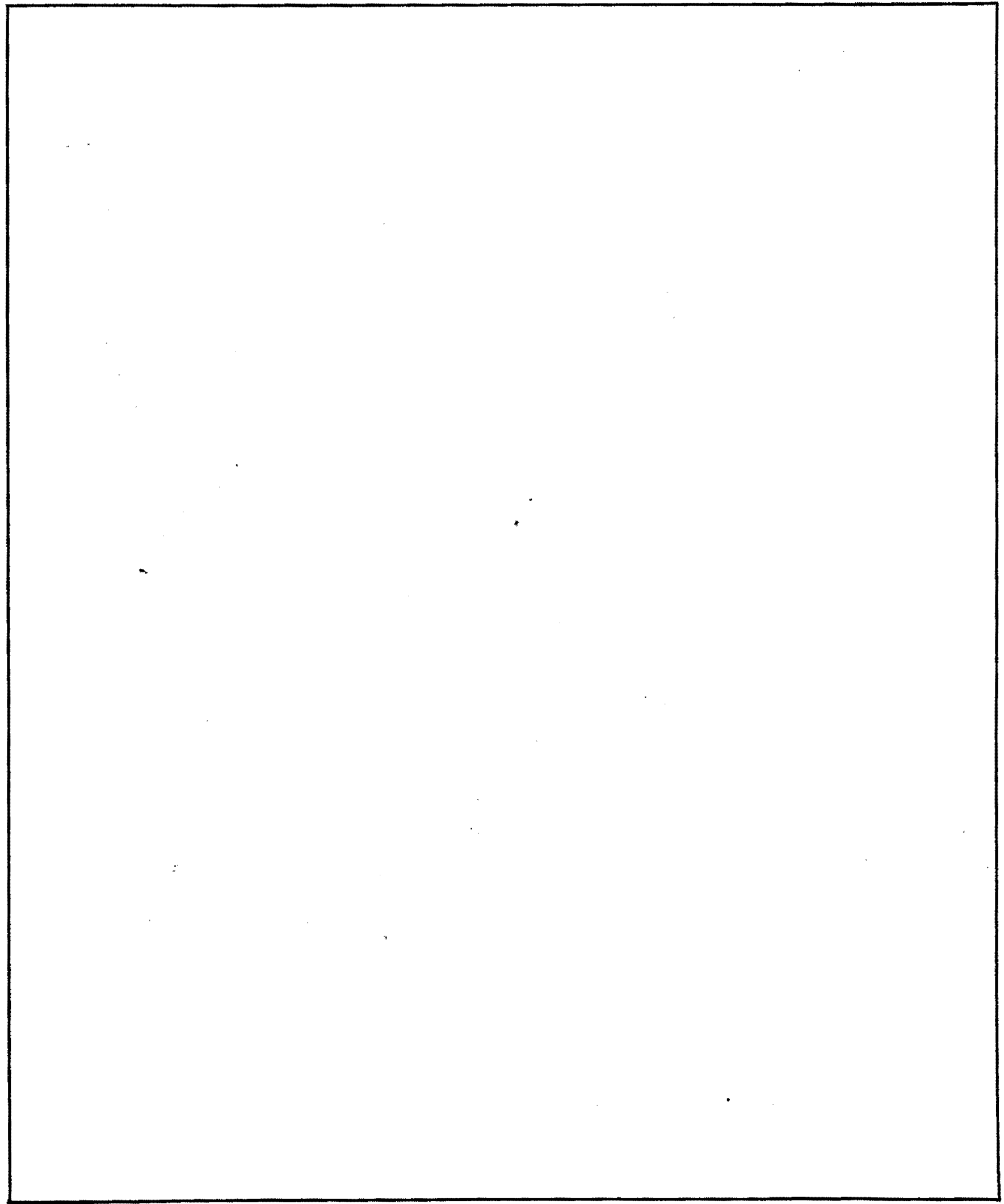

Circulation in 48-Hour Chick Embryo-Injected Specimen. 


\section{Representative Sections of the 48-Hodr Embryo ${ }^{3}$}

A. Section through the upper part of head (Fig. 23)

This section was taken through the head at a level just below the floor of the brain in the region of the cephalic flexure. For this reason it shows the mesencephalon (9) as a thick-walled rounded structure quite separate from the thin-roofed myelencephalon (1). In the mid-line between the two is a small portion of the notochord (4). Alongside the left ventrolateral margin of the myelencephalon is a heavy condensation in the mesenchyme (2). This is the semilunar ganglion of the trigeminal nerve (V). The nerve proper (3) can be seen leaving the lower side of the ganglion. The other trigeminal

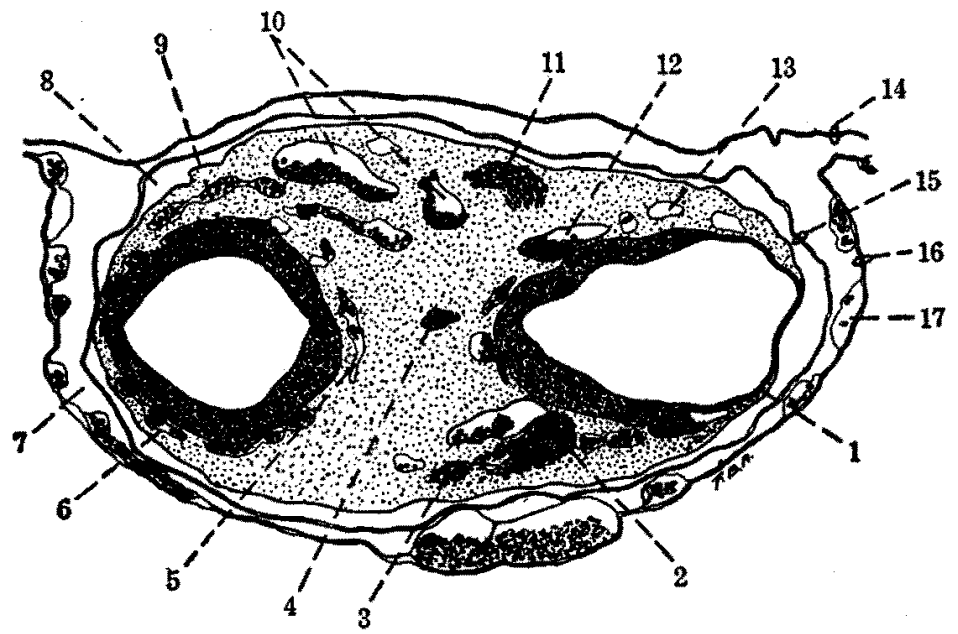

Fig. 23. Section through the head of a 48-hour chick at the level of the mesencephalon.

nerve (11) has been cut so that it appears as a small band of fibers in the mesenchyme on the opposite side. The anterior cardinal veins (12) also lie along the ventrolateral margin of the myelencephalon, and the one shown on the right side (10) extends forward toward the mesencephalon. Small branches of this vein (13) are located alongside the myelencephalon. Closely applied to the surface of the mesencephalon are a number of small blood vessels $(5,6)$ which represent portions of the capillary plexus of the internal carotid artery supplying the brain. Surrounding the head are: the amnion (15), which forms a closed sac; the chorion (14), which lies outside the amnion; and the yolk sac (16), also covered by the chorion and containing numerous blood vessels (17). The amniotic cavity (8) and the exocoel (7) are also shown.

B. Section through the upper end of aortic arch $I$ at the point of origin of internal carotid arteries (Fig. 24)

In this section the head is cut twice, owing to the cranial flexure, and the posterior end is almost completely separated from the anterior end. In the posterior end note the thin-roofed myelencephalon (1), alongside which lie the otic vesicles $(2,20)$. Owing to the tilt in the plane of section, the left (2) appears to be just invaginating but the right (20) appears as a closed vesicle. Associated with the left otic vesicle is the acoustic ganglion (3) of the auditory nerve VIII. The anterior cardinals (19) lie at the ventrolateral angles of the myelencephalon; the notochord (4) is ventral to it. Immediately above or dorsal to the gut are the paired dorsal aortae (18).

In the anterior portion of the head the brain is represented by the thick-walled, oval-shaped diencephalon (12) which is constricted ventrally to form the infundibulum (13). Beneath the infundibulum is Rathke's pocket (9), which represents an evagination of the stomodeum (8), and which, in association with the infundibulum, forms the hypophysis or pituitary body. Extending alongside the stomodeum is a pair of elongate blood vessels. These are the internal carotids (16) and the first aortic arch

${ }^{1}$ All sections are shown exactly as they appear in the microscope. Deseriptions apply only to the sections illustrated in the manual. The student will probably encounter some variations in the sections studied by him. 
(17) combined. Small branches of the carotids (11) lie close to the brain. Branches of the anterior cardinals (10) are evident in the lateral areas. The right optic cup (14) is cut so that it shows as a hollow structure containing the solid lens primordium (15). The pharynx shows two lateral outpocket-

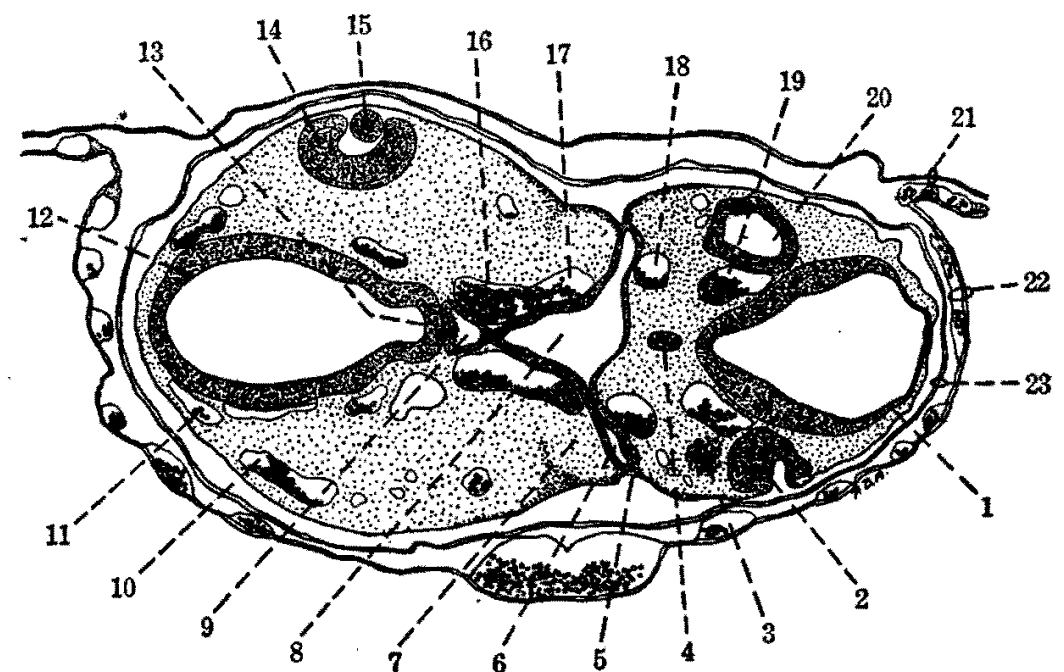

Fig. 24. Section through the head of a 48-hour chick at the level of the eye and ear.

ings which form the first visceral pouches (6). Anterior to the first pouch on the right side, the head shows a distinct bulge which represents the first visceral arch (7), in which the first aortic arch flows. The first viseeral groove (5) is to be seen on the side of the head.

C. Section through the body proper and heart (Fig. 25)

At this level, and throughout the rest of the series, four typical structures are to be seen in the midline arranged from dorsal to ventral, as follows: spinal cord (1), notochord (2), dorsal aorta (3), gut (4). Lateral to the spinal cord are paired thickenings in the mesoderm constituting the dermatomes (14)

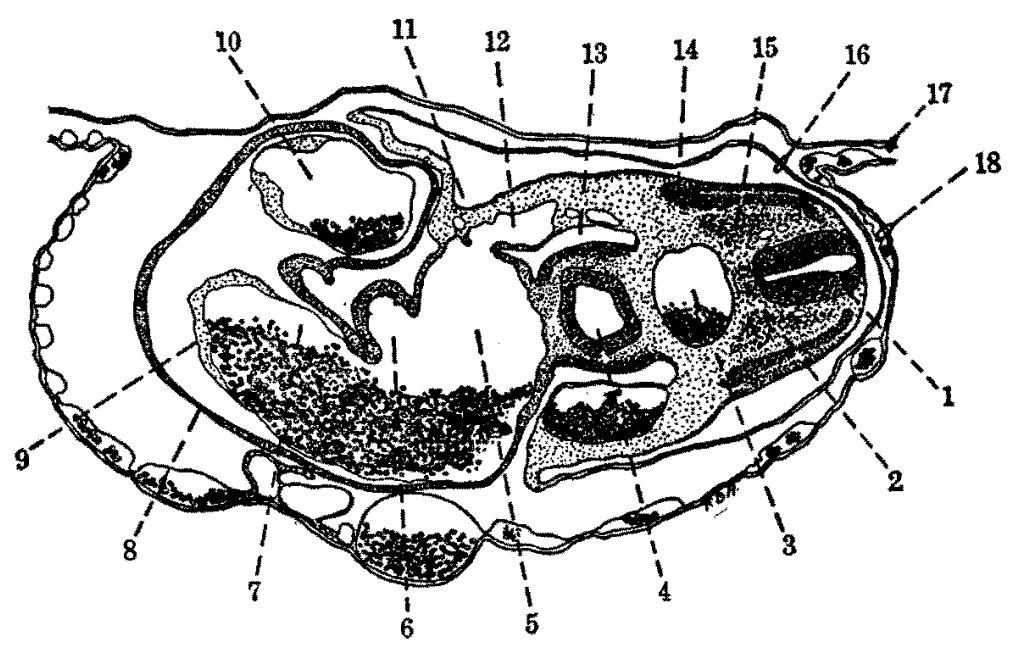

Fra. 25. Section through the heart of a 48 -hour chick.

of a somite. Lateral to the gut are two cavities which represent forward extensions of the coelom (13). The left, in this section, communicates directly with the exocoel. In the ventrolateral extensions of the body wall are large paired blood vessels, the common cardinals (12), and of these the right communicates with the sinus venosus of the heart. The parts of the heart are arranged in order forming a loop and marked off by slight constrictions, as follows: sinus venosus (5), atrium (6), ventricle (7), bulbus arteriosus (10). Note the thin endothelial lining (9) of the bulbus and ventricle contrasting with the thicker outer epimyocardium (8). 
D. Section through the mid-body at the level of origin of vitelline arteries (Fig. 26)

At this level the thick-walled neural tube (10) which lies below the surface ectoderm is somewhat elliptical in outline. The notochord lies beneath the neural tube. The dorsal aorta (3), paired at this level, lie beneath the notochord but slightly lateral in position. The vitelline arteries (1) course outward laterally from them. The endoderm of the wide-open mid-gut (2) forms the basal layer. Lateral to the neural tube are the paired somites. In these we may distinguish a heavy platelike dermatome

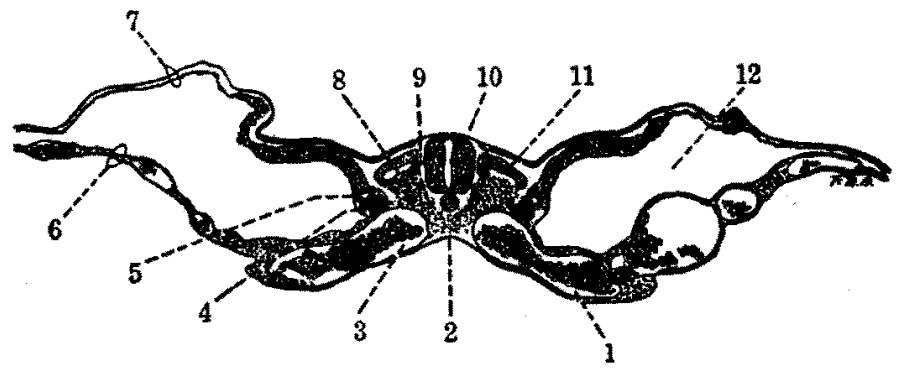

Fia. 26. Section through the body of a 48-hour chick at the point of origin of the vitelline arteries.

(11) closely associated with the surface ectoderm, the poorly defined sclerotome (8) lying next the spinal cord and notochord, and the myotome (9), or somite proper, forming an inner hook on the dermatome. The nephrotome has already differentiated into the nephric duct (5) and tubules (4); the duct being thick-walled and circular in outline while the tubule is ventromedial to it and irregular in section. The lateral sheets of mesoderm are divided into the upper somatic layer, which is associated with the ectaderm to form the somatopleure (7), and the lower splanchnic layer associated with endoderm to form the splanchnopleure (6). The exocoel (12) lies between these layers.

\section{E. Section through base of tail fold (Fig. 27)}

The tail fold has begun to protrude above the surface of the blastoderm in a manner similar to that of the head fold. Into it a blind extension of the endodermal tube, the hind-gut (3), will extend,

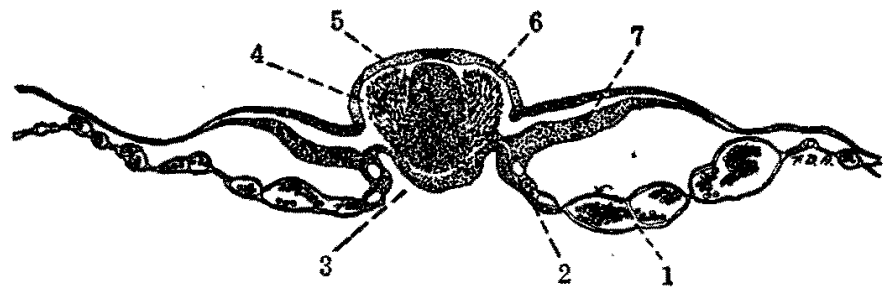

FIa. 27. Section through the tail fold of a 48-hour chick.

and at this level the posterior intestinal portal, which represents the point of communication with the mid-gut, is to be seen. The bulk of the tail fold is made up of a solid mass of mesodermal cells $(4,5)$. Ectoderm (6), somatic mesoderm (7), splanchnic mesoderm (1), and endoderm (2) are clearly recognizable.

\section{Laboratory Directions}

C. Study the serial sections provided and find, draw, and label sections illustrating the following levels:

(1) Section through the head showing developing eye or ear (Fig. 24).

(2) Section through the heart (Fig. 25).

(3) Section through mid-body region showing the amniotic raphe (which is the level at which the lateral folds of the amnion meet above the embryo).

(4) Section through the tail fold (Fig. 27). 


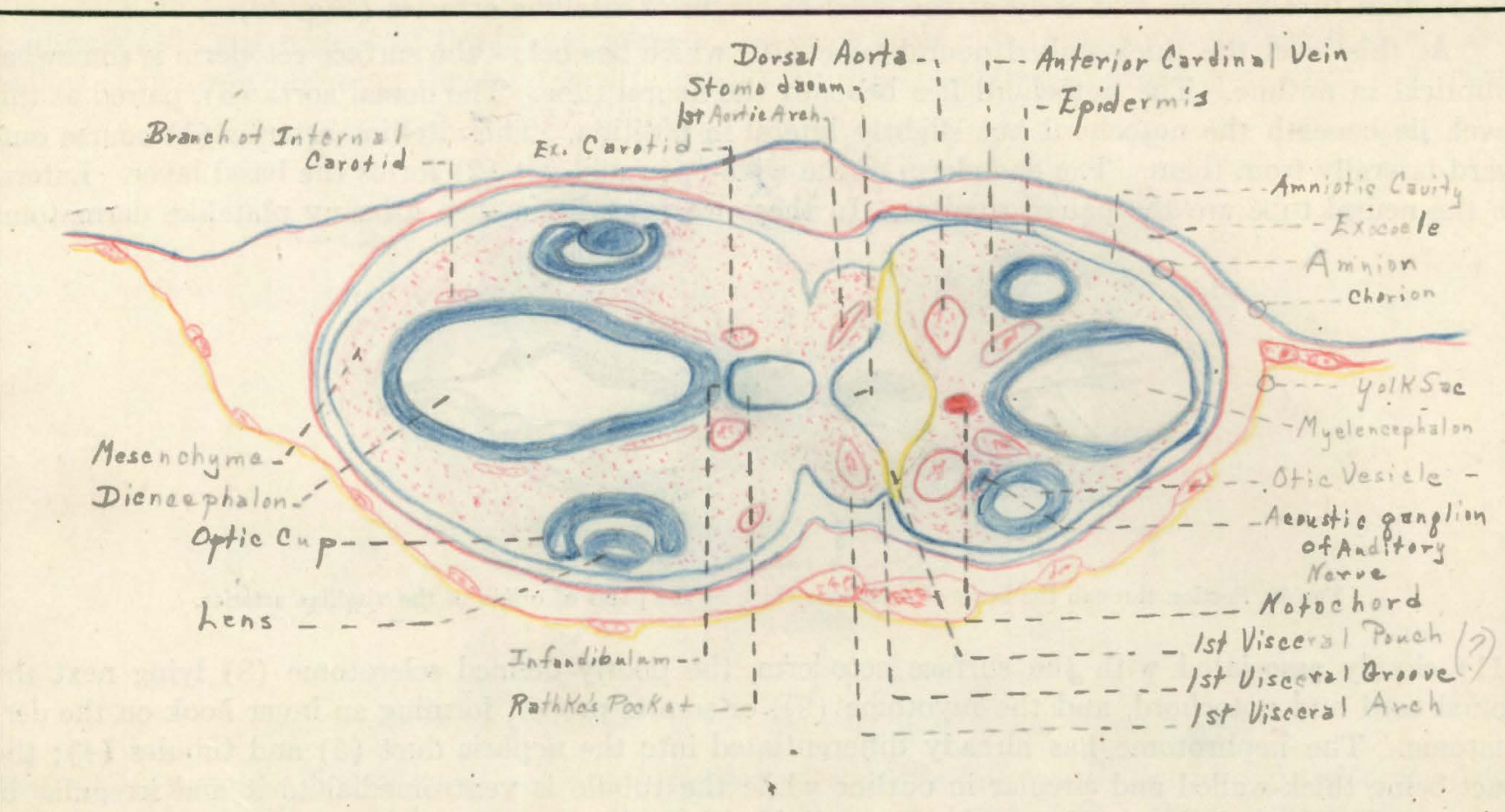

(1) Section through the head.

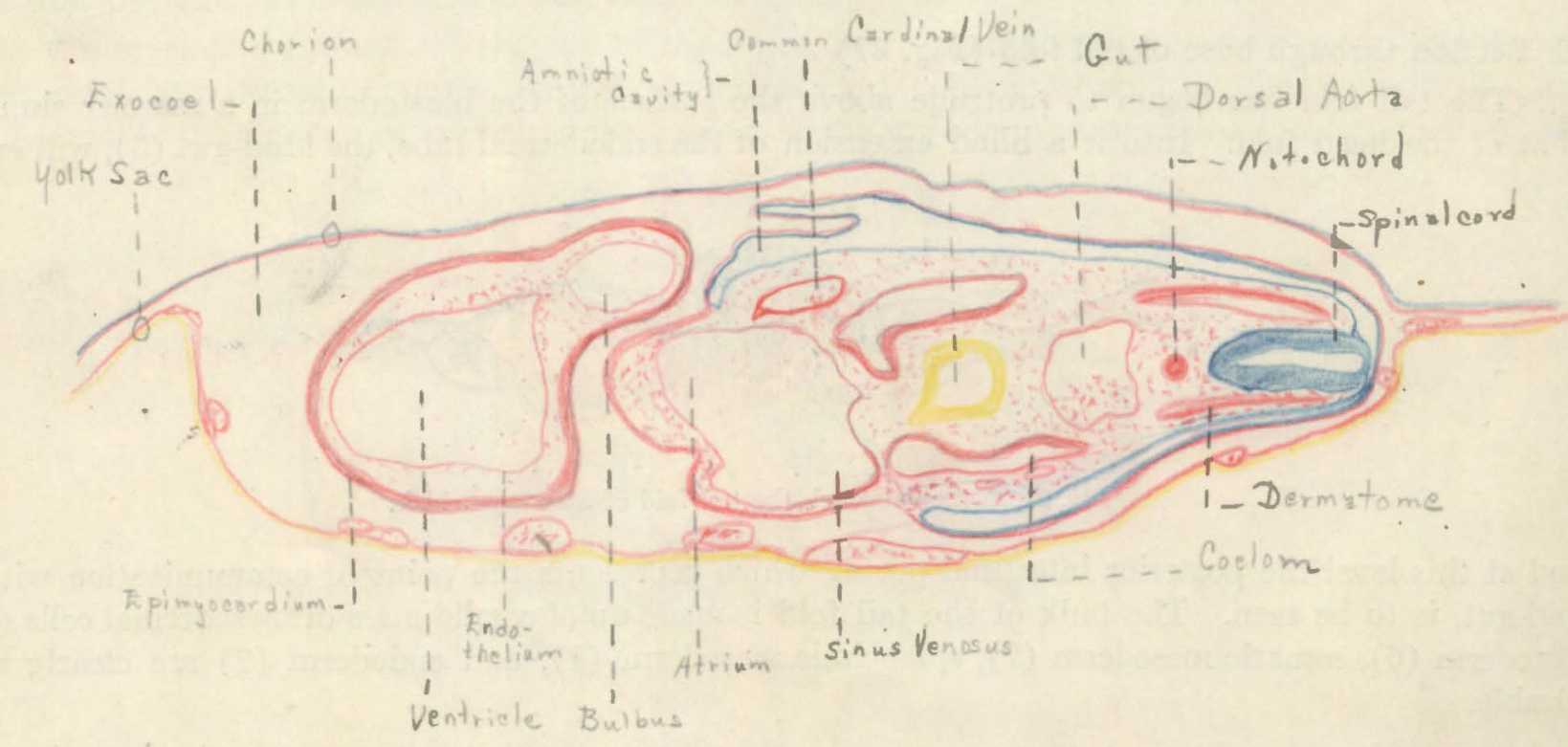

(2) Section through the heart.

48-Hour Chick Embryo. 


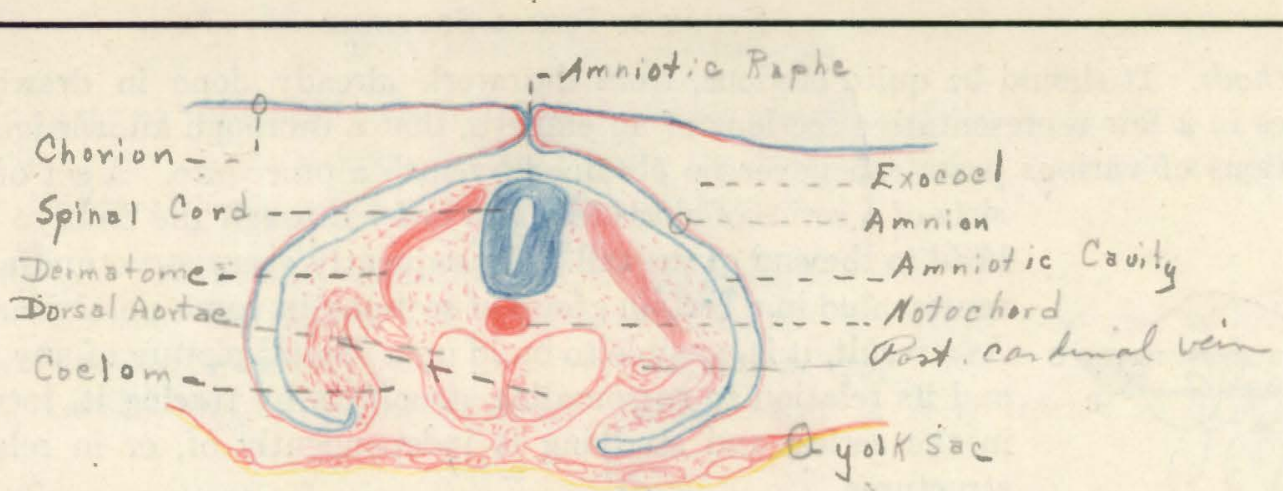

(3) Section through mid-body region.

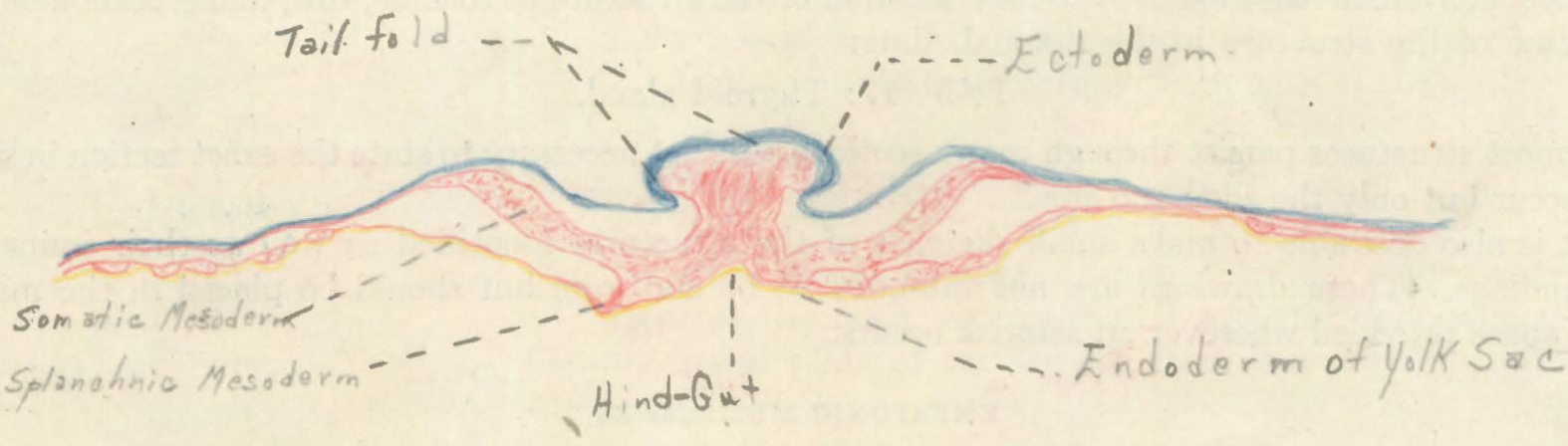

(4) Section through the tail fold. 


\section{Study of Serial Sections}

Methods. It should be quite obvious, from the work already done in drawing and identifying structures in a few representative sections of an embryo, that a thorough knowledge of its anatomy and the relations of various parts can never be obtained by such a procedure. A set of serial sections con-

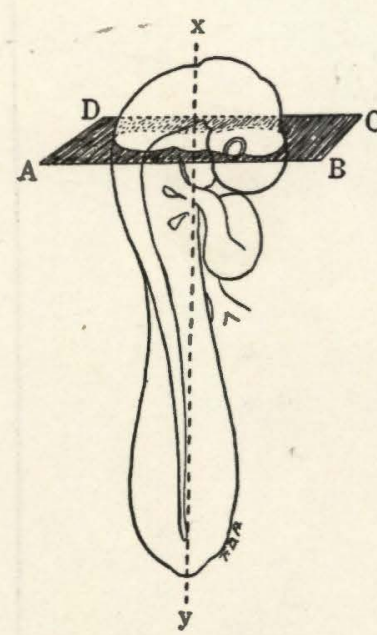

Fig. 28. Diagram illustrating the relation of the plane of section $A B C D$ to the longitudinal axis of the body $x-y$. sists of a series of slices taken in order through the embryo from the tip of the head to the end of the tail. Consequently every structure in the embryo will be represented in a certain group of sections in some particular part of the series. As a result, it is possible to build up a mental picture of any particular structure and its relation to surrounding structures by tracing it, forward and backward in the series, and studying it independently of, or in relation to, associated structures.

It is highly desirable, therefore, that the student should now attempt to substitute this method of study for the time-honored process of making drawings, except, for example, in the case of the total mount. The drawings already made have served a useful purpose in making the student familiar with the general appearance and structural plan of sueh organs as the neural tube, gut, and blood vessels.

Orientation of the Sections (Fig. 28). Before beginning to study a series of sections it is always advisable to try to get some conception of the plane of section $A B C D$ in relation to the longitudinal axis of the body $x-y$. It should be realized that no two series are absolutely identical because the plane of section may be tilted in many ways from left to right or from front ta back. It is possible, for example, to cut the eye on one side of the head and miss it altogether on the other. The use of a ruler laid across a total mount drawing will often enable the student to appreciate the plane of sectioning.

Records. As the study progresses a record should be kept of the various structures encountered. The most convenient method is to list the location of the structure as to slide, row, and section alongside. the name of the structure in the manual, thus:

\section{1/5/17: Thyroid gland.}

Since most structures persist through many sections, it is not necessary to state the exact section in which they occur but only the slide and row.

It is also desirable to make small sketches of the structures identified as well as their immediate surroundings. These drawings are not intended to be elaborate but should be placed in the manual in the space provided wherever an asterisk occurs.

\section{EMBRYONIC MEMBRANES}

In beginning the study of a set of sections of the 48-hour chick, the amnion, chorion, and yolk sac show to advantage in the first few sections through the head. These structures may always be recognized by the following characteristics.

* Amnion. A thin membrane composed of ectoderm (inner layer) and somatic mesoderm (outer layer) lying next to the body but separated from it by a space, the amniotic cavity.

* Chorion. A thin membrane also composed of ectoderm (outer layer) and somatic mesoderm (inner layer) forming a second covering layer outside the amnion. The space between amnion and chorion is the exocoel.

- Yolk Sac. A thin membrane composed of endoderm and splanchnic mesoderm lying outside the amnion. It may be distinguished from the chorion by the fact that its mesodermal layer contains vitelline blood vessels, whereas none are present in the chorion. 


\section{ECTODERMAL DERIVATIVES}

EPIDERMIS. A single layer of ectoderm cells forming the outer covering of the body.

BRAIN AND SPINAL CORD. In working down into the series the first prominent structure encountered is the brain. ${ }^{3}$ Learn to recognize its parts by the following diagnostic features:

Myelencephalon. Very thin roof. Associated with otic vesicle.

Metencephalon. Located in front of the myelencephalon but behind or posterior to the narrow isthmus which separates mesencephalon and metencephalon.

Mesencephalon. Located in front of the isthmus. In cross-section it is thick-walled and almost always round.

Diencephalon. Associated with the eye.

Telencephalon. Associated with the nose. Located at the anterior end of the neural tube.

Spinal Cord. The thick-walled, narrow, tubular extension of the neural tube posterior to the myeleǹcephalon.

\section{ORGANS OF SPECLAL SENSE ${ }^{2}$}

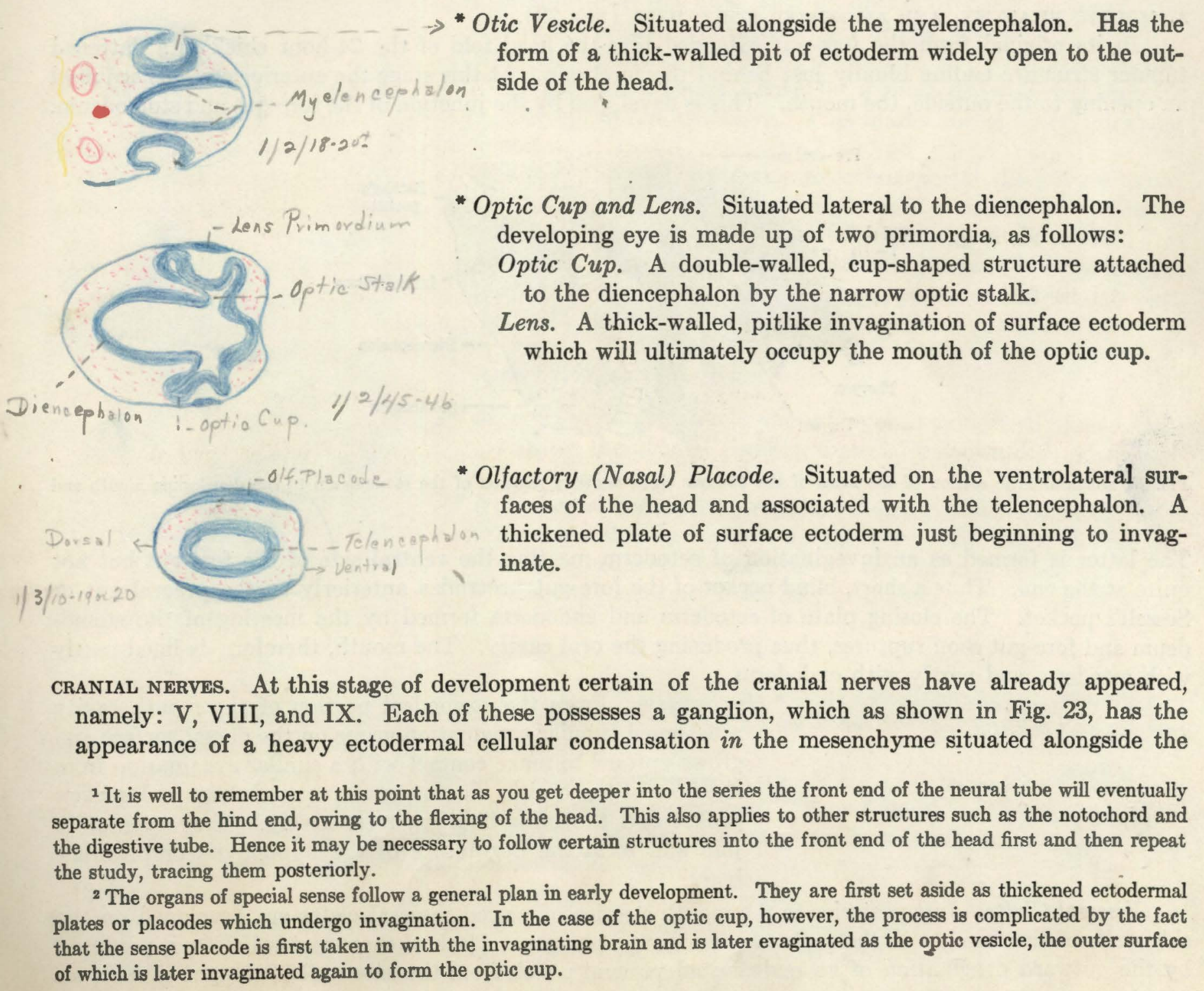


brain. Using the otic vesicle as a landmark, identify the following nerves associated with the myelencephalon:

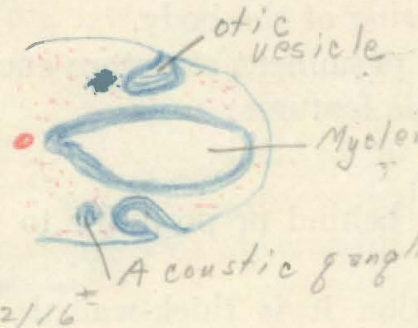

* Anterior to otic vesicle.

(VIII) Acoustic ganglion of the auditory nerve. Located immediately in front of, or anterior to, the otic vesicle and also slightly ventral to it.

(V) Semilunar ganglion of the trigeminal nerve. This ganglion is quite large and lies in front of VIII near the anterior end of the myelencephalon.

* B. Posterior to otic vesicle

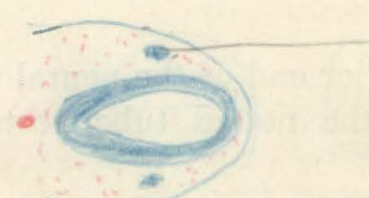

(IX) Superius ganglion of the glossopharyngeal nerve. A heavy mass of nerve cells lying immediately posterior to the otic vesicle and slightly dorsal to it. If present, this ganglion is usually quite small.

\section{ENDODERMAL DERIVATIVES AND ASSOCIATED STRUCTURES}

A. MOUTH, PHARYNX, AND ASSOCIATED STRUCTURES (FIG. 29).

In its original form the fore-gut extended into the head fold of the 24-hour chick as a flattened tubular structure ending blindly just behind the forebrain. At this stage the anterior end has acquired an opening to the outside, the mouth. This is developed by the junction of the fore-gut and stomodeum.

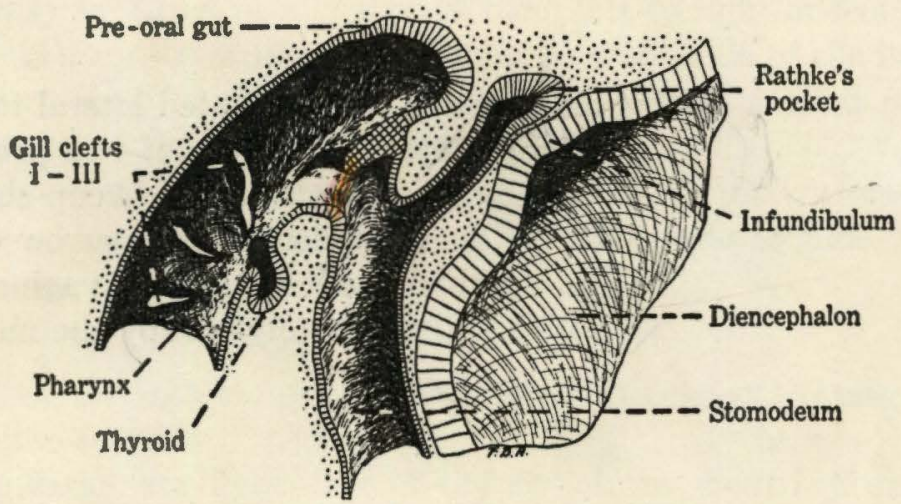

Frg. 29. Diagrammatic section of the head of the 48-hour chick showing relation of the stomodeum to the developing mouth and pituitary body.

The latter is formed as an invagination of ectoderm meeting the ventral side of the fore-gut but not quite at the end. Thus a short, blind pocket of the fore-gut protrudes anteriorly as the preoral gut or Sessell's pocket. The closing plate of ectoderm and endoderm formed by the meeting of the stomodeum and fore-gut soon ruptures, thus producing the oral cavity. The mouth, therefore, is lined partly with ectoderm and partly with endoderm.

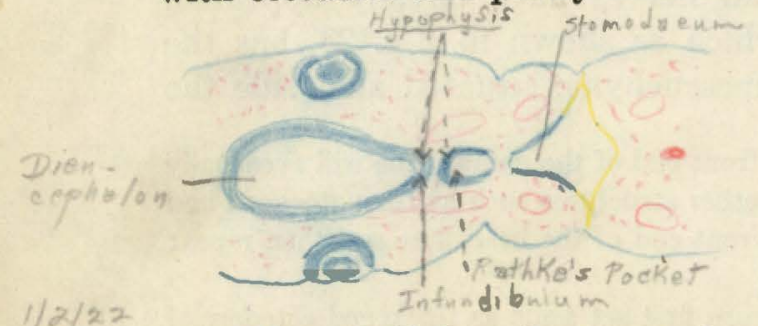

" Hypophysis. From the stomodeal portion of the mouth cavity a flattened tubular evagination arises on the dorsal surface and grows upward to make contact with a similar evagination from the floor of the brain. These structures are known as Rathke's pocket and the infundibulum, respectively. They eventually join and form the beginnings of the hypophysis or pituitary body:

Visceral Clefts. Just posterior to the mouth a series of paired visceral clefts are developed on the side.walls of the fore-gut in the region known as the pharynx. Each of these visceral clefts is produced by the outward evagination of an endodermal visceral pouch from the side wall of the gut to meet an 
inward invagination or branchial groove formed from surface ectoderm. The process is similar to that by which the mouth is formed. The rupture of the ectendodermal closing plate produces a visceral cleft or gill slit. ${ }^{1}$ At 48 hours three pairs of these are present.

Thyroid Gland. In the floor of the pharynx opposite the second branchial arch the thyroid gland has begun to form as a rounded ventral diverticulum which communicates with the pharynx by means of the widely open thyroglossal duct. The cells constituting the wall of the thyroid diverticulum are characteristically tall and columnar at this stage.

B. DIGESTIVE TUBE POSTERIOR TO PHARYNX

Fore-gut. A thick-walled tube of small bore posterior to the pharynx. Circular in cross-section.

- Liver. Just in front of the anterior intestinal portal there is a narrow ventral diverticulum from the floor of the gut. This projects downward toward the meatus venosus and by cellular proliferation invades the walls of the vitelline veins which are prominent at this level, thus producing irregular masses of cells which represent the primordium of the liver.

* Anterior Intestinal Portal. Posterior to the liver diverticulum the gut continues as a tube for a short distance and then its floor opens out ventrally. This marks the anterior intestinal portal.

Mid-gut. From the anterior intestinal portal the gut continues backward as the floorless mid-gut until it reaches the posterior intestinal portal which marks the beginning of the tail fold.

Hind-gut. At the level of the posterior intestinal portal the gut again assumes a flattened tubular appearance and extends back into the tail fold as a blind tube, the hind-gut.

\section{MESODERMAL DERIVATIVES}

- Mesenchyme. Loose reticular embryonic connective tissue. Constitutes the general padding material between organs and surface ectoderm.

* Notochord. Cylindrical, rodlike (sometimes sinuous in outline). Situated directly beneath neural tube. Represents the embryonic forerunner of the skeletal system and hence curves to follow the contour of the floor of the brain.

CIRCULATORY SYSTEM

A. VENOUS SYSTEM

CARDINAL VEINS. Have the general form of the letter $H$, of which: the upper limb represents the anterior cardinals, the lower limb represents the posterior cardinals, and the cross bar represents the common cardinals.

Anterior Cardinals. Drain the head. Arise from a capillary plexus over the brain. The main trunks lie at the ventrolateral margins of the neural tube. They follow the neural tube closely until the level of the heart is reached. At this level they work ventrally but lateral to the dorsal aorta to join the common cardinals.

${ }^{1}$ It should be noted at this point that the visceral clefts are separated by pillars of tissue, which are known as visceral or branchial arches. These are important at this stage as the territory through which certain blood vessels, the aortic arches, flow. They are identified numerically as follows: visceral arch I lies in front of visceral cleft I: visceral arch II lies in front of visceral cleft II, etc. (See Table 1 on pagn 7, Figs. 10 and 31.) 
Common Cardinals. Receive blood from both anterior and posterior cardinals. Drain into the dorsolateral angles of the sinus venosus.

Posterior Cardinals. Drain the posterior end of the body. Situated dorsal to the mesonephric tubules. Join the common cardinal veins.

VITELLINE VEINS. Return blood to the heart from the yolk sac.

\section{B. ARTERIAL SYSTEM}

AORTIC ARCHES AND RELATED vessels. In a section such as that shown in Fig. 24 we encounter the upper end of the first aortic arch near the point where it joins the dorsal aorta and where the latter is prolonged forward into the head as the internal carotid artery. Trace these vessels deeper into the series and also identify the second and third aortic arches, etc., as follows:

* Internal Carotid. Runs forward into the head to form a capillary plexus closely associated with the brain.

* First Aortic Arch. Separates from the dorsal aorta. Runs through the first branchial arch. Eventually swings into the mid-line at its point of origin from the heart.

Dorsal Aortae. Situated beneath notochord, lateral to the midline and just dorsal to the gut. They receive, in order posteriorly, the first, second, and third aortic arches. At the level of the heart they fuse into a single vessel. Finally divide again to form the two caudal arteries.

* Second Aortic Arch. Runs through second visceral arch lateral fe to pharynx. Note association with thyroid gland.

Third Aortic Arch. Runs through third visceral arch and hence is found a few sections posterior to the second arch.

Vitelline Arteries. Arise from dorsal aorta just posterior to level at which the vessel splits to form the caudal arteries.

Intersegmental Arteries and Veins. Small paired vessels which supply the somites. Situated between somites. Arteries arise from the dorsal aorta. Veins join the anterior or posterior cardinal veins, depending on the level of section.

* C. parts of heart

Bulbus Arteriosus. Usually circular in cross-section. Its anterior end lies in the mid-line beneath the aortic arches. Its posterior end swings laterally to the right and so comes to lie near the chorion.

Ventricle. Usually oval in section. Its long axis lies across the section. It is farthest out ventrally from the body proper. It has a delicate endothelial lining. Its wall is thickened by the presence of a reticulum of developing muscle cells.

Atrium. Thin-walled. Situated ventral to sinus venosus.

Sinus Venosus. Thin-walled. Situated in mid-line beneath gut. Receives the common cardinal veins at its dorsolateral angles.

Meatus Venosus. Although not a part of the heart, it is a single tube entering the sinus venosus. It represents the fused vitelline veins. 
DIFFERENTIATION OF THE SOMITES

It is usual to consider the lateral sheet of mesoderm as being made up of three regions which are clearly distinguishable at this stage (Fig. 30).

(a) Somite proper. The mesoderm lying alongside the notochord is divided by transverse constrictions into small paired blocks or somites from very early stages of development. The cavity in the somite is the myocoel. Each somite undergoes a typical differentiation, which is clearly shown in any of them, occurring about mid-way back in the body. It will be seen by reference to Fig. 30 that three regions can be identified. Of these the deeply staining layer lying just below the surface ectoderm is well marked out and forms the dermatome. The hook of tissue continuous with the dermatome and adja-

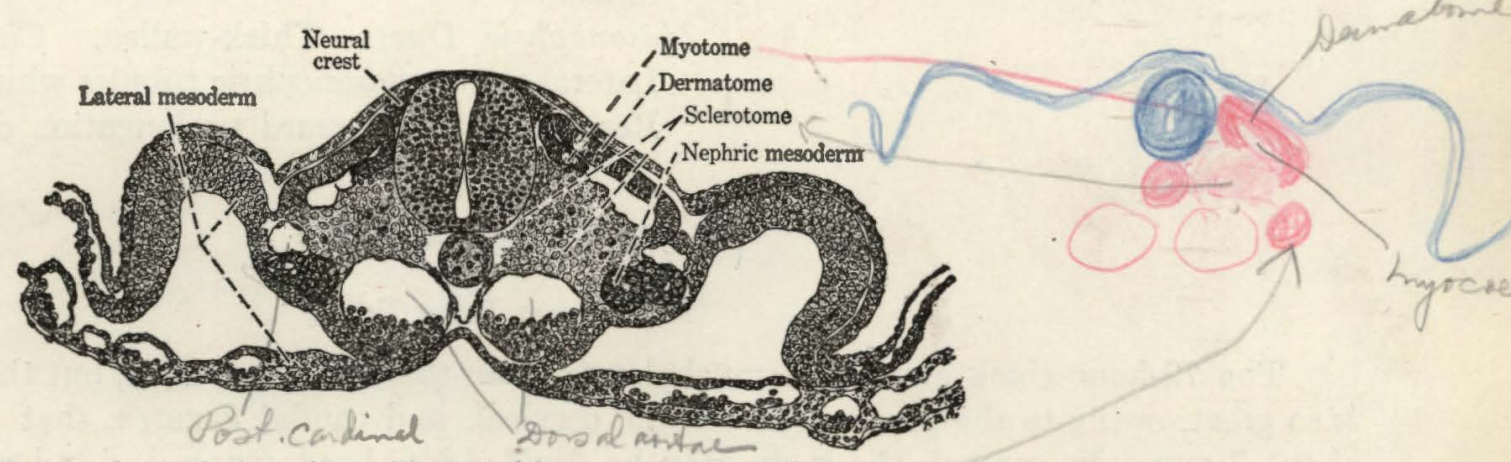

Fra. 30. Differentiation of a typical somite as illustrated by a section through mid-body of a 48-hour chick.

cent to the spinal cord is not very clearly marked out but in later development gives rise to skeletal muscles, and hence is known as the myotome. The remainder of the mesodermal block made up of the bulk of the somite is the sclerotome, and it will give rise to skeletal structures.

(b) Nephrotome. the chick) by the transverse constrictions which separate the somites. The cavity in the nephrotome is the nephrocoel.

(c) Lateral mesoderm. The broad lateral sheet of mesoderm not marked off by transverse divisions. It is split tangentially into two layers, the somatic, or outer layer lying next to the ectoderm, and the splanchnic, or inner layer, lying next to the endoderm. The cavity between these layers is the coelom.

COELOM

At this stage little progress has been made toward closing in the ventral side of the body by lateral undercutting. Consequently the coelom is in wide-open communication with the exocoel. There is, however, a blind pouchlike extension of the coelom forward but lateral to the fore-gut in the region of the heart (Fig. 25). The pericardial cavity is continuous with the exocoel.

EXCRETORY SYSTEM

* PRonephros. The excretory system of the chick is first developed as a pronephros or head kidney. This structure is composed of a series of pronephric tubules which grow backward and unite so as to form the pronephric duct. At 48 hours a number of these tubules usually persist about the level of the fifteenth somite. Anterior to this they are degenerate. Identify where possible:

Pronephric Tubules. Contorted thick-walled tubules. Equipped with a nephrostome or opening to the coelom.

Pronephric Duct. Thick-walled, circular in cross-section. Formed by union of backward extensions of pronephric tubules. 
* MESONEPHRos. The excretory system is represented in the 48-hour chick in the main by the mesonephros, a series of individual mesonephric tubules which develop from the nephrotomes posterior to the pronephros and communicate with the mesonephric duct. In the case of the chick the nephrotome is tucked up under the somite proper, and hence the mesonephric tubules appear to lie at the lateral angles of the somite. A close association with the dorsal aorta and posterior cardinal vein is evident. Identify:

$\rightarrow$ Mesonephric Tubule. Thick-walled. Contorted and irregular in shape.

Mesonephric Duct. Thick-walled. Circular in cross-section. Lateral to the mesonephric tubules which empty into the duct. Represents a backward prolongation of the pronephric duct.

\section{2-HOUR EMBRYO}

\section{General Body Form}

The 72-hour chick embryo is much larger than the 48-hour embryo, but the curvature of the body is so great, owing to the presence of cranial, cervical, and caudal flexures, that its total length is only about $7 \mathrm{~mm}$. In general, the body may be divided into head, trunk, and tail regions, and, in addition, the beginnings of the appendages are apparent in the form of anterior limb buds at the level of the seventeenth to nineteenth somites and hind limb buds at the level of the twenty-sixth to thirtysecond somites.

The head, which is almost bent backward, shows a series of prominent bulges corresponding to the divisions of the brain. The cerebral hemispheres of the telencephalon cause prominent lateral bulges in the extreme front end. Diencephalon and mesencephalon are clearly marked out, and, posterior to the isthmus, the metencephalon and thin-roofed myelencephalon. Associated with the extreme ventrolateral surfaces of the head are the groovelike nasal pits. The optic cup and lens are clearly apparent alongside the diencephalon, and the otic vesicle can be seen as a small saclike structure alongside the myelencephalon.

The pharyngeal region is marked by the presence of the first three visceral clefts. The fourth, although indicated, has not broken through. Anterior to the first visceral cleft the first visceral arch is prominently developed, and the maxillary process, primordium of the upper jaw, has grown forward to become attached to the head proper. The mandibular process, which is the primordium of the lower jaf constitutes the main body of the arch. In total mount preparations the maxillary and mandibular processes have the appearance of a heavy, bilobed tissue mass lying just above the heart.

The heart is attached prominently to the ventral side of the body just below the pharynx. It is still a looped structure (Fig. 22), and consequently the bulbus arteriosus as well as the more posteriorly located ventricle form the uppermost limb of the heart. It will be noted that the anterior end of the bulbus swings to the mid-line ventral to the gill slits. The atrial region is beneath the ventricular limb but situated well forward. It communicates with the sinus venosus, which is located in the median line posterior to the atrium. The vitelline veins from the yolk sac converge toward the posterior end of the sinus venosus.

In the body proper the neural tube swings backward in the mid-line and paired somites lie alongside it. The somites, of which there are thirty-five pairs, begin just posterior to the otic vesicle and extend back into the tail. The vitelline arteries leave the dorsal aorta at approximately the mid-level of the body.

The tail fold is lifted above the blastoderm and curves slightly forward. At this level the allantois protrudes out ventrally as a prominent vesicle.

Covering the whole body are the delicate amnion and chorion, which are almost entirely closed in by fusion of the head and tail folds. 


\section{Laboratory Directions}

Study carefully a total mount of a 72-hour embryo, and make a drawing showing the structures identified.

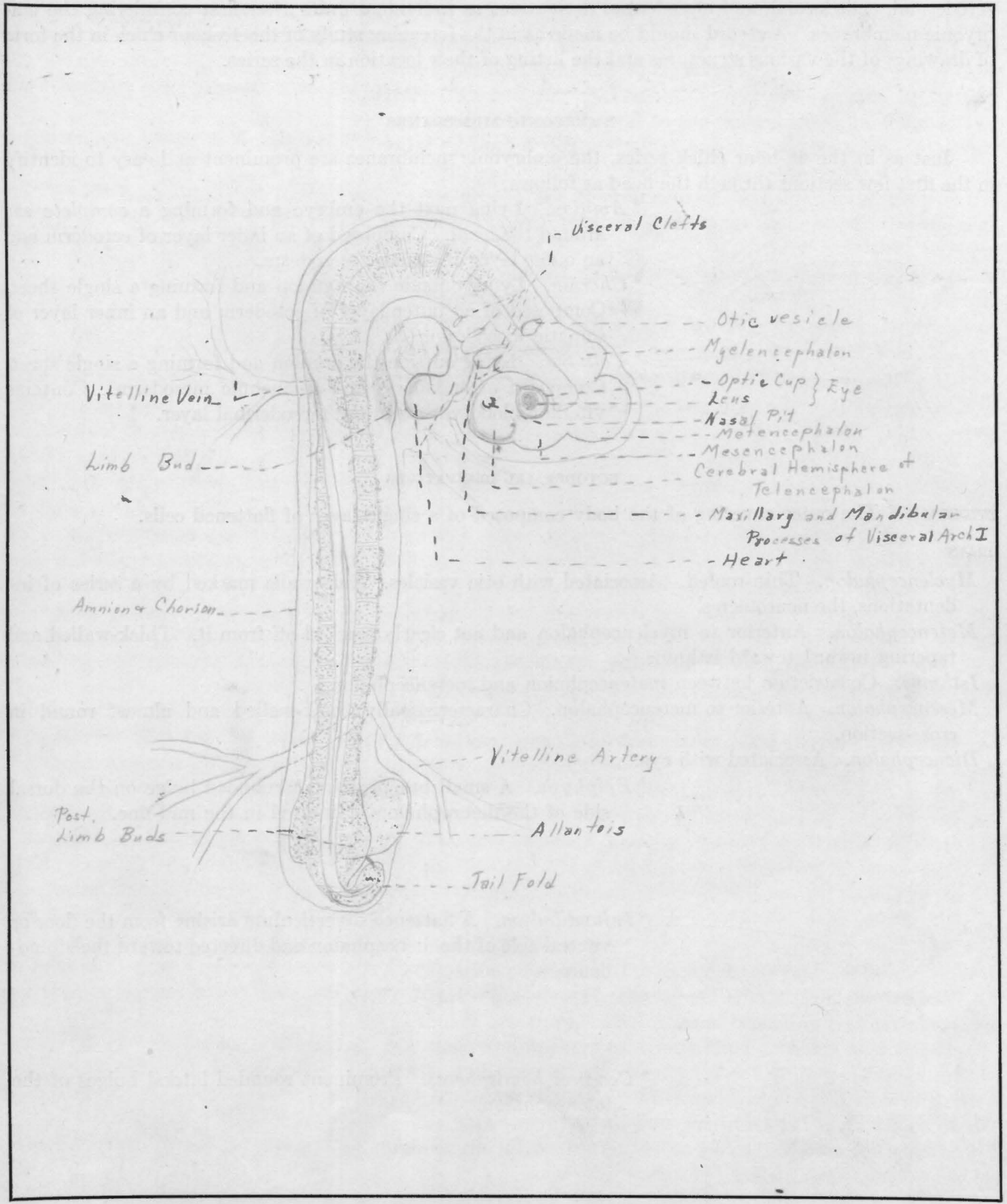




\section{Directions for Study of Transverse Serial Sections}

For convenience in working out and identifying the structures of the 72-hour chick we shall study ectodermal, endodermal, and mesodermal derivatives as individual units after first considering the embryonic membranes. A record should be made as-in the-foregoing-study of the-48-hour chiek in the form of drawings of the various structures and the listing of their location in the series.

\section{EMBRYONIC MEMBRANES}

Just as in the 48-hour chick series, the embryonic membranes are prominent and easy to identify in the first few sections through the head as follows:

* Amnion. Lying next the embryo and forming a complete sac around the head. Composed of an inner layer of ectoderm and an outer layer of somatic mesoderm.

* Chorion. Lying outside the amnion and forming a single sheet. Composed of an outer layer of ectoderm and an inner layer of somatic mesoderm.

Yolk Sac. Lying outside the amnion and forming a single sheet. Composed of endoderm and splanchnic mesoderm. Contains vitelline blood vessels in the mesodermal layer.

\section{ECTODERMAL DERIVATIVES}

EPIDERMIS. The outer covering of the body composed of a single layer of flattened cells.

BRAIN

Myelencephalon. Thin-roofed. Associated with otic vesicles. Side walls marked by a series of indentations, the neuromeres.

Metencephalon. Anterior to myelencephalon and not clearly marked off from it. Thick-walled and tapering inward toward isthmus.

Isthmus. Constriction between metencephalon and mesencephalon.

Mesencephalon. Anterior to metencephalon. Characteristically thick-walled and almost round in cross-section.

Diencephalon. Associated with eye.

$$
\begin{aligned}
& \text { see } b e / 0^{*}=\text { Epiphysis. A small but prominent rounded bulge on the dorsal } \\
& \text { side of the diencephalon. Situated in the mid-line. }
\end{aligned}
$$

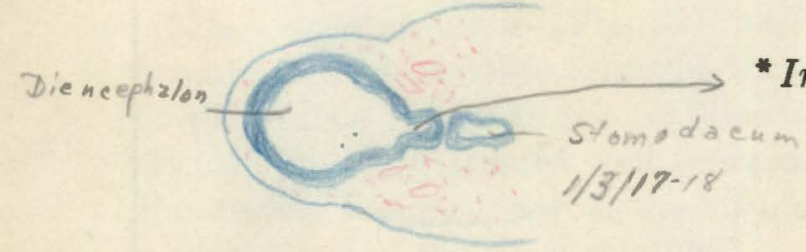

* Infundibulum. A flattened diverticulum arising from the floor or ventral side of the diencephalon and directed toward the stomodeum.

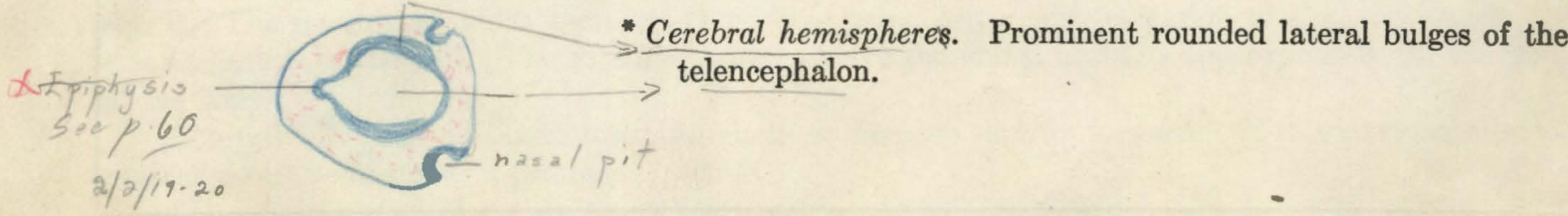

Telencephalon. Associated with the nasal pits. 
SPINAL CORD. The extension of the neural tube posterior to the myelencephalon. A narrow thick-walled tube. Situated just beneath the dorsal surface of the body.

ORGANS OF SPECIAL SENSE

* Otic Vesicle. Thick-walled, hollow oval vesicle. Lateral to myelencephalon. Frequently retains connection to the outside of the head by the endolymphatic duct.

chome Optic Cup and Lens. The developing eye is made up of two Groove primordia situated lateral to the diencephalon, as follows:

Optic Cup. A double-walled, cup-shaped structure. Attached to diencephalon by the optic stalk on the under side of which is a groove, the choroid groove. Its thick inner layer is the retinal layer. Its thin, dark, outer layer constitutes the pigmented layer.

Lens. A rounded, ball-like structure occupying the mouth of the optic cup.

" Olfactory Pit.' Situated on the extreme ventrolateral surfaces of the head adjacent to the telencephalon. Thick-walled. External orifice much more constricted than at 48 hours.

\section{CRANIAL NBRVES}

NERVES ASSOCIATED WITH MYELENCEPHALON

* A. Anterior to otic vesicle and listed in order anteriorly

(VIII) Acoustic ganglion of the auditory nerve.

$B / / 2 / 2 /-22$

(VII) Geniculate ganglion of the facial nerve. Closely associated with VIII.

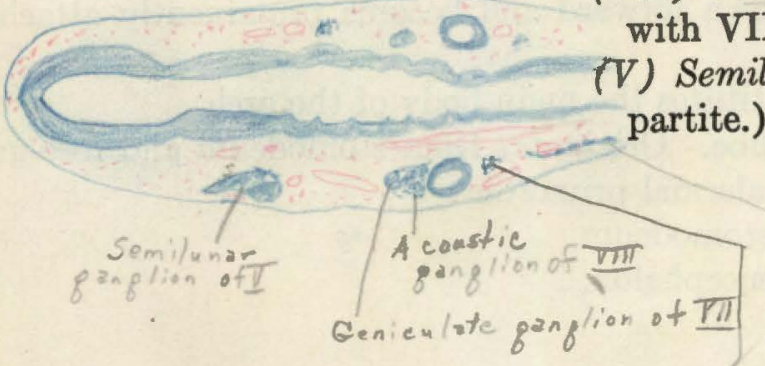

* B. Posterior to otic vesicle and listed in order posteriorly

(IX) Superior ganglion of the glossopharyngeal nerve.

(X) Jugular ganglion of the vagus nerve. (Seldom present.)

(XI) Spinal accessory. The external branch is best developed at this stage and appears as a long band of fibers adjacent to the myelencephalon.

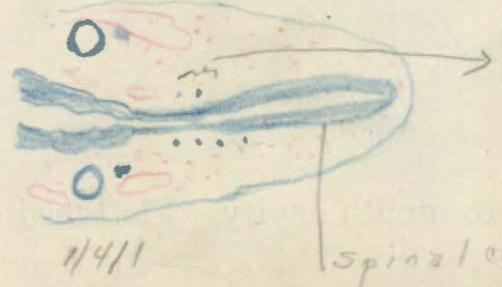

(XII) Hypoglossal nerve. When present the roots of this nerve appear as a row of small dots ventrolateral to the floor of the brain at the level where it is just separating from the spinal cord. 


\section{NERVES ASSOCIATED WITH MESENCEPHALON}

* (III) Oculomotor. This nerve arises from the floor of the mesencephalon. Hence it is found beneath the brain and its basal portion is directed almost straight away from the brain.

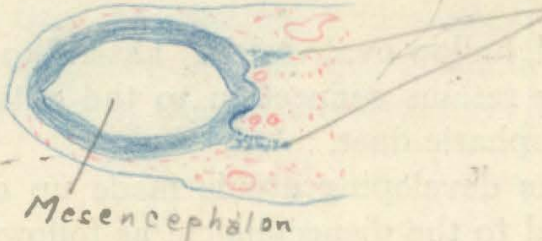

NERVES ASSOCIATED WITH TELENCEPHALON

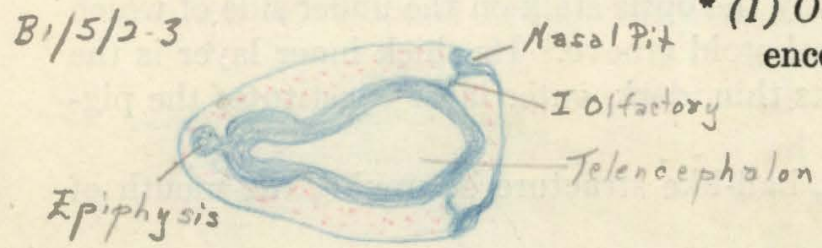

* (I) Olfactory. This nerve runs laterally from the wall of the telencephalon to the nasal pit.

* sPINAL NERVES. The primordia of the segmentally arranged dorsal root ganglia are located dorsolateral

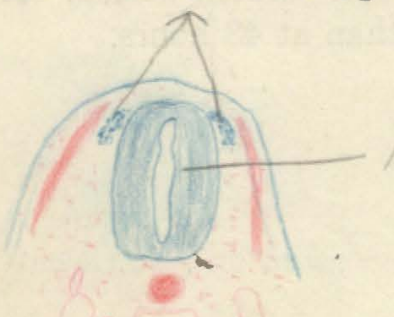
to the neural tube as paired condensations of neural crest tissue. They are usually somewhat difficult to recognize (Fig. 30 ).

$B / / 5 / 9-10$

ENDODERMAL DERIVATIVES AND ASSOCIATED STRUCTURES

Oral Aperture. The external opening of the mouth cavity formed by invagination of the ectodermal stomodeum. Situated beneath or ventral to head. Bounded by:

Maxillary process of first visceral arch which has grown forward and become prominently attached to the head proper.

Mandibular process of first visceral arch which constitutes the main body of the arch.

Mouth Cavity. The anterior chamber of the digestive tube. Originates from stomodeum and fore-gut.

" Pituitary Body. Consists of two closely associated ectodermal primordia:

(1) Rathke's pocket, a dorsal diverticulum of the stomodeum.

(2) Infundibulum, a ventral diverticulum of the diencephalon.

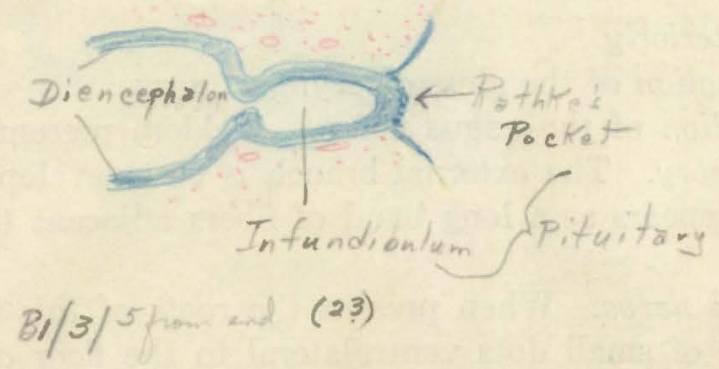

Pharynx. The broad anterior end of the original fore-gut posterior to mouth cavity. Flattened dorsoventrally. Marked by presence of visceral clefts. 
Visceral Clefts. Paired lateral openings extending from the sides of the head into the pharynx. Formed by the junction of:

(1) Visceral pouches, which represent lateral outpocketings of the gut.

(2) Visceral grooves, which represent inpocketings of the surface ectoderm. Three pairs are present -2 fourth usually so.

At this time it is highly desirable to learn to identify the visceral grooves and the visceral arches which lie between them. This is important because of their relation to the aortic arches. (fole page In such a section as that in Fig. 31 the arches and grooves are clearly indicated. Learn to identify:

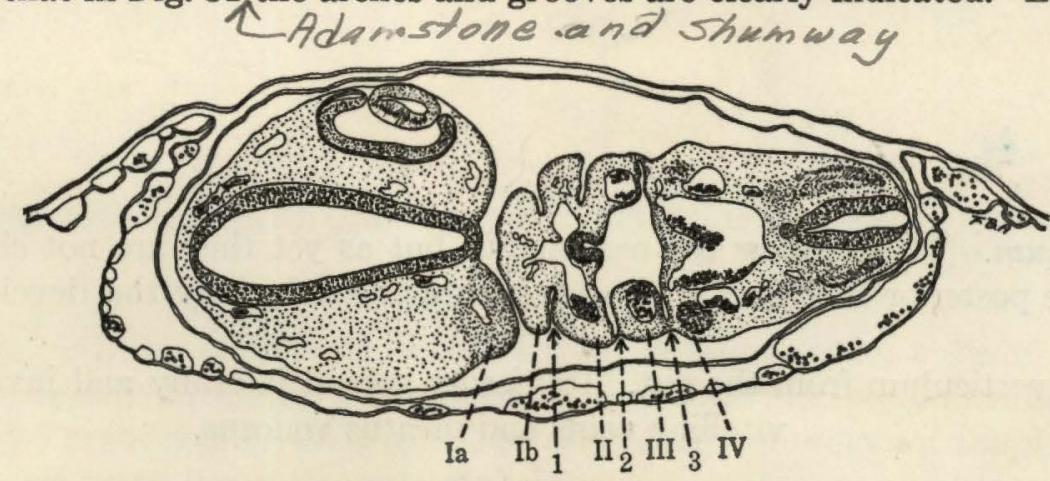

Fra. 31. Section through the head of a 72-hour chick showing relation between visceral arches and grooves. $B / / 3 / 22 \cdot 24$

(Ia) Maxillary process of arch I attached to the head proper.

(Ib) Mandibular process of arch I attached to the body proper.

(1) Hyomandibular cleft between arches I and II.

(II) Hyoid arch next dorsal to Ib.

(2) Visceral cleft II between arches II and III.

(III) The third arch.

(3) Visceral cleft III between arches III and IV.

(IV) The fourth arch.

- Thyroid Gland. A rounded median ventral diverticulum from the floor of the pharynx.

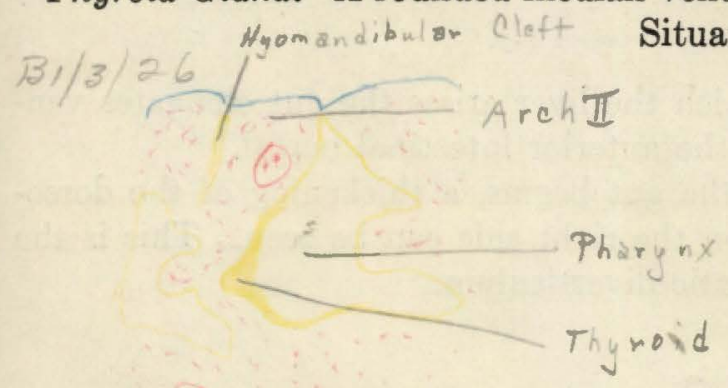

* Laryngotracheal Groove. Posterior to the fourth pharyngeal pouch the gut elongates ventrally. The dorsal portion represents the oesophagus, the ventral, the beginnings of the trachea.

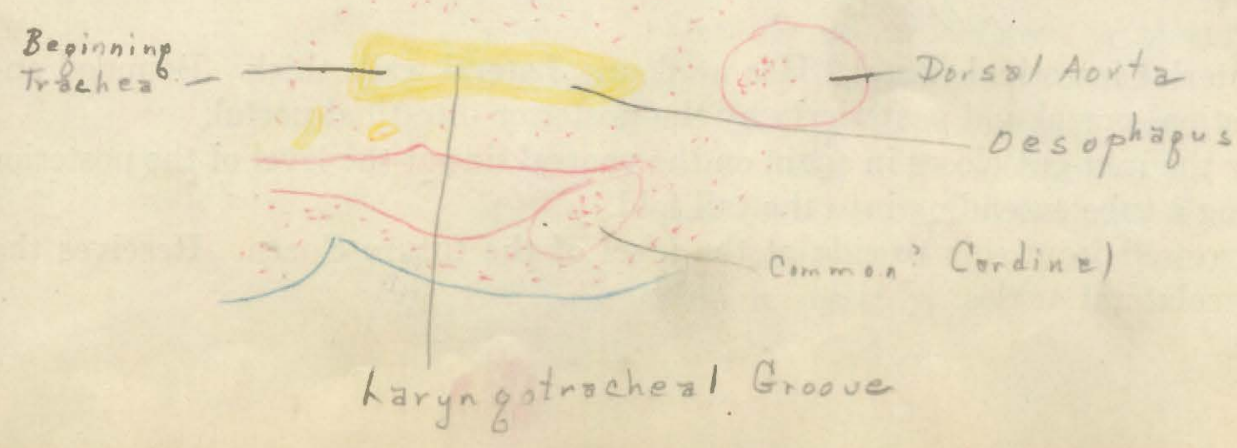


Oesophagus. The oesophagus continues beyond this level as a thick-walled oval tube.

* Primary Bronchi. The posterior end of the tracheal portion of the laryngotracheal groove bifurcates

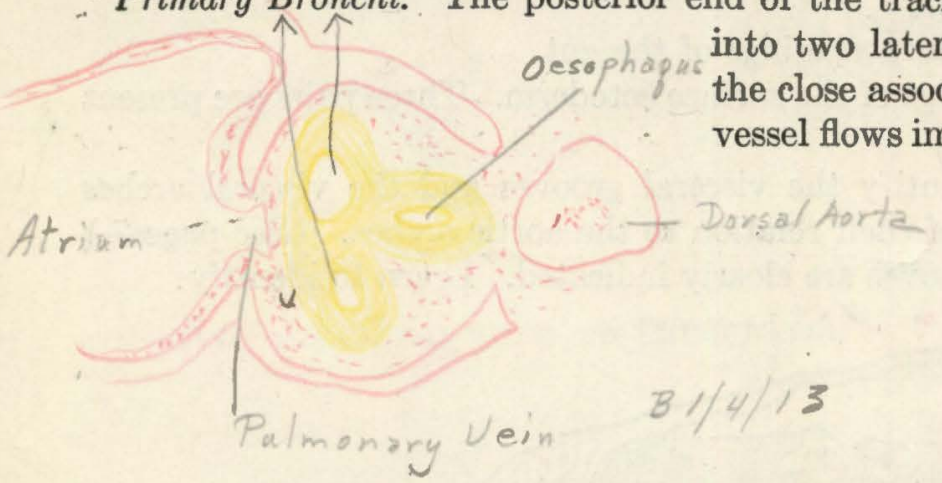

Stomach and Duodenum. These follow the oesophagus but as yet they are not clearly defined except for the fact that the posterior boundary of the duodenum is marked by the development of the liver diverticulum.

* Liver. A ventral diverticulum from the gut. Its tissues spread laterally and invade the walls of the vitelline veins and meatus venosus.

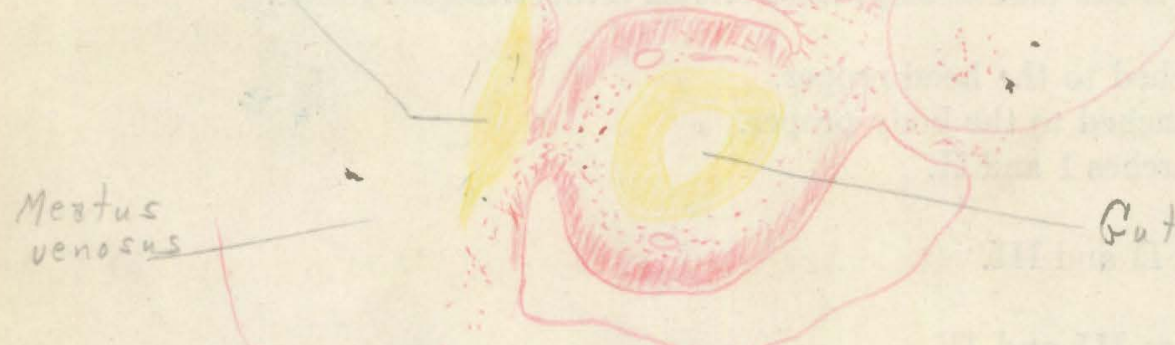

$B / / 4 / 27$

Anterior Intestinal Portal. Just posterior to the level at which the liver arises the gut elongates ventrally once more to open out on the yolk sac. This marks the anterior intestinal portal.

- Pancreas. At the level at which the ventral elongation of the gut begins, a thickening of the dorsolateral wall of the gut on the right side can be seen. This is the beginning of the pancreatic diverticulum.

\section{$B / 5 / 24: 25$}

Mid-Gut. Posterior to the anterior intestinal portal. Has no floor. Lateral walls thick. Bounded anteriorly by the anterior intestinal portal and posteriorly by the posterior intestinal portal.

Hind-Gut. Traced posteriorly the mid-gut closes in again on the ventral side at the level of the posterior intestinal portal, thus forming a tube extending into the tail fold.

Cloaca. The gut becomes narrowed from side to side at the level of the future cloaea. Receives the mesonephric ducts at its dorsolateral angles. 
* Allantois. A small, rounded, bladderlike, ventral diverticulum from the hind-gut growing out into the

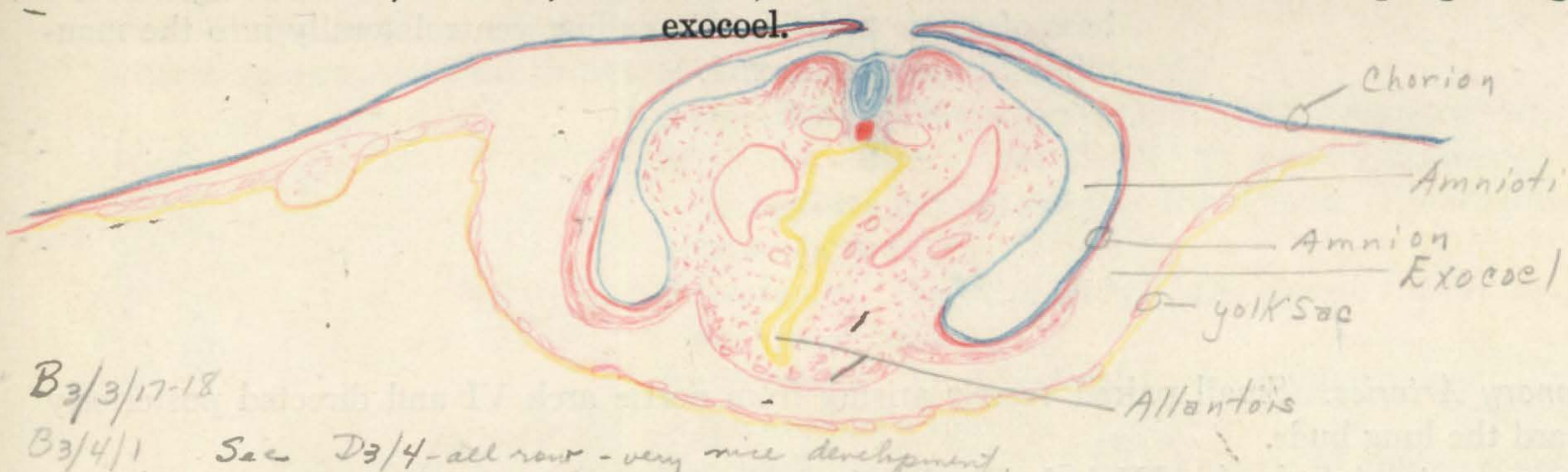

Postcloacal Gut. The extension of the hind-gut into the tail fold posterior to the cloaca.

\section{MESODERMAL DERIVATIVES}

Mesenchyme. Loose, reticular embryonic connective tissue filling spaces between organs in the head. Notochord. A solid rodlike structure representing the embryonic forerunner of the skeletal system. Located beneath the brain and spinal cord. Curves to follow contours of the floor of the brain. Circular in cross-section-sometimes elongate and sinuous.

\section{CIRCULATORY SY'STEM}

A. VENOUS SYSTEM

CARDINAL VIINS. These vessels still have the general form of the letter $\mathrm{H}$ but conform to the contours of the body and are still paired throughout.

Anterior Cardinals. Drain the head.

Common Cardinals. Receive anterior and posterior cardinals. Drain into dorsolateral angles of sinus venosus.

Posterior Cardinals. Drain posterior part of body.

Vitelline Veins. Large paired vessels which drain the yolk sac and converge to form the meatus venosus before entering the sinus venosus.

Allantoic Veins. These vessels are not yet well developed but are represented by a capillary plexus in the ventrolateral body wall posterior to the level of the sinus venosus.

Pulmonary Veins. Closely associated with the primary bronchi. Located ventral to the bronchi.

Drain into the left side of the atrium.

B. ARTERIAL SYSTEM

* aORTIC ARChes AND RELATEd vessels. Since the aortic arches flow through the corresponding $B / / 3 / 15$ Dors $/$ Aort 3 visceral arches they can be easily identified when once the visceral Internal Cartid arches have been worked out as described above (pages 7 and

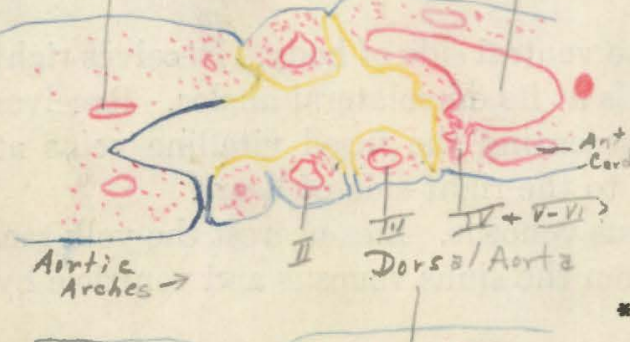
$61)$. It is well to begin the study of the aortic arches with a section such as Fig. 31, working forward in the series to their union with the radices of the dorsal aorta and then backward to their origin from the bulbus arteriosus. Remembering that the aortic arches flow through the corresponding visceral arches, identify aortic arches II, III, IV, and V-VI (usually combined).

* Internal Carotid Arteries. Anterior extension of dorsal aortae to form capillary plexus over brain.

Dorsal Aorta. Paired radices dorsal to pharynx. These vessels may be confused with the anterior cardinals at this level but can be readily distinguished because of the fact that they are situated more toward the mid-line. Traced posteriorly they fuse to form a single vessel. 


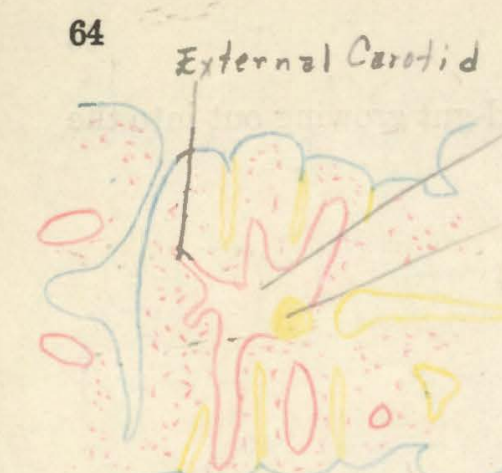

ANATOMY OF CHICK EMBRYOS

* External Carotid Arteries. Minute paired vessels arising from the , base of aortic arch II. Extending ventrolaterally into the mandibular process of arch $\mathrm{I}$.

Pulmonary Arteries. Small paired vessels arising from aortic arch VI and directed posteriorly toward the lung buds. Di/4/5-

* Intersegmental Arteries (and Veins). Small paired vessels ramifying between the somites. First encountered posterior to the otic vesicle. The arteries anastomose with the intersegmental veins which in turn join the anterior or posterior cardinals.
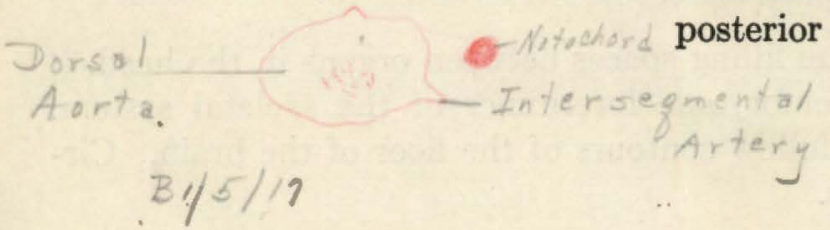

Mesenteric Arteries. The dorsal aorta can be followed posteriorly for a considerable distance, giving off small mesenteric arteries ventrally to the gut and small paired dorsolateral intersegmentals between the somites.

Vitelline Arteries. A pair of large vessels which are given off from the dorsal arta ventrally, and at about the level of somite twenty-two course out over the yolk sac.

Caudal Arteries. Extensions of dorsal aorta into the tail fold. At the level of the posterior limb buds these usually give off lateral capillaries, which are the forerunners of the iliac arteries, and which in turn give off small vessels to the allantois, the allantoic arteries.

" c. PARTS OF THE HEART. The heart of the 72-hour chick is greatly increased in size but it still has the general form of a looped tube. It is attached to the body proper at two points: (1) In the region beneath the visceral clefts by the bulbus arteriosus, and (2) at a more posterior level by the sinus venosus. The looped tube is appended ventrally. Hence, while it is usually possible to find a section where the regions of the heart can be easily identified, it is always necessary to trace the parts of the loop very carefully.

Sinus Venosus. Attached to ventral side of body. Receives right and left common cardinals at its dorsolateral angles. Receives the meatus venosus representing the fused vitelline veins at its posterior end. Shifts to the right side of heart.

Atrium. Ventral to the sinus venosus. Lies nearest the yolk sac. It is usually delimited from the sinus venosus and ventricle by slight constrictions.

Ventricle. Ventral to atrium. Represents the outer curved portion of the loop and hence lies transversely across the section.

Bulbus Arteriosus. Lies lateral to the other parts of the heart and nearest the chorion. Communicates with the ventricle and also with the artic arches. It usually appears sharply defined as circular or oval in cross-sections. 
DIFFERENTIATION OF THE sOMITES. The parts of a typical somite are essentially the same as those already encountered in the 48-hour embryo, as follows:

* SOMITE PROPER. Lateral to neural tube and consisting of:

Dermatome. Thick, dorsolateral plate. Primordium of the dermis.

Myotome. The dorsal "hook" of mesoderm continuous with the dermatome but nearest the neural tube. Primordium of the axial musculature.

$>$ Sclerotome. The main body of the somite consisting of loose mesenchymal cells.

Nephrotome. Ventrolateral to the somite proper. Primordium of the excretory tubules.

Lateral Mesoderm. The broad sheets of the mesoderm extending out laterally from the body proper between ectoderm and endoderm. Somatic mesoderm adjacent to the ectoderm is separated from splanchnic mesoderm by the coelom.

COELOM

At the 72-hour stage the lung buds have begun to develop. They extend out laterally into the anterior coelomic pouches which now become part of the pleural cavity. They are also being undercut by medial extensions from this cavity so as to form the pleural grooves.

At the posterior end of the body the tail fold has developed and in it the cloaca is taking form. A pair of backward extensions of the coelom extend alongside the cloaca into the tail fold.

In the trunk the lateral undercutting is more extensive and consequently the coelom within the body is more clearly delimited from the exocoel.

The pericardial cavity is still continuous with the exocoel.

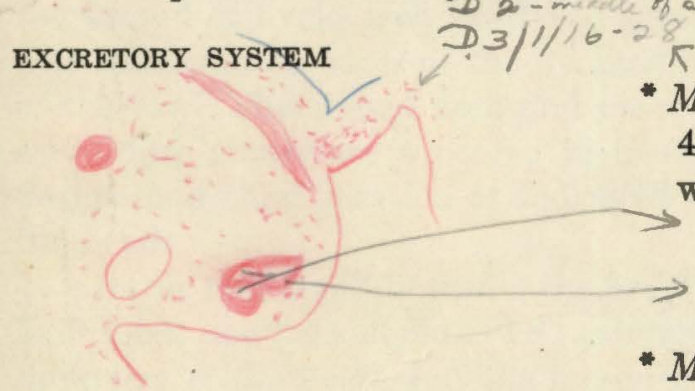

$\kappa \rightarrow B 2$

Mesonephros. This system of tubules already encountered in the 48-hour embryo is still present at 72 hours. A close association with the dorsal aorta and postcardinal vein is apparent.

Mesonephric Tubules. Thick-walled. Contorted shapes.

Mesonephric Duct. Thick-walled. Circular in cross-section.

Lateral to mesonephric tubule. Empties into cloaca.

* Metanephros. The mesonephros is replaced in later development by the metanephros, which is also made up of a series of tubules. These, however, have a very different origin. The metanephros is not always present at.72 hours, but when beginning to develop the following parts may be identified:

Ureter. A dorsal evagination from the mesonephric duct at the point where it joins the cloaca. It may show several bifurcations.

Nephrogenous Tissue. A heavily staining, caplike condensation of nephrogenous mesoderm over the end of the ureter. 
PART III

\section{ANATOMY OF THE 10-MM. PIG}

\section{EXTERNAL FORM}

The 10-mm. pig is a much larger and more complicated embryo than the 72-hour chick last studied, and it has not only begun to take on its final external form but it has also developed the primordia of nearly all the organs and organ systems. The body is clearly divisible into head, trunk, and tail regions and the limb buds are well developed.

The head is bent sharply almost at right angles to the longitudinal axis of the body owing to the cervical and cranial flexures. The head is marked by prominent lateral bulges corresponding to the location of the five vesicles of the brain. At the ventrolateral angles of the head the olfactory pits are clearly evident, bounded by the median and lateral nasal processes. The eye, lateral to the diencephalon, bulges prominently. The depression surrounding it is joined to the nasal pits by the nasolacrymal groove which marks the anterior boundary of the maxillary process of the first visceral arch. The mandibular procềss, or primordium of the lower jaw, which is the main body of the first arch, lies posterior to the maxillary process, the primordium of the upper jaw. The mandibular process is separated from the second or hyoid arch by the hyomandibular groove which gives rise to the external auditory meatus. The tuberculated edges of the hyomandibular groove furnish small tissue masses which form the pinna of the ear. The second arch and groove are followed by the third arch and groove, but the fourth and succeeding arches are squeezed in beneath the head in the region of the future neck by the cervical flexure and their location is indicated only by the cervical sinus, a pitlike depression on the side of the head.

In the region of the trunk, the heart is visible through the thin epidermis just below the head. The liver lobes and mesonephros lie posterior to the heart in the order given. The liver is approximately the same size as the heart, but the mesonephros is very large, occupying most of the space between the anterior and posterior limb buds. Along the dorsolateral sides of the body adjacent to the spinal cord a series of small bulges marks the position of the spinal nerves and indicates the number of somites present. The anterior limb buds project from the sides of the body at the level of the heart and the posterior limb buds at the level of the posterior end of the mesonephros. The body stalk is attached to the ventral abdominal body wall.

On the ventral side of the body at the base of the tail is a small rounded prominence, the genital tubercle, which is the primordium of the external genitalia.

\section{Laboratory Directions}

Study a 10-mm. pig embryo, and make a drawing showing the external features. Label fully.

\section{General Directions}

\section{INTERNAL ANATOMY}

In studying the $10-\mathrm{mm}$. pig embryo it is advisable to work out ectodermal, endodermal, and mesodermal derivatives separately. A careful record should be kept as usual, and a series of small sketches should be made recording the location and identification of various structures. 


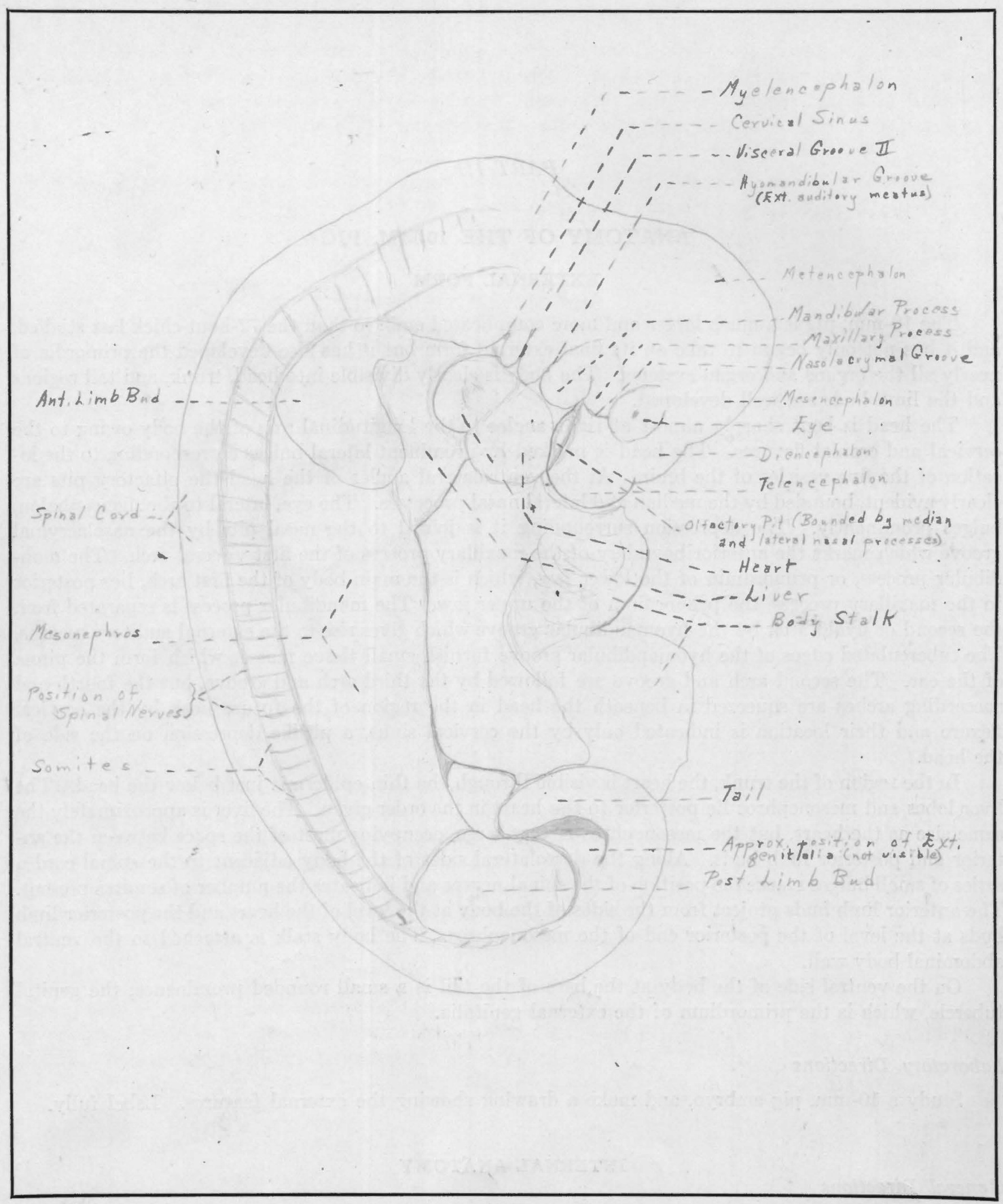

10-mm. Pig Embryo. 


\section{Ectodermal Derivatives}

The brain, organs of special sense, cranial nerves, spinal nerves, and developing sympathetic ganglia constitute the chief ectodermal derivatives which are present at this stage in addition to the epidermis. These will be considered independently. Constant reference should be made to Fig. 32 .

A. EPIDERMIS. A layer of cells constituting the outer covering of the entire body.

B. BRAIN

1. vesicles. The brain is already divided into five vesicles. These are encountered as you work down through the series in the following order:

* (a) sections SUCH as those at level 1, Fig. 32

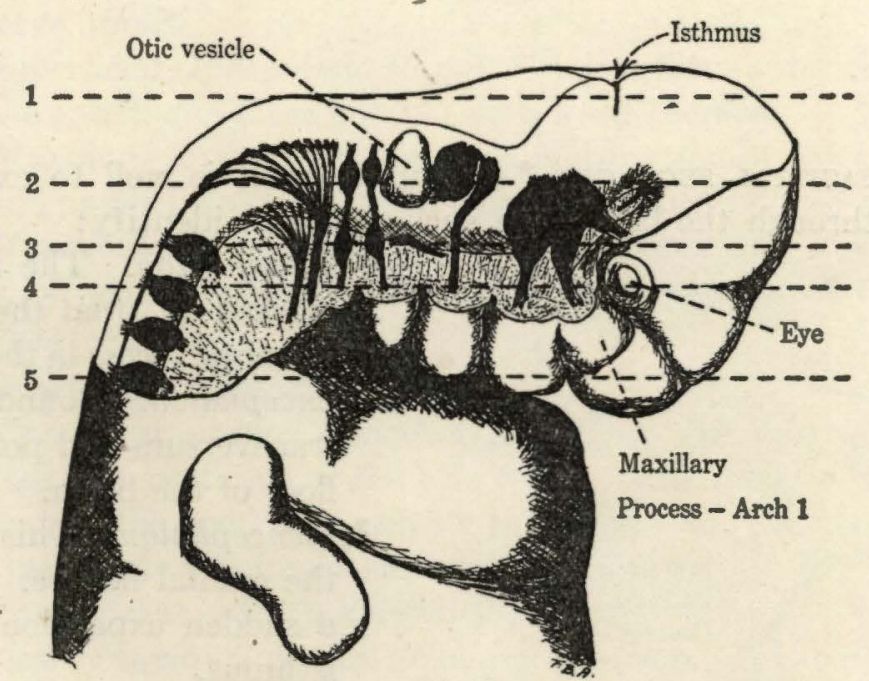

Fra. 32. Lateral view of dissected head of a $10-\mathrm{mm}$. pig showing relation of cranial nerves to brain and organs of special sense.

Mesencephalon. Thick-walled. Section typically round in shape.

Isthmus. Constriction between mesencephalon and metencephalon.

Metencephalon. Just posterior to isthmus. Thick-walled. Widens gradually behind isthmus.

Myelencephalon. Posterior to metencéphalon-tapering gradually toward spinal cord. Roof of anterior part thin-walled. Side walls thick and marked by a series of indentations, the neuromeres, which were once thought to represent primitive segmentation of the brain.

* (b) Sections Such as those at LeVEl 4, Fig. 32

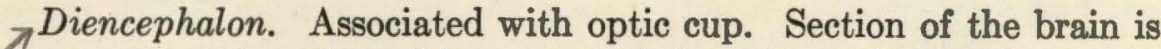
round at junction with mesencephalon. It gradually changes to an oval at the level of the optic cups, which are connected to the brain by the optic stalk. 
* (c) sections such as those at level 5, fig. 32

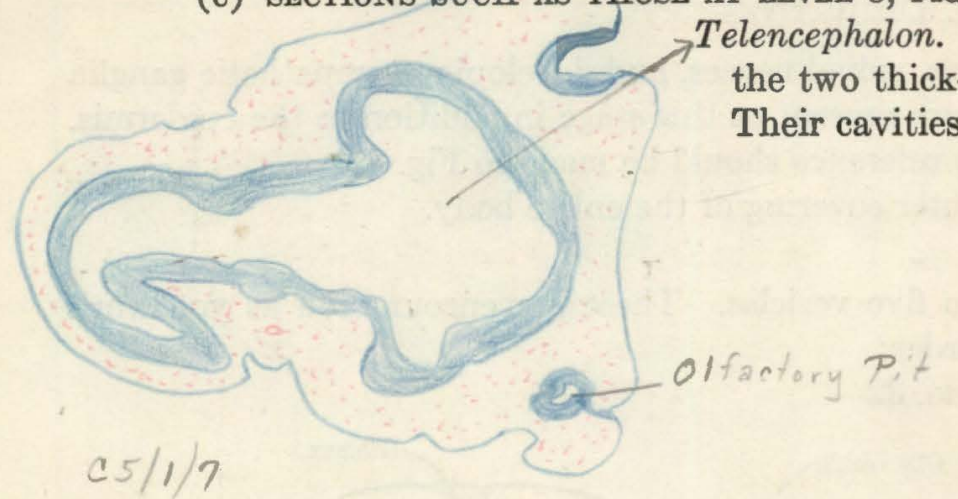

2. sagittal section. *At this stage it is well to examine a single typical mid-sagittal section through the brain. In such a section identify:

Telencephalon. The most anterior vesicle of the brain which is marked off from the diencephalon by two constrictions, namely the optic recess in the floor and the velum transversum in the roof.

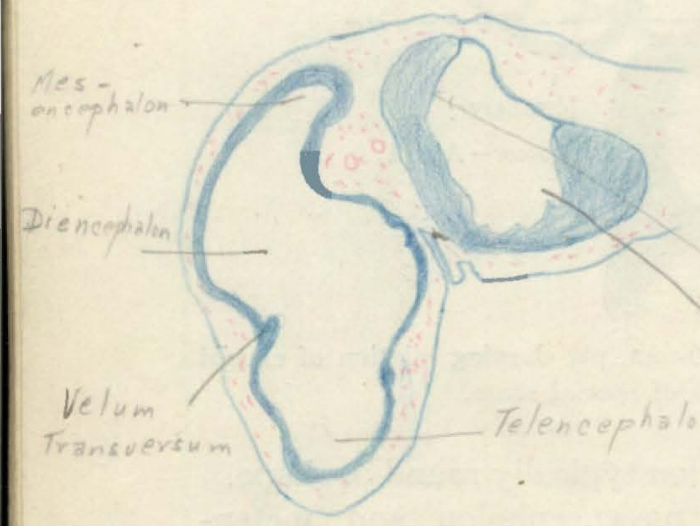

Diencephalon. Bounded anteriorly by the optic recess and velum transversum and posteriorly by the tuberculum posterius on the floor of the brain.

Mesencephalon. This part of the brain is located in the region of the cranial flexure. It appears posterior to the diencephalon as a sudden expansion and is bounded posteriorly by the narrow isthmus.

Metencephalon. This division lies just posterior to the isthmus. It is marked by a comparatively thick roof.

Myelencephalon. There is no sharp line of demarcation between this part of the brain and the metencephalon. The thin roof, however, is quite characteristic.

C. CRANIAL NERVES. Working down through the series identify the various cranial nerves, as follows:

1. NERVES ASSOCIATED WITH ISTHMUS. LEVEL 1, FIG. 32

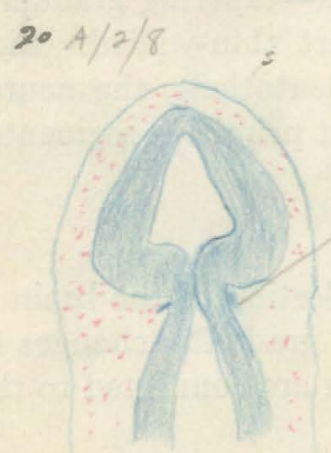

* (IV) Trochlear. Very small, inconspicuous. Leaves the brain on the upper side of the isthmus where the mesencephalon just joins the metencephalon. This nerve cannot be traced very far at this stage but it eventually innervates the superior oblique muscle of the eye. 
2. NERVES ASSOCIATED WITH LATERAL WALLS OF MYELENCEPHALON. LEVEL 2, FIG. 32

* (a) ANTERIor to THE OtIC VESICLle (LISTED IN ORDER ANTERIORLY)

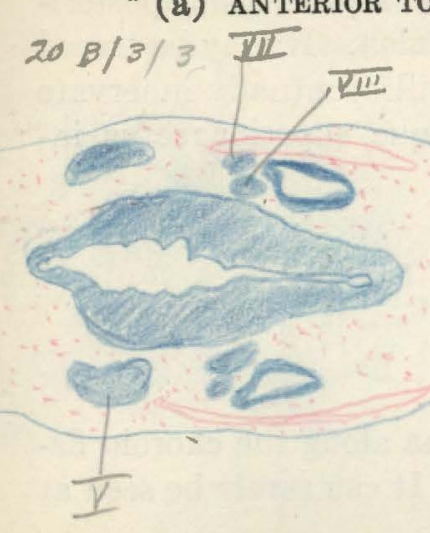

(VIII) Auditory Nerve: Acoustic Ganglion. Innervates the otic vesicle.

(VII) Facial Nerve: Geniculate Ganglion. Closelyrassociated with VIII. The nerve is directed posterolaterally and innervates the side of the head, its fibers passing into visceral arch II.

(V) Trigeminal: Semilunar Ganglion. Situated at the broad anterior end of the myelencephalon. The ganglion is half-moon shaped. Traced deeper into the body, three main branches of the nerve appear:

(a) Superficial Ophthalmic Ramus. Arises from anterior end of the ganglionic mass and passes toward the eye.

(b) Maxillary Ramus. Arises from mid-portion of the ganglion and passes into the maxillary process of the first visceral arch.

(c) Mandibular Ramus. Arises from posterior end of the ganglion and passes into the mandibular process of the first visceral arch.

- (b) Posterior to otic vesicle (Listed in ORder POSTERIoRLy)
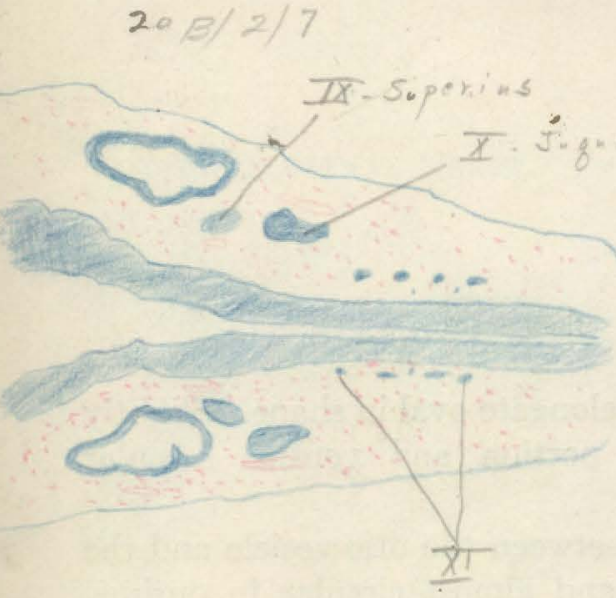

(IX) Glossopharyngeal: Superius

Situated just posterior to the otic vesicle. Its fibers are directed deeper into the head to innervate the tongue and pharynx. The superius ganglion is found near the point of origin. The petrosal ganglion is located farther down the nerve.

(X) Vagus: Jugular Ganglion; Nodose Ganglion. Its fibers at first run parallel to those of IX but may be traced well down into the

$\Gamma$ body, where they innervate the visceral organs. The jugular C/2/7 ganglion is located near the point of origin. The nodose is found $m$ if by tracing the nerve somewhat deeper into the series.

(XI) Spinal Accessory: Froriep's Ganglion. This nerve arises from a series of small roots, which, therefore, appear like a row of dots alongside the posterior end of the myelencephalon. The ganglion is obscure. The internal branch of the nerve runs parallel to the vagus down to the shoulder, whereas the external branch runs alongside the hind brain and parallels the spinal cord. It may thus appear as a long band of fibers adjacent to the myelencephalon, or, deeper in the series, as a minute fiber wedged in between the dorsal roots of the spinal nerves and the spinal cord.

3. NERVES ASSOCIATED WITH THE FLOOR OF MYELENCEPHALON. LEVEL 3, FIG. 32. A section through a level such as this will show the spinal cord, base of the floor of the myelencephalon and the mesencephalon, or possibly the diencephalon.

* (VI) Abducens. This small nerve arises from the ventrolateral portion of the floor of the myelencephalon. Its fibers are directed forward and outward toward the eye, where it will eventually innervate the external rectus muscle.

* (XII) Hypoglossal. Arises as a series of roots from the ventro$\mathrm{C} / 2,1 / 4$

Alateral sides of the myelencephalon before the brain narrows to the spinal cord. Appears as a row of dots bridging the gap between the spinal cord and base of myelencephalon. This nerve innervates the tongue. 
4. NERVES ASSOCIATED WITH THE FLOOR OF MESENCEPHALON. LEVEL 2, FIG. 32

* (III) Oculomotor. The fibers of this nerve protruding posteriorly arise from the floor of the mesencephalon. It may be traced some distance toward the eye, where it will eventually innervate certain eye muscles, namely: inferior oblique, superior rectus, inferior rectus, and internal rectus.

5. NERVES ASSOCIATED WITH DIENCEPHALON.' LEVEL 4, FIG. 32

(II) Optic. This nerve runs from the retina along the choroid fissure on the under side of the optic stalk. It can rarely be seen at this stage.

6. NERVES ASSOCIATED WITH TELENCEPHALON. LEVEL 5, FIG. 32

* (I) Olfactory. This nerve runs from the olfactory pit to the tel-

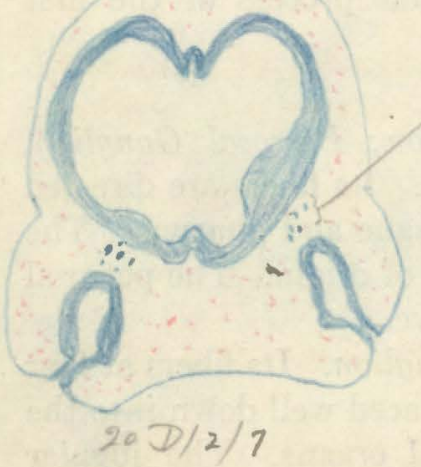
encephalon. It can usually (though not always) be seen.

(Ia) Terminal. Not present at this stage.

D. ORGANS OF SPECIAL SENSE

* 1. OTIC VESICLE. Lateral to the myelencephalon. Thick-walled and elongate oval in shape. Slightly Mortion.
Endolymphatic Duct. Situated between the otic vesicle and the
myelencephalon. Thick-walled and almost circular in outline.
Joins the lower or saccular portion of the otic vesicle.

*2. OPTIC CUP AND LENS. Located alongside the diencephalon to which the optic cup is attached by means of the optic stalk. The lens is almost solid and located within the rim of the optic cup. optic cup darkened by the deposit of pigment.

$c_{4} / 1 / 12$ 
* 3. olfaCtory pIT. Located at the anterior ventrolateral surfaces of the head. Has the form of a

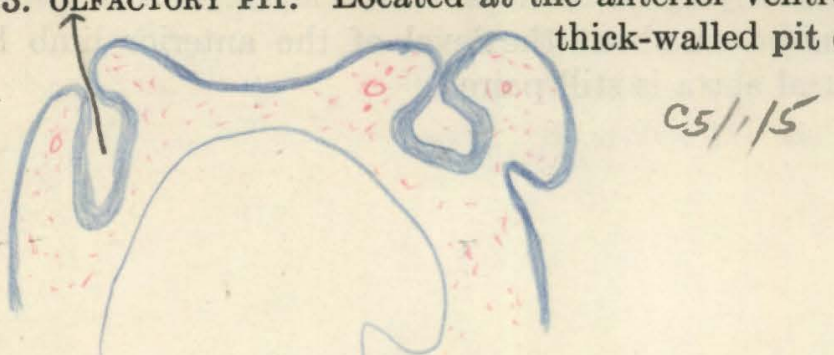

* E. SPINal CORD. Fig. 36. At almost any level past the head, preferably one about midway through the C 7series, typical sections of the spinal cord and associated spinal nerves can be found. Identify:

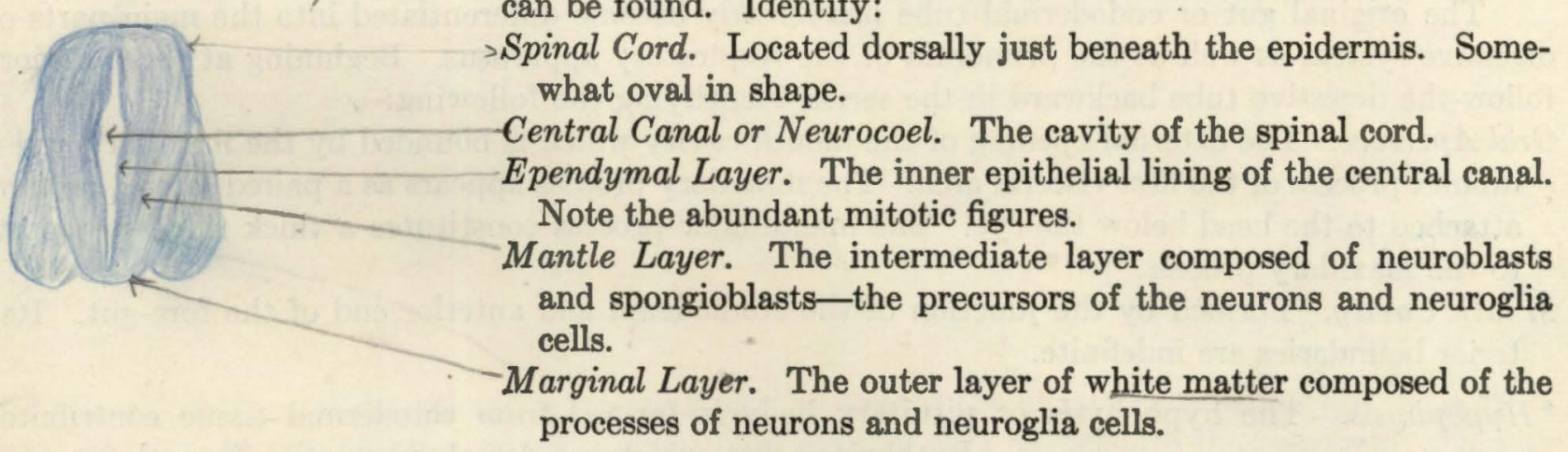

* F. Typical spinal Nerve. Paired. Located ventrolateral to the spinal cord.

C6/1/9

$\rightarrow$ Dorsal Root. The bundle of afferent nerve fibers joined to the dorsolateral wall of the spinal cord.

Dorsal Root Ganglion. A prominent mass of neurons located on the dorsal root close to the point of origin from the spinal cord and lying alongside the cord.

$\rightarrow$ Ventral Root. The bundle of efferent nerve fibers joined to the ventrolateral wall of the spinal cord.

$\rightarrow$ Spinal Nerve. The main trunk formed by junction of the dorsal and ventral root. It gives off three branches or rami, as follows:

Dorsal Ramus. The branch arising from the main trunk and ascending to the dorsolateral body wall to supply the skin and muscles of the trunk.

$\rightarrow$ Lateral Ramus. The branch directed laterally to the ventral body wall.

Communicating Ramus. The branch directed ventrally and medially toward the ganglia of the sympathetic system.

* G. NERVE PLeXUS

Brachial Plexus. At the level of the anterior limb buds the lateral rami of the spinal nerves are interconnected, thereby forming the brachial plexus which innervates the limb bud.

Lumbosacral Plexus. The nerve plexus supplying the posterior limb bud. 
* H. Sympathetic ganglia. Paired ganglionic masses lying dorsolateral to the aorta. These are most (2) $C 3 / 3 / 8$ readily recognized at about the level of the anterior limb buds where the dorsal aorta is still paired.

ENDODERMAL DERIVATIVES AND ASSOCIATED STRUCTURES

The original gut or endodermal tube has already become differentiated into the main parts of the digestive system as well as the primordia of the respiratory apparatus. Beginning at the anterior end, follow the digestive tube backward in the series, identifying the following:

Oral Aperture. The external opening of the mouth cavity which is bounded by the maxillary and mandibular process of the first visceral arch. The maxillary process appears as a paired lateral prominence attached to the head below the eye. The mandibular process constitutes a thick ridge just posterior to the maxillary process.

Mouth Cavity. Formed by the junction of the stomodeum and anterior end of the fore-gut. Its posterior boundaries are indefinite.

* Hypophysis. The hypophysis or pituitary body is formed from ectodermal tissue contributed by $20 \mathrm{C} / 2 / 9$ Rathke's pocket, which is a dorsal evagination from the stomodeum and the infundibulum.

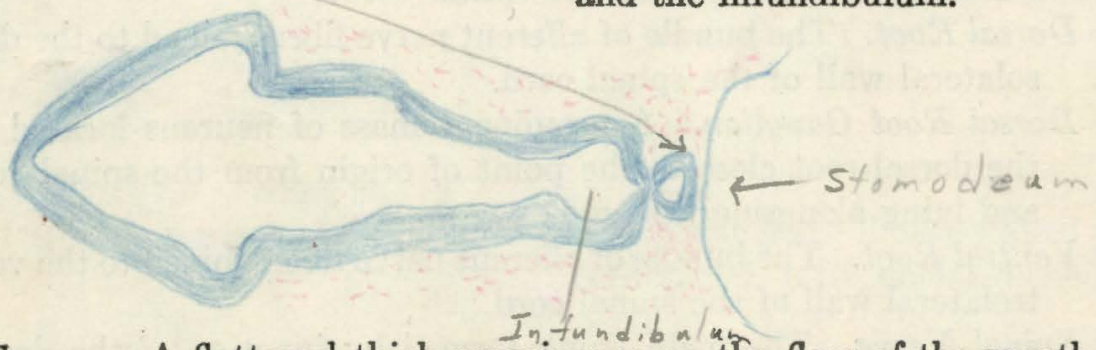

Tongue. A flattened thick prominence on the floor of the mouth formed of tissues contributed by all $20 \mathrm{c} / 1 / 15$ three germ layers.

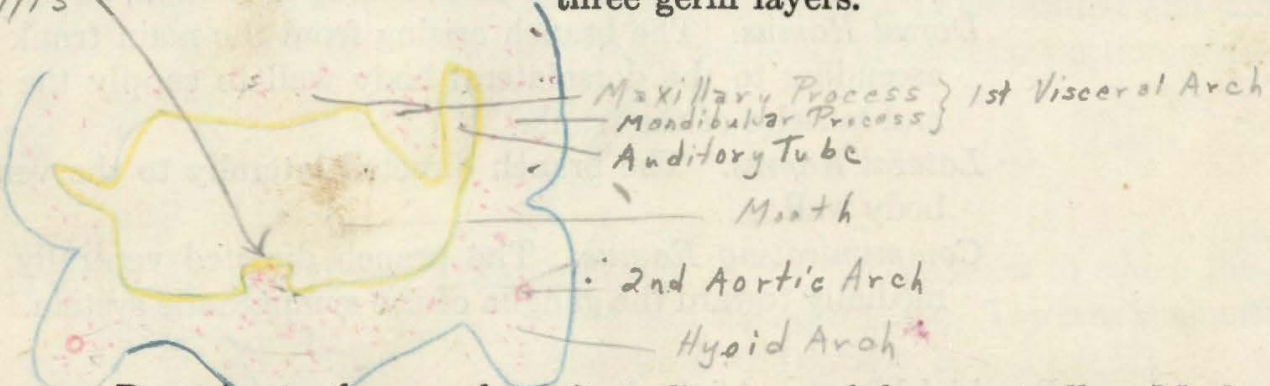

Pharynx. Posterior to the mouth cavity. Compressed dorsoventrally. Marked by the presence of four paired, lateral visceral pouches. These meet the corresponding visceral grooves but the closing plates do not rupture to form a row of clefts. The visceral arches are pillars of tissue between the pouches. The parts of visceral arch I form the boundaries of the mouth opening, the maxillary process being the primordium of the upper jaw and the mandibular process, the primordium of the lower jaw. Next in order posteriorly are arches II (the hyoid), III, and IV. Note the similarity to what has already been encountered in the 72-hour chick.

Auditory Tube. Proximal end of visceral pouch I.

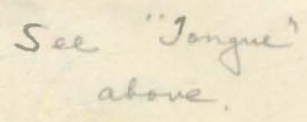

* Cavum Tympani. Dilated terminal portion $\curvearrowleft$ of visceral pouch I. 
* Parathyroid Glands. Located at the upper (or dorsal) ends of third and fourth visceral pouches. These primordia have the appearance of irregular thickenings or buddings of the endoderm running into the adjacent mesenchyme of arches III and IV.

tracheal Grove

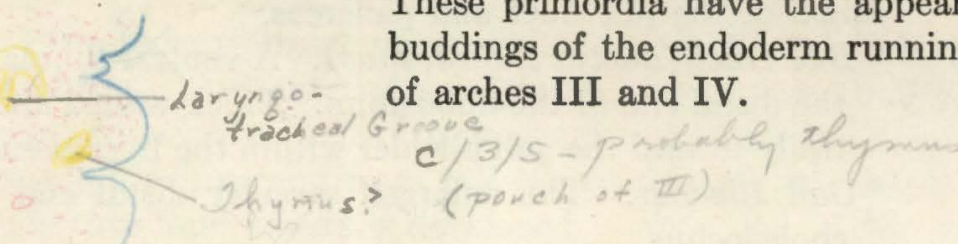

Thymus Glands. Located at the lower or ventral ends of the third and fourth visceral pouches. Their appearance is similar to that of the parathyroids.

Thyroid Gland. A ventral diverticulum arising from the floor of the pharynx at the level of the second visceral pouch. At this stage of development it has already sunk deeper into the mesoderm and will be much more readily identified when the aortic arches are studied.

* Laryngotracheal Groove. Posterior to the fourth visceral pouch the tube narrows greatly and develops a deep longitudinal depression on its ventral surface, known as the laryngotracheal groove. The groove is prolonged posteriorly so that its distal end separates off from the main tube, thus forming the trachea and leaving the oesophagus in the position of the original tube.

Trachea. Ventral to the oesophagus. Round in cross-section.

$2 / 2 / 4-5$

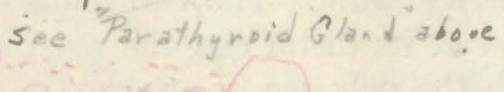

$\checkmark$ * Eparterial Bronchus. A single rounded, budlike protuberance

on the right side of the trachea.
* Primary Bronchi. The rounded bifurcated ends of the trachea.

Oesophagus. Round and thick-walled in section. Forms the connection between pharynx and stomach.

* Stomach. Elongate and thick-walled. Broader than oesophagus. Supported by the dorsal mesentery. Directed ventrolaterally and toward the right. 
Duodenum. Round and thick-walled. Begins where stomach narrows posteriorly. Ends at point of $G / 2 / 4$

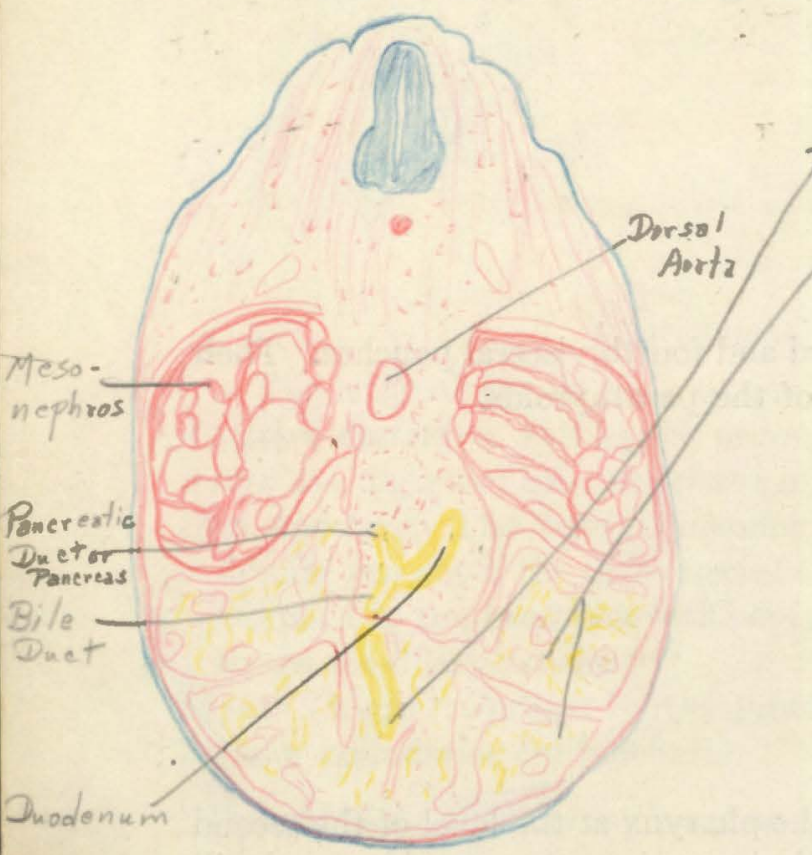
origin of the bile duct and pancreas.

* Bile Duct (ductus choledochus). A ventral tubular canal joining the distal end of the duodenum. Thick-walled and directed ventrally toward the gall bladder within the liver tissue.

* Gall Bladder. The enlarged saccular distal end of the ductus choledochus.

" Eiver (Fig. 36). Both ductus choledochus and gall bladder are entirely surrounded by the liver tissue, which is almost spongy in appearance owing to the extensive ramifications of the blood vessels and capillaries throughout the entire structure. As a result, liver tissue is endodermal in origin as regards the secretory tissue but has also a great deal of tissue of mesodermal origin whch forms the walls of the blood sinusoids:

- Pancreas. A dorsal diverticulum from the duodenum near the level at which the bile duct enters. It forms an irregular mass lying in the dorsal mesentery distinguishable mostly on the basis of its staining reaction. Slight indication of the ventral pancreatic diverticulum is sometimes found in the form of a minute, budlike prominence just at the point of entrance of the bile duct into the duodenum. It is directed dorsally and to the right.

Intestine Proper. A thick-walled tube of small bore continuing backward from the duodenum. It is supported by the dorsal mesentery and is accompanied by the vitelline arteries and veins.

"Intestinal Loop. At the level of the body stalk the intestine swings ventrally out into the body stalk

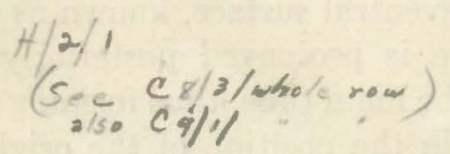
and then back into the body cavity again. The two limbs of this loop are in close proximity, and at its distal end the narrow yolk stalk, which communicates with the yolk sac, is attached.

Colbn. After re-entering the body cavity the tube continues backward toward the cloaca.

Cloaca. An enlarged cavity into which the colon enters (Fig. 33).

Norg. This structure is of considerable importance and will be dealt with more fully when the nephric system is considered.

Allantoic stalk, A partighly collapsed duct opening into the ventral side of the cloaca. Runs through the body stalk to communicate with the bladderlike allantois, which
is usually removed before sectioning.
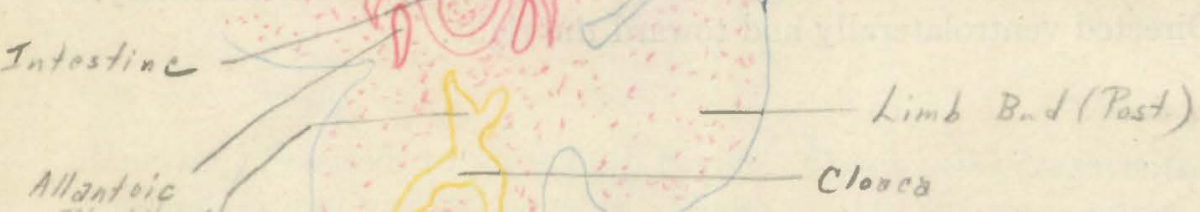

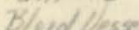

Allan toic

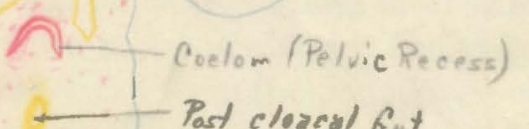

Stalk 


\section{Mesodermal Derivatives}

MESENCHYME. The loose reticular tissue which fills spaces between developing organs throughout the body of the embryo. This material is of great importance in that it constitutes the forerunner of the various types of connective tissue. It is composed of the cell body containing a nucleus, and protoplasmic processes which extend from cell to cell forming a delicate reticulum, in the interstices of which a more or less fluid matrix is developed.

NотосновD. A cylindrical rodlike structure forming the skeletal axis of the embryo. Circular in crosssection. Located ventral to the spinal cord. Extends from region of mesencephalon to tail.

somites. In the 10-mm. pig embryo there are approximately forty-four somites. These have already undergone the early differentiation corresponding to that studied in the chick, and consequently in a typical somite occurring about midway through the body we may recognize:

Dermatome. A dense strip of cells situated lateral to the spinal cord just beneath the ectodermal epidermis.

Myotome. The proximal hooklike end of the strip of cells constituting the dermatome but bent under or ventral to it and hence located closer to the spinal cord.

Sclerotome. The main bulk of the somite consisting of more loosely arranged cells.

Myocoel. The cavity of the somite. Located beneath or ventral to the dermatome and usually obliterated.

Nephrotome. The intermediate mesoderm is already differentiated into the complicated mesonephros which will be considered under the excretory system.

Lateral Mesoderm. The lateral sheets of mesoderm are already differentiated into a somatic and splanchnic layer. Identify:

Somatic Layer. In close association with the ectoderm of the outer body wall.

Splanchnic Layer. Covering the mesonephroi and also forming the mesentery supporting the gut and associated structures.

concom. In the 10-mm. pig the pleural cavities and pleural grooves are already present at the level of the lung buds. In the region of the cloaca the backward extensions of the coelom form a saddleshaped pelvic recess beneath the urogenital sinus of the cloaca.

Within the trunk a blind coelomic pocket has been formed in the mesentery owing to the shifting of the position if the stomach. As a result the dorsal mesentery is wrapped around the surface of the stomach, as it were, and so forms a blind pouch, the omental bursa. This communicates with the coelom by means of the epiploic foramen (foramen of Winslow).

PARTITIONING OF COELOM. The transverse partitioning of the coelom into thoracic and abdominal regions has begun in the 10-mm. pig with the development of the septum transversum, "which forms a sort of semicircular shelf attached to the ventral body wall situated between the heart and liver.

- mesenteries. During early embryonie development the splanchnic mesoderm envelops the gut. As a result the digestive tube is attached to the dorsal coelomic wall by the dorsal mesentery and to the ventral wall by the ventral mesentery. Only the dorsal mesentery persists, however, and the usual regions may be recognized:

Mesogaster-supporting the stomach.

Mesoduodenum-supporting the duodenum.

Mesentery proper-supporting the main body of the gut.

Mesocolon-supporting the colon.

In addition the gastrohepatic omentum is a persisting portion of the ventral mesentery joining the gut to the liver. 


\section{EXCRETORY SYSTEM}

PRONEPHROS. In the pig a transitory pronephros is found in the most anterior nephrotomes. It has already degenerated and been superseded by the mesonephros at the $10-\mathrm{mm}$. stage.

* mesonephros. The mesonephroi which constitute the functional kidney of the $10-\mathrm{mm}$. pig are very conspicuous and almost disproportionately large in comparison with the rest of the body. They are located posteri $\mathbf{r}$ to the liver and develop in behind the splanchnic mesoderm; hence they are said to be retroperitoneal in position. They are so large, however, that they protrude down into the coelom. Well-marked differentiation of parts is apparent at this stage, but it should be remembered that individual mesonephric tubules make up the entire structure. Select a mid-body section (Fig. 36 ) and identify:

* Bowman's Capsule. The enlarged, double-walled chamber situated at the terminal end of the tubule and containing a glomerulus. Usually located near the mid-line. These structures are usually quite irregular in shape.

Glomerulus. The knot of capillaries contained within the inner cup of the Bowman's capsule. Irregular in shape, compact in appearance. - Located near the mid-line.

Mesonephric Tubule. The tubules lead from Bowman's capsule to the mesonephric duct. The tubules are hollow, curving tubes. Usually situated laterally.

* Mesonephric Duct. The common collecting duct leading backward to the cloaca. Located on the ventrolateral border of the mesonephros. Thick-walled and prominent. Usually flattened oval in cross-section.

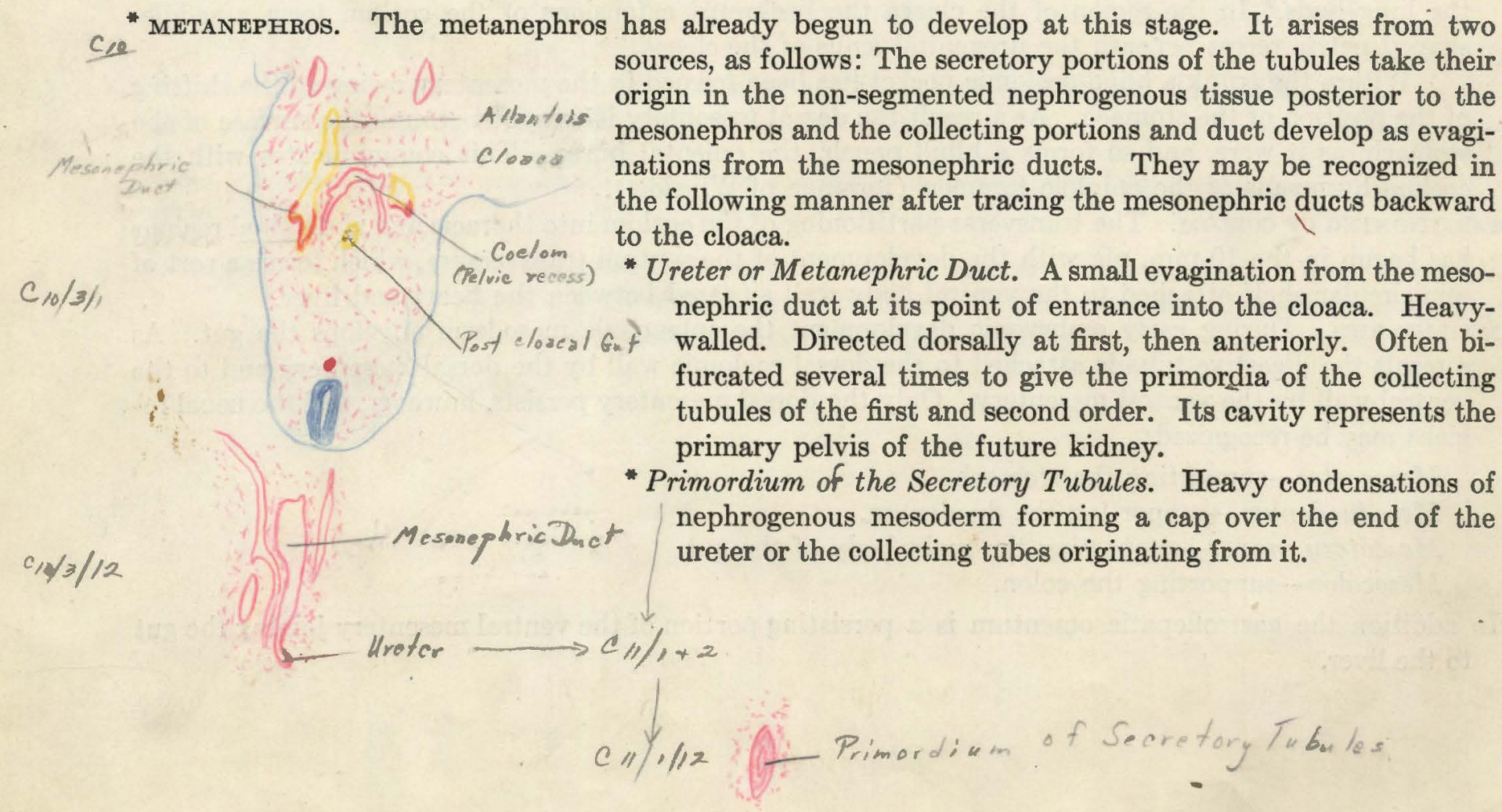


DIFFERENTIATION OF CLOACA (FIG. 33)

The cloaca is a structure of considerable importance at this stage, and consequently it should be studied with care. Two regions may be recognized as follows:

* Urogenital Sinus. The broad, saddle-shaped anterior portion of the cloaca which receives the allantois, and, at its lateral margins, the mesonephric and metanephric ducts.

NotE. It is important not to confuse this portion of the cloaca with the pelvic recess of the coelom which also extends underneath the saddle-shaped urogenital sinus. In cross-section, both are curved, arc-shaped cavities but the coelom lies within the are of the urogenital sinus.

$\operatorname{cro} / 2 / 5$

Rectum. The posterior narrow portion of the cloaca receiving the gut and postcloacal gut.

* Cloacal Plate. The closing plate formed by apposition of the

7 lateral walls of the terminal portion of the cloaca.
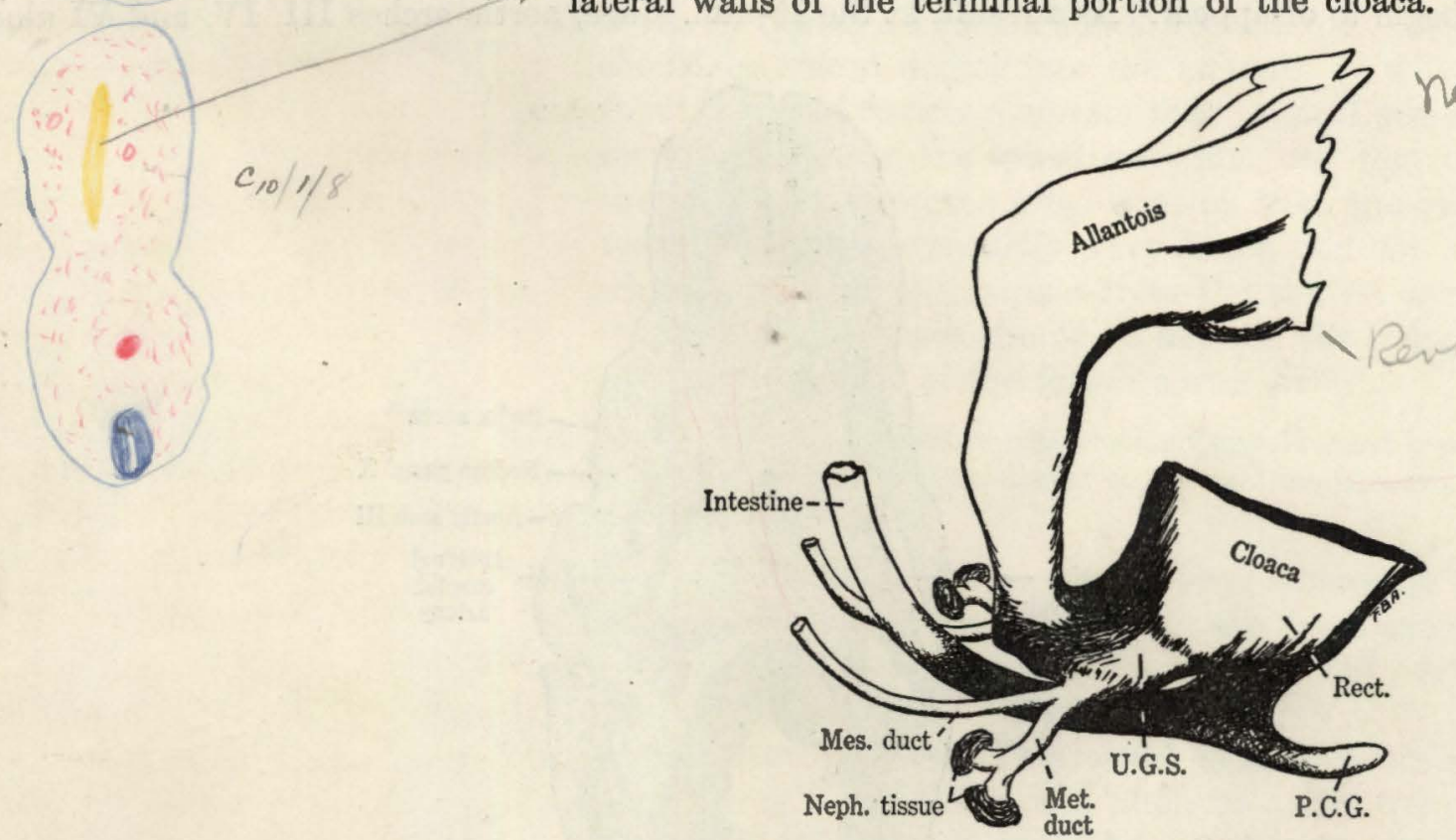

Fig. 33. Reconstruction of the cloaca and related structures in the 10-mm. pig. Mes. duct, mesonephric duct; Met. duct, metanephric duct; Neph. tissue, nephrogenous tissue; P.C.G., post cloacal gut; Rect., rectum; U.G.S., urogenital sinus.

\section{REPRODUCTIVE SYSTEM}

The gonads of the embryo are represented in the $10-\mathrm{mm}$. pig only by the merest rudiments in the form of thickened genital ridges on the ventromesial side of the mesonephros. These structures are located about midway back along the mesonephroi. Identify:

* Germinal Epithelium. The irregular, thickened splanchnic meso$c_{7} / 1 / 9$

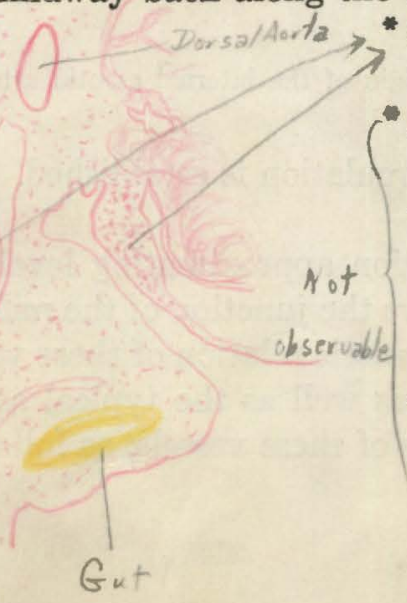
derm forming the surface layer.

Primordial Germ Cells. Prominent cells with large vesicular nuclei situated in the tissue underlying the germinal epithelium.

Gonoducts. Since the sex of the individual pig is quite uncertain Mesoncphices at this stage, the gonoducts have not yet been differentiated. However, if the animal is to be a male, the mesonephric duct will eventually function as a ductus deferens.

External Genitalia. No differentiation of the external genitalia can be recognized, but the genital tubercle is the primordium of these structures. 


\section{CIRCULATORY SYSTEM}

At this stage of development the circulatory system has become very complex, for the early stages of development corresponding to those of the 33- to 72-hour chick have already been completed. As a consequence it will be found highly desirable to work out the circulatory system in separate units:

\section{ARTERIAL SYSTEM AND HEART}

\section{A. ARTERIES OF THE HEAD}

\section{AORTIC ARCH SYSTEM}

In the pig, just as in other vertebrates, the aortic arches develop as a series of six pairs of blood vessels associated with the visceral arches. They also do not all develop at once and the ones formed first soon begin to disappear. As a result, at the $10-\mathrm{mm}$. stage, aortic arches III, IV, and VI alone per-

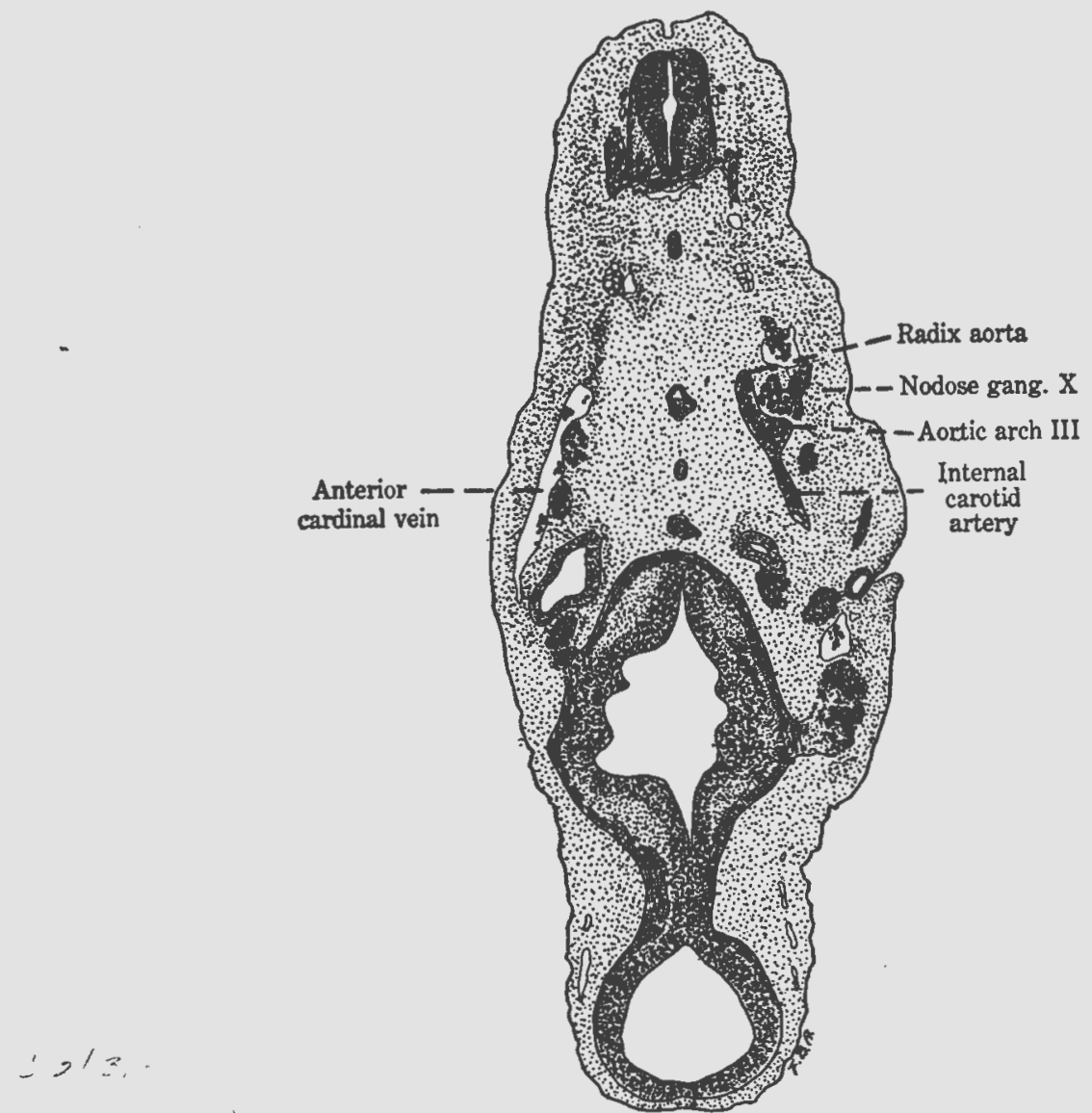

FIG. 34. Section through the head of a 10-mm. pig at the level of origin of the internal carotid arteries.

sist. These constitute the basis on which the adult plan of the circulation is established. Consequently they should be carefully worked out in detail.

As a key point for tracing these blood vessels, select a section approximating level 3, Fig. 32, as illustrated in Fig. 34. Such a section is significant because it shows the junction of the radix of the aorta, the third aortic arch, and the internal carotid artery. The characteristic relation of these vessels is clearly shown in the figure (subject to slight modifications, of course) as well as the typical association with the nodose ganglion of the vagus nerve $X$. Trace out the courses of these vessels, as follows: 
* (a) Internal Carotid Artery. This vessel can be traced forward in the head to the side of the diencephalon. In this region it becomes broken up into a multiplicity of capillaries running out over the brain. The main channel, however, can be picked up again beneath the floor of the mesencephalon. Here the two vessels unite to form the basilar artery which continues backward beneath the floor of the brain as a somewhat uncertain channel to the beginning of the spinal cord. At this level the basilar flows into the paired vertebrals which continue backward, paired, to the level of the limb buds. Here they anastomose with the subclavian arteries but also continue backward and eventually fuse to form the spinal artery which flows beneath the spinal cord.

ind

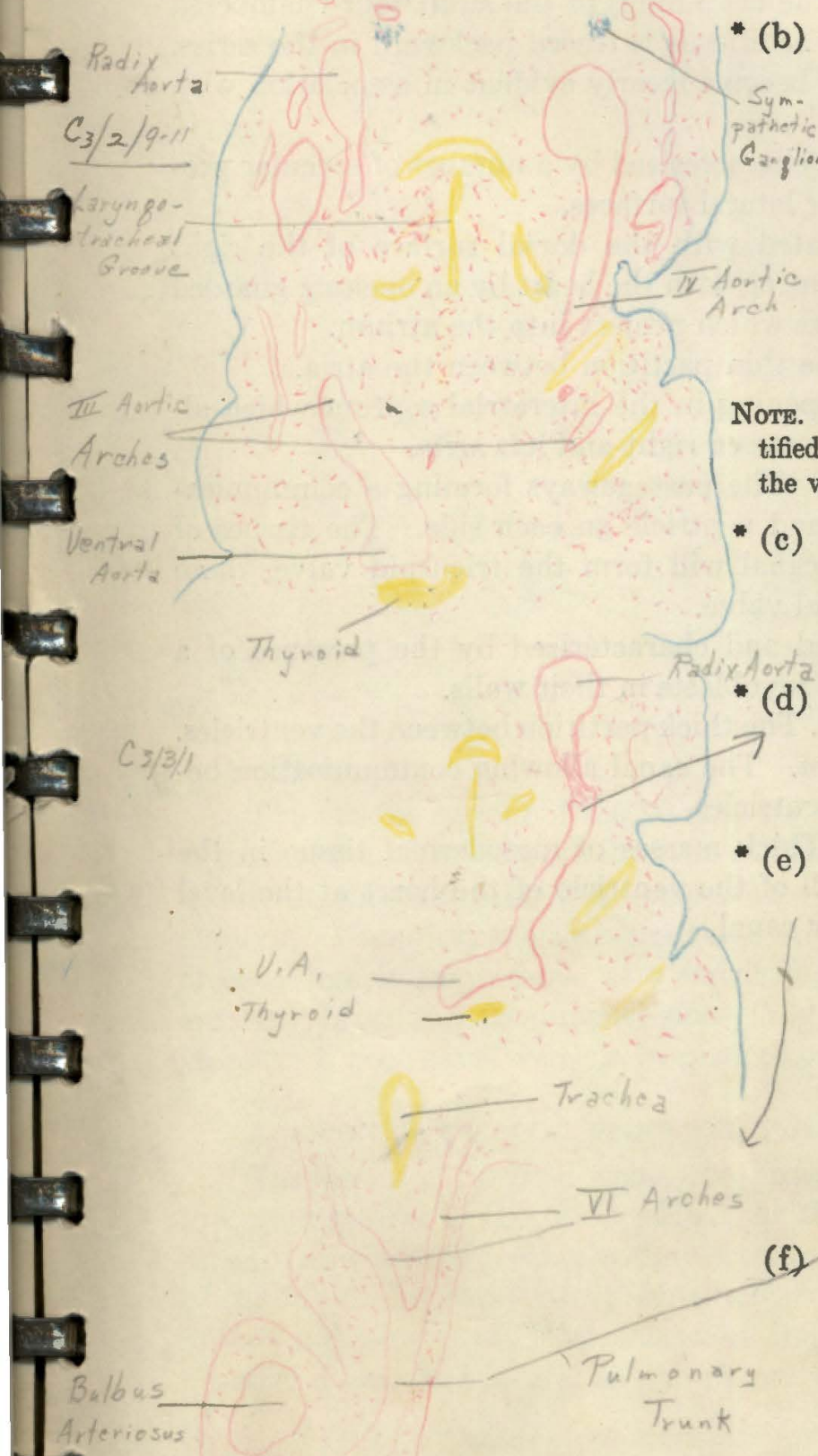

Radix of Dorsal Aorta and Third Aortic Arch. These vessels should be traced deeper into the animal. It will be found that the paired radices maintain their original position in the section relative to the spinal cord, etc., and that the paired third aortic arch moves steadily away from the radix. The two third arches eventually meet in the mid-line at a point which represents their origin from the ventral aorta. Near this level sharp watch should be kept on the radix aorta for the junction point of the fourth aortic arch.

NoтE. This is the point at which the developing *thyroid gland is readily identified as a small caplike condensation of endodermal tissue above the end of ventral aorta.

(c) External Carotid Artery. At the level where the two third arches arise from the ventral aorta, the small external carotids are found coursing obliquely forward and outward into the mandibular arch.

$\mathrm{C}_{3 / 2 / 6}+\mathrm{C}_{3 / 2 / 2}$

(d) Fourth Aortic Arch. This vessel usually persists through only a very few sections, and often its origin from the ventral aorta and junction with the dorsal aorta can be seen in the same section. This gives it. a characteristic $U$ shape.

e) Sixth Aortic Arch. A few sections posterior to the level at which the fourth arch can be identified the junction points) of the sixth and dorsal aortae are encountered. When traced deeper these vessels are seen to arise not directly from the ventral aorta but rather from a separate trunk-the pulmonary trunk-which has been separated off from the ventral aorta. At this level it is usual to speak of the ventral aorta as the systemic trunk. Note the characteristic $\mathrm{Y}$ shape of the sixth arches at their point of separation from the pulmonary trunk.

f) Pulmonary Arteries. These arteries which are quite small arise from a point about midway along the sixth aortic arch and may be traced deeper in the body toward the lung buds. 
2. HWART

$$
\text { C5/113 }
$$

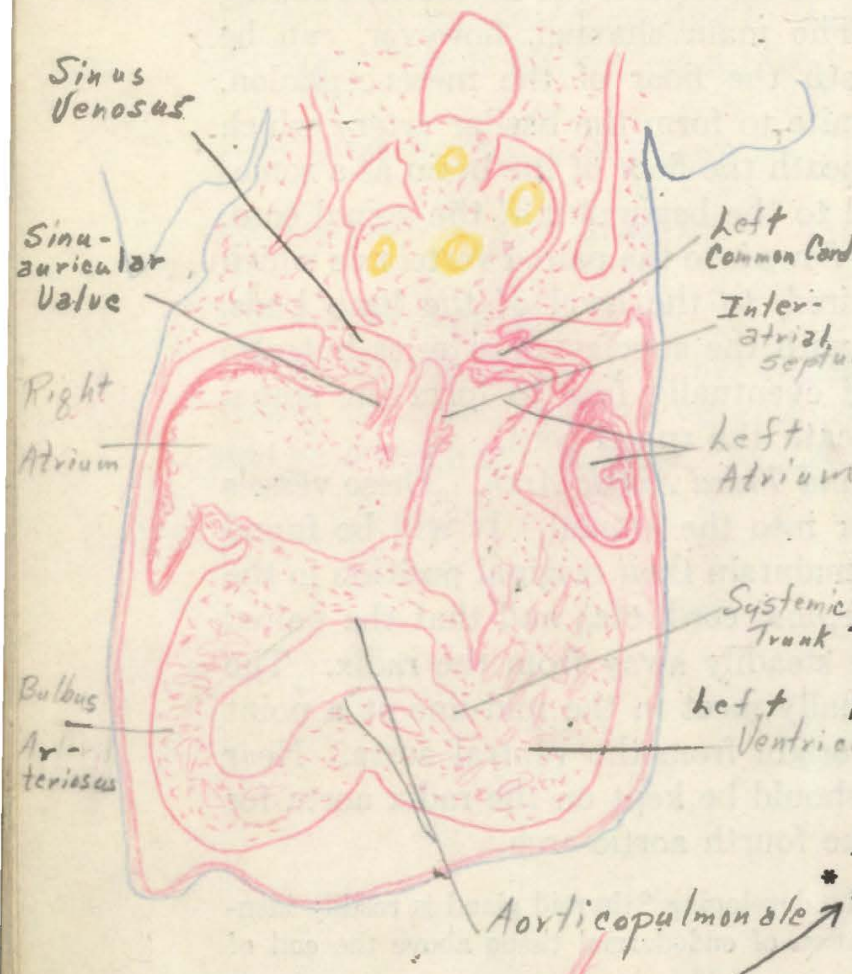

$C_{5} / 1 / 5$

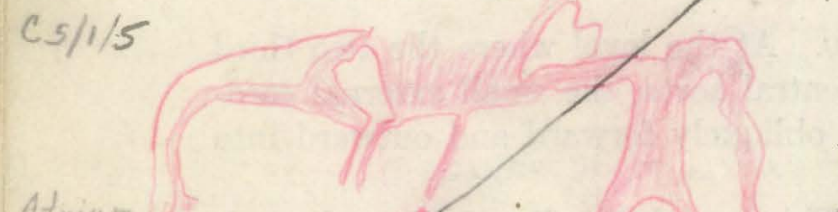

* Bulbus Arteriosus. Follow the systemic and pulmonary trunks deeper to their point of origin from the bulbus arteriosus. This channel is very thick-walled and will be found to show a tendency toward division into two channels near the ventricular region of the heart. This is indicated by the presence of a ridgelike thickening on both its dorsal and ventral wall. The ridge is the beginning of the septum aorticopulmonale. The potential pulmonary trunk will be found to communicate with the right ventricle and the systemic trunk with the left ventricle.

The heart is already divided into atrial and ventricular regions and these in turn are incompletely partitioned into right and left halves, thus forming the beginnings of the adult four-chambered heart. As the bulbus arteriosus is traced backward in the series, the parts of the heart become clearly evident in association with it, as follows:

Atria. Thin-walled and characterized by a number of saccular projections on their upper lateral surfaces.

Sinus Venosus. Associated with the dorsal surface of the right atrium and communicating with the heart by an opening guarded by a pair of thin valves which project into the atrium.

Interatrial Septum. The thin partition between the atria.

* Foramen Ovale. The opening in the interatrial septum which allows communication between right and left atria.

Atrioventricular Canals. The passageways forming a communication between atrium and ventricle on each side. The tissues of the rim of the right canal will form the tricuspid valve, those of the left, the bicuspid valve. $C 5 / 2 / 4-9$

Ventricles. Thick-walled and characterized by the presence of a reticular syncytium of myoblasts in their walls.

Interventricular Septum. The thick partition between the ventricles. Interventricular Foramen. The canal allowing communication between right and left ventricles. C $5 / 2 / 5-9$

Endocardial Cushion. Thick masses of mesodermal tissue in the dorsal and ventral wall of the ventricle of the heart at the level of the atrioventricular canal. c $5 / 2 / 5-9$ 
3. ARTERIES OF THE BODY. As the dorsal aorta courses backward in the body, a series of branches are given off, as follows:

$C_{6 / 2 / 6 \cdot 7}$

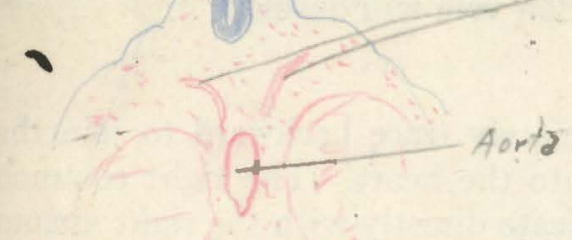

$c_{6} / 2 / 1$
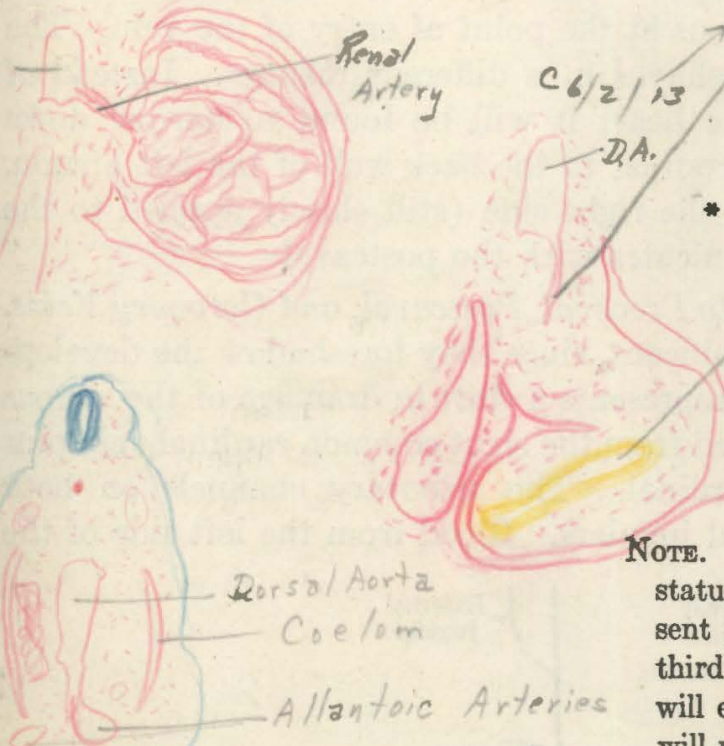

$2 / 8$

\section{VENOUS SYSTEM}

The venous system of the $10-\mathrm{mm}$. pig, like the arterial system, is already quite complicated, and it is desirable, therefore, to work it out in a similar manner by studying individual units. In the pig, just as in the chick, the cardinal system constitutes the basic series of veins draining the body proper in the early embryo. Moreover, the vitelline veins bring back blood from the yolk sac, which, in the pig, is large and of considerable importance as a nutritional organ. To these must be added the allantoic veins, which are very large and prominent, since they constitute the drainage from the placenta. Finally a new vessel, the post caval vein, is in process of being established as one of the main drainage channels.

\section{A. ANTERIOR CARDINAL VEINS AND TRIBUTARIES}

The anterior cardinal veins are broad sinuslike vessels which course backward along the sides of the brain lateral to the otic vesicle. At this level they are easily identified (Fig. 34). When traced forward toward the forebrain they soon break up into a capillary network anastomosing with branches of the internal carotid artery which cover the surface of the brain. These ramifications are difficult to follow and give little information of importance. Traced posteriorly, however, they soon take up a position dorsal and lateral to the paired dorsal aortae which they accompany posteriorly.

Nоте. (1) The typical close association of these vessels with the ganglia and fibers of the vagus nerve $\mathbf{X}$.

(2) Intersegmental veins, draining independent areas of the side of the head, brain, and spinal cord, can be seen at regular intervals emptying into the cardinals. 
Notk. (3) At the level of the visceral arches fairly large but uncertain vessels join the cardinals laterally and ventrally. These represent beginnings of the external jugulars.

(4) At the level of the limb buds a number of vessels draining the appendages join the anterior cardinals. From the most prominent of these the subclavian vein will develop.

\section{B. COMMON CARDINAL VEINS}

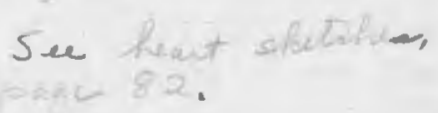

The anterior cardinals ultimately trace backward to. join the common cardinals which flow into the heart. The right common cardinal will be seen to communicate directly with the right atrium of the heart by way of the sinus venosus. Note the prominent c $4 / 3 / 8-12$ valves of the sinus venosus at the point of entry of the vein. The left common cardinal behaves in a different manner. Instead of flowing directly.into the heart it will be found to narrow down greatly, assume a close contact to the back wall of the left atrium, and then loop across to the right side (still closely applied to the heart), where it communicates with the postcaval or an

Relation of Anterior Cardinals and Common Cardinals to Precaval, Postcaval, and Coronary Veins. The conditions encountered in the $10-\mathrm{mm}$. pig are highly significant, since they foreshadow the development of the precaval and coronary veins. The precaval vein represents a shift in drainage of the venous blood into the right side of the heart. Its main trunk.is formed from the right common cardinal vein plus a small portion of the proximal part of the right anterior cardinal. The tributary channels on both sides are the subclavian veins and the internal and external jugulars. Blood from the left side of the
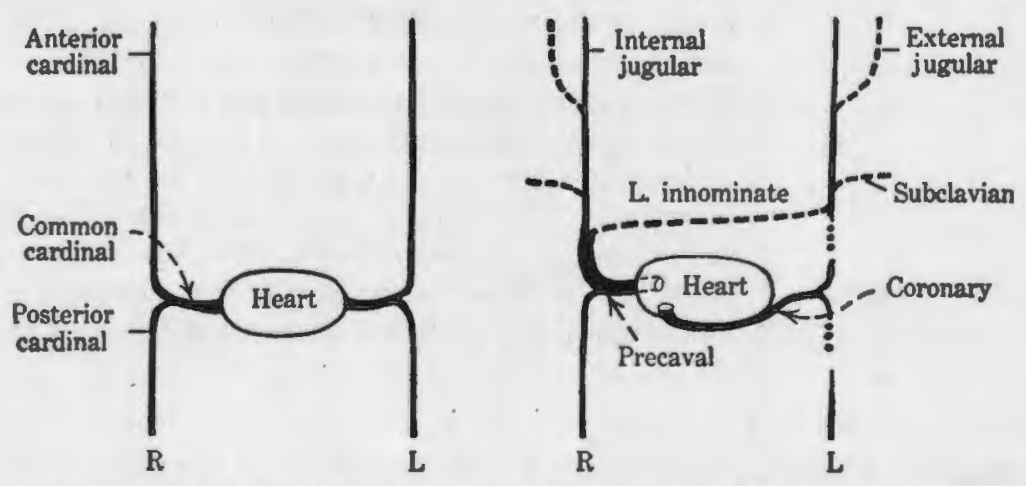

Fro. 35. Changes occurring in the cardinal veins of the pig during development. Left, primitive condition; Right, adult condition.

Vessels added -...-.-.-.

head ultimately will flow across to the right by the development of a new channel, the left innominate vein, which will form an anastomosis from the left to the right (Fig. 35). As yet these developments are not definitely under way. However, the striking manner in which the left common cardinal is associated with the heart at this stage indicates. that it is being taken over to drain the wall of the heart, for, along with small portions of the proximal ends of the left anterior and posterior cardinals, it thus becomes the coronary vein.

\section{PULMONARY VEINS}

At this stage the pulmonary veins are too uncertain and too poorly developed to trace successfully.

D. VEINS OF THE POSTERIOR PORTION OF THE BODY (FIG. 36)

There are four main venous channels to consider in working out the drainage of the posterior part of the body.

1. Posterior Cardinals. These are vessels of dwindling importance. They originally drain the dorsolateral portion of the body wall and adjoining organs and hence are located dorsal to the meso- 
nephros. Beginning at the point of junction with the common cardinal, they may be traced backward deeper into the series and will be found to maintain their original dorsolateral position with reference to the dorsal aorta. "As they are followed backward a level is finally reached where a new type of tissue suddenly appears lying across the vessel, thus dividing it into an upper and lower half. The new
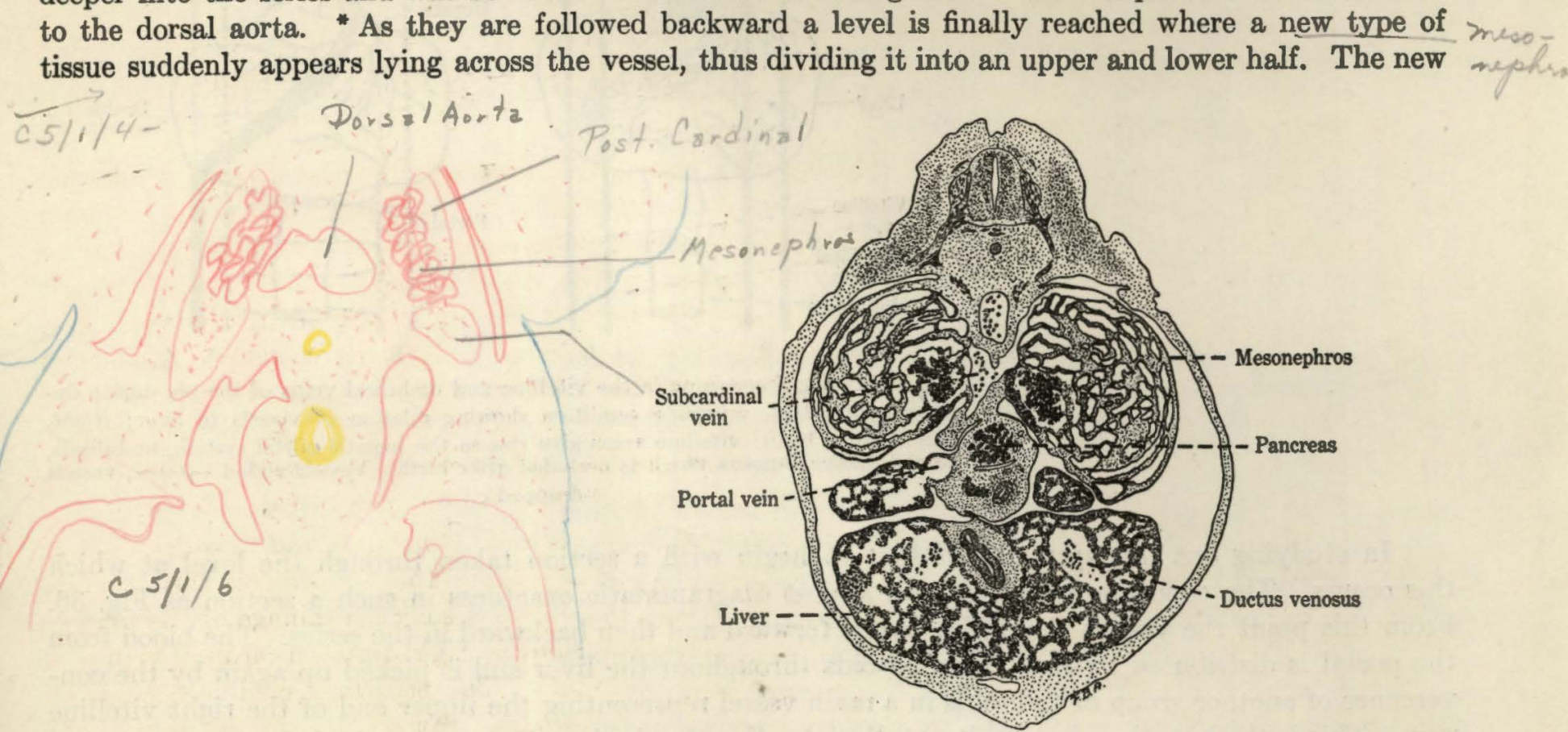

Fia. 36. Section through mid-body of the 10 -mm. pig.

tissue represents the anterior tip of the mesonephros, and the cardinal is thus separated into a dorsal posterior cardinal and a ventral subcardinal, each of which receives numerous tributaries from the mesonephros. The posterior cardinals from this point back gradually dwindle and may even be obliterated for a time. Farther back in the body they may be picked up once more, again in a position dorsal to the mesonephros, and from this point they may be traced back into the tail.

2. Hepatic-Portal System. The hepatic-portal system is derived from the paired vitelline veins of the younger embryo. These vessels originally course inward along the lateral walls of the gut from the yolk sac to the heart.

With the increase in size of the developing liver primordium, which arises originally as a ventral diverticulum from the gut, the closely associated vitelline vessels become broken up into a series of capillary channels running through the liver. By the time the $10-\mathrm{mm}$. stage is reached the liver has become a large and prominent organ; modification of the vitelline vessels is under way; and the beginnings of the hepatic-portal system are apparent.

Posterior to the liver a series of transverse anastomoses, together with the occlusion of intervening portions of the original channels, transforms the vitelline veins into a vessel tending to spiral around the intestine. It will be found that the right vitelline forms the upper or anterior end of this spiral and that at this point the vessel, now the portal, suddenly moves across from the gut into the liver (Fig. 37). 

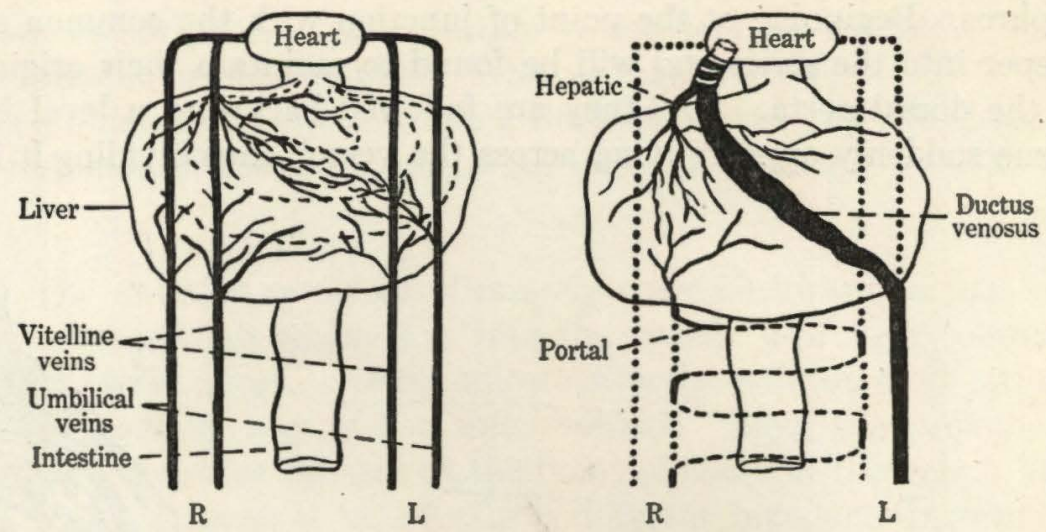

Fia. 37. Changes occurring in the vitelline and umbilical veins of the pig during development. Left, primitive condition showing relation of vessels to liver; Right, condition at birth: vitelline veins give rise to the hepatic portal system, umbilicals, to the ductus venosus which is occluded after birth. Vessels added -...--.--, vessels dropped ........

In studying out this system it is best to begin with a section taken through the level at which this occurs. The condition is shown with almost diagrammatic exactness in such a section as Fig. 36. $7 / 2 / 1 / 2$ From this point the vessels should be traced forward and then backward in the series. The blood from the portal is distributed by capillary sinusoids throughout the liver and is picked up again by the convergence of another group of sinusoids in a main vessel representing the upper end of the right vitelline vein. This is the hepatic vein, and it usually joins the developing postcaval vein before entering the heart. The proximal portion of the left vitelline vein contributes little save a few capillary sinusoids in the liver.

3. Umbilical Veins (transitory). The blood distributed by the umbilical arteries to the allantois is returned to the heart by the umbilical veins. These vessels course inward along the body stalk as a pair of broad venous channels. At the level at which the umbilical cord joins the ventral surface of the body, they move into the adjacent liver and become involved with it as a series of capillary sinusoids in a manner recalling the condition affecting the vitelline veins (Fig. 37).

$\mathrm{C}_{6}+\mathrm{C}_{7}$

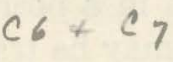
It is evident in the $10-\mathrm{mm}$. stage that the right umbilical vein
Meseneptis losing its importance and dwindling in size. The left, on the other hand, becomes large and prominent and takes over a series of capillary sinusoids in the liver to make a direct path across the liver from left to right toward the heart. This shortcut through the liver is the $\Rightarrow$ ductus venosus. It usually joins the postcaval vein before entering the heart.

In working out these vessels a section at a level approximating Fig. 36 should be chosen as a starting point and the umbilical veins traced forward to the heart and back into the umbilical cord where they are fused into a single vessel.

* 4. Postcaval Vein. In the adult animal most of the blood is returned to the heart by way of the postcaval vein. This vessel has already begun to establish itself in the $10-\mathrm{mm}$. pig. The greatest impetus to its development seems to be the fact that blood from the mesonephros requires a more direct passage to the heart than the circuit through the original posterior cardinals. As a result a pair of somewhat uncertain channels, ventral and medial to the mesonephros, first appear (Fig. 38). These are the subcardinals. They receive tributaries from the mesonephros but empty into the upper ends of the posterior cardinals. At the $10-\mathrm{mm}$. stage these upper vessels connecting with the posterior cardinals are still both present but dwindling in importance, and the two subcardinals have begun to join across the mid-line by a series of anastomoses. This establishes what amounts to a single vessel which can be

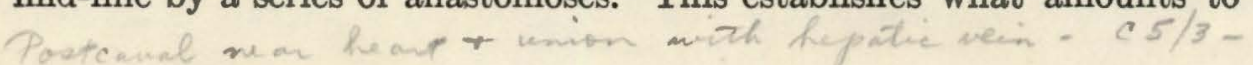




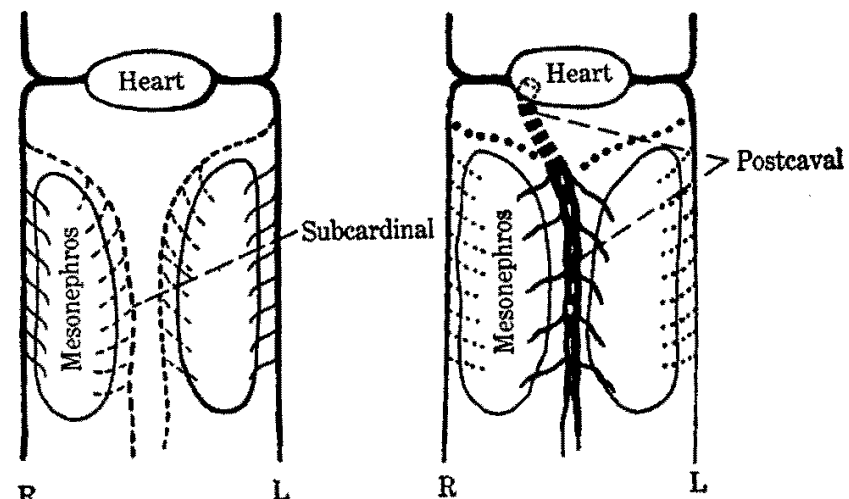

Fro. 38. Development of the postcaval vein in the pig. Left, subcardinals added to drainage of mesonephroi in $10 \mathrm{~mm}$. pig, in addition to original posteardinals; Right, fusion of subcardinals to form postcaval. Vessels added ........, vessels dropped ........

traced forward into the heart by way of a new addition to its anterior end. The whole channel is the developing postcaval vein. It should be noted that other vessels also contribute to the development of the postcaval but at this stage they cannot be clearly demonstrated.

In order to work out the postcaval vein and its relationships, it is convenient to start with a section about midway back through the body, such as Fig. 36, and work forward and back in the series.

5. Mesonephric Veins. Small vessels arising from the mesonephros which communicate with the postcaval vein.

6. Intersegmental Veins. Small vessels draining the dorsolateral body wall and flowing into the posterior cardinals. 